Florida International University

FIU Digital Commons

$6-22-2020$

\title{
Examining Maternal Emotion Regulation in Children with and without ADHD: A Multimodal Approach
}

Alexis Garcia

Florida International University, agarcia15@fiu.edu

Follow this and additional works at: https://digitalcommons.fiu.edu/etd

Part of the Child Psychology Commons, and the Clinical Psychology Commons

\section{Recommended Citation}

Garcia, Alexis, "Examining Maternal Emotion Regulation in Children with and without ADHD: A Multimodal Approach" (2020). FIU Electronic Theses and Dissertations. 4512.

https://digitalcommons.fiu.edu/etd/4512

This work is brought to you for free and open access by the University Graduate School at FIU Digital Commons. It has been accepted for inclusion in FIU Electronic Theses and Dissertations by an authorized administrator of FIU Digital Commons. For more information, please contact dcc@fiu.edu. 


\section{FLORIDA INTERNATIONAL UNIVERSITY}

Miami, Florida

EXAMINING MATERNAL EMOTION REGULATION AMONG CHILDREN WITH AND WITHOUT ADHD: A MULTIMODAL APPROACH

A dissertation submitted in partial fulfillment of the requirements for the degree of DOCTOR OF PHILOSOPHY

in

PSYCHOLOGY

by

Alexis M. Garcia 
To: Dean Michael R. Heithaus

College of Arts, Sciences and Education

This dissertation, written by Alexis M. Garcia, and entitled Examining Maternal Emotion Regulation Among Children with and without ADHD: A Multimodal Approach, having been approved in respect to style and intellectual content, is referred to you for judgment.

We have read this dissertation and recommend that it be approved.

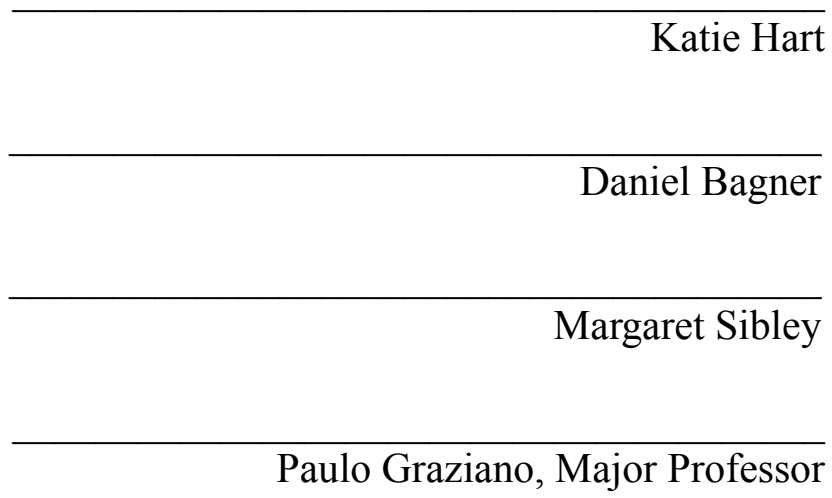

Date of Defense: June 22, 2020

The dissertation of Alexis M. Garcia is approved.

Dean Michael R. Heithaus

College of Arts, Sciences and Education

Andrés G. Gil

Vice President for Research and Economic Development and Dean of the University Graduate School

Florida International University, 2020 
(C) Copyright 2020 by Alexis M. Garcia

All rights reserved. 


\section{DEDICATION}

To my beautiful family: Tony, Patty, Anthony, Jazlyn, Jayden, and Christy. Thank you for believing in me. 


\section{ACKNOWLEDGMENTS}

First and foremost, I would like to thank my mentor, Dr. Paulo Graziano for his unwavering support over the last decade. Since my undergrad days, you went above and beyond as a mentor to ensure I was supported during ALL of life's challenges. You've empowered me to never settle and always hold myself accountable for my success. I look forward to continue learning from you and celebrating life's achievements together.

Dr. Katie Hart, thank you for taking me under your wing the summer of 2010. You were the catalyst to my academic career. You have been an incredible role model during graduate school and will continue to admire your commitment to your students and the community.

Drs. Margaret Sibley and Daniel Bagner, thank you so much for lending your expertise across various stages of my graduate career. From providing feedback on grant proposals to collaborating on manuscripts, I am so thankful for the learning opportunities you have provided me.

To members of the S.E.L.F-Regulation lab and the FIU community: Research assistants, research coordinators, post docs, and fellow graduate students, thank you for helping me reach this amazing milestone. The gracious families who consented to participate in this project; thank you for sharing a glimpse of your lives with our team. I hope the information collected in this dissertation project informs and improves mental health services for children and families. 


\author{
ABSTRACT OF THE DISSERTATION \\ EXAMINING MATERNAL EMOTION REGULATION AMONG CHILDREN \\ WITH AND WITHOUT ADHD: A MULTIMODAL APPROACH \\ by
}

Alexis M. Garcia

Florida International University, 2020

Miami, Florida

Professor Paulo A. Graziano, Major Professor

Objectives: This study utilized a multimodal approach to explore profiles of emotion regulation (ER) in mothers of young children with and without attentiondeficit/hyperactivity disorder (ADHD). We also sought to understand how parent factors (i.e., skills, stress, ADHD symptoms) as well as child factors were associated with membership to these profiles. Methods: The final sample consisted of 182 parent-child dyads. Sixty-six children were in the typically developing group (Mean age $=5.47, \mathrm{SD}=.90,74.2 \%$ males), and there were 116 children in the ADHD group (Mean child age $=5.41, \mathrm{SD}=.75,80.2 \%$ males $)$. Dyads completed a stress-inducing task (clean up) during which mothers' heart rate variability (HRV), specifically, respiratory sinus arrhythmia and pre-ejection period, was collected. Maternal ER strategies and parenting behaviors (proportion of DO and DON'T skills) were coded during the same clean up task. Mothers also completed self-reports of their ER strategies, parenting stress, parenting behaviors, and ADHD symptoms. Mothers and teachers completed questionnaires on child ER and ADHD symptoms. Children completed two frustration tasks to assess domains of emotion dysregulation. Results: 
Latent profile analysis included maternal ER as indicators (HRV, self report, coding) and yielded 4 distinct profiles: mixed $(n=64)$, moderate $(n=49)$, low $(n=12)$, and high $(n=57)$ ER. Mothers in the low ER profile demonstrated the highest levels of observed ER difficulties. The moderate ER profile demonstrated some co-activation of the autonomic nervous system (ANS), yet were more behaviorally regulated than mothers in the low ER group. There were no differences between mixed and high ER profile on behavioral measures of ER but there was evidence of co-activation of the ANS for the mixed ER profile. Lastly, proportion of DON'T skills were associated with the probability of membership to each profile. Parenting stress and child hyperactivity/impulsivity symptoms was predictive of membership to high ER profile. There was a significant difference between diagnostic groups and membership to profiles, Pearson $\chi^{2}(3)=8.39, \mathrm{p}<.05$, such that there were more children with ADHD in the low ER profile. Conclusions: Four distinct profiles of maternal ER emerged, highlighting the heterogeneity in maternal ER. Negative parenting behaviors, parenting stress, and child symptomology may also play a significant role in the development and maintenance of these maternal ER strategies. Future clinical trials should examine maternal ER as a potential therapeutic target. 
TABLE OF CONTENTS

CHAPTER

PAGE

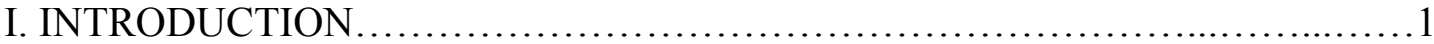

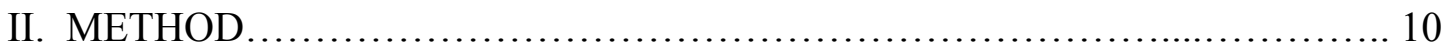

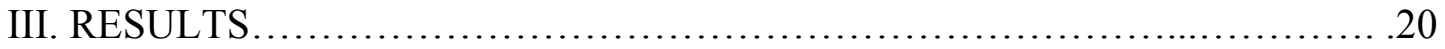

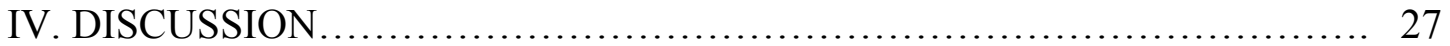

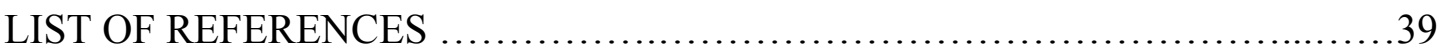

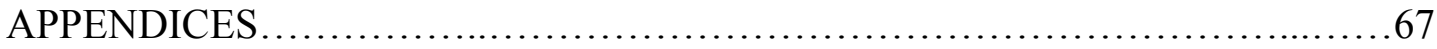

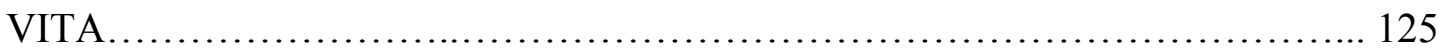




\section{LIST OF TABLES}

TABLES

PAGE

1. Maternal Demographics by Child Diagnostic Group .....................52

2. Maternal ER by Child Diagnostic Group ..............................53

3. Child Symptomology and ER differences by Diagnostic Group ..............54

4. Correlation Among Emotion Regulation Measures and Maternal Factors .....55

5. Maternal Demographics by ER profile ............................... 56

6. Fit Indices for Profile Solutions.................................... 57

7. Maternal Emotion Regulation Profile Membership by Diagnostic Group ..... 58

8. Maternal Demographics by ER profile ............................... 59

9. Comparison of Maternal Emotion Regulation Latent Profiles on Indicator Variables .................................................... 60

10. Comparison of Maternal Factors and Profile Membership ................ 61

11. Comparison of Child Factors and Profile Membership ................... 62

12. Regression Predicting Emotion Regulation Profile Membership from Maternal Factors ............................................... 63

13. Regression Predicting Emotion Regulation Profile Membership from Child

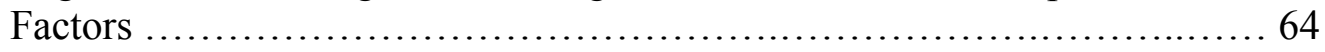

14. Regression Predicting Emotion Regulation Profile Membership from Maternal and Child Factors 65 


\section{ABBREVIATIONS AND ACRONYMS}

ADHD

ANS

$\mathrm{BL}$

DERS-SF

DPICS

ER

HRV

LPA

ODD

PEP

PEP-R

PNS

RSA

RSA-W

SNS

TD
Attention deficit/hyperactivity disorder

Autonomic nervous system

Baseline

Difficulties in Emotion Regulation Scale - Short form

Dyadic Parent-Child Interaction Coding System

Emotion regulation

Heart rate variability

Latent profile analysis

Oppositional defiant disorder

Pre-ejection period

Pre-ejection period reactivity

Parasympathetic nervous system

Respiratory sinus arrhythmia

Respiratory sinus arrhythmia withdrawal

Sympathetic nervous system

Typically developing 


\section{INTRODUCTION}

Attention-Deficit/Hyperactivity Disorder (ADHD) is a neurodevelopmental disorder characterized by a triad of symptoms; inattention, hyperactivity, and impulsivity (Barkley, 2014). Impairments associated with ADHD affect 10 to $25 \%$ of young children (DuPaul \& Kerns, 2011; Willcut, 2012; Voeller, 2004) and are the most common reason for child mental health referrals (Cormier, 2008). Impairments associated with the symptoms of ADHD affect social, academic, and familial functioning (Barkley \& Mash, 2003). For example, behaviors associated with ADHD symptoms affect a parent's employment status (Harvey, 1998) and create added expenses for families due to additional health care services such as psychosocial and pharmacological treatments (Foster et al., 2007; Matza, Paramore, \& Prasad, 2005; Pelham et al., 2007). Cognitive theories of ADHD have shown that deficits in selfregulation, primarily in executive functioning $(\mathrm{EF})$ are one of the cornerstone features of ADHD (Barkley, 1997; Sjöwall, Roth, Lindqvist, \& Thorell, 2013). However, recent work by Graziano and Garcia (2016) has demonstrated that emotion regulation (ER) dysfunction is also a hallmark of ADHD and independent from other impairing conduct problems. Considering the high heritability of ADHD ( .8) (Larsson, Chang, D'Onofrio, \& Lichtenstein, 2014) and persistent nature of ADHD symptoms (Guelzow, Loya, \& Hinshaw, 2016), it is important to consider the impact of parent ADHD on the development and maintenance of these dysfunctional ER skills in both parents and their children (Han et al., 2016). 


\section{Parenting}

Decades worth of research have shown the effects of positive versus negative parenting on child outcomes (Kaiser, McBurnett, \& Pfiffner, 2011; Yap, Schwartz, Byrne, Simmons, \& Allen, 2010). Positive parenting includes factors such as warmth, consistent parenting, and praise (Kaminski, Valle, Filene, \& Boyle, 2008). Negative parenting is generally described as being ineffective, punitive, inconsistent, and power assertive (Blair, 2002; Hoffman, 2001). From a cultural context, parents from ethnically diverse groups tend to engage in higher rates of negative parenting, and have children who are rated by teachers as being more disruptive (Fontes, 2002; Ryser, 2011). Being a parent to a child with ADHD amplifies these parenting difficulties when compared to parents of typically developing children (Wymbs, Wymbs, \& Dawson, 2015). Not surprisingly, behavioral parent training (BPT) is the first line of treatment for young children with ADHD (Attention-Deficit, 2011) which focuses on increasing positive parenting/interactions (Bagner, Fernandez, \& Eyberg, 2004; Kaminski et al., 2008), and implementing effective behavior management skills (Pelham \& Fabiano, 2008; Webster-Stratton, Reid, \& Beauchaine, 2011). One important factor that is crucial to examine in the context of parenting and as a target of BPT is stress related to parenting.

\section{Parenting Stress}

More than 30 years of research has suggested that the stress of being a parent is greater than other domains, such as work-related stress (Crnic \& Greenberg, 1990; Deater-Deckard, 2008; Quittner, Glueckauf, Jackson, \& psychology, 1990). There is an abundance of literature stating that chronic stress has serious negative implications 
across biological (Ansell, Rando, Tuit, Guarnaccia, \& Sinha, 2012; Jackson, Knight, \& Rafferty, 2010; Miller \& Blackwell, 2006) and mental health outcomes (Jackson et al., 2010; Staufenbiel, Penninx, Spijker, Elzinga, \& van Rossum, 2013). Although parenting stress typically declines as a child gets older (Neece, Green, Baker, \& disabilities, 2012), this association is maintained when parents have higher levels of psychopathology (Eiden, Colder, Edwards, \& Leonard, 2009; Knappe et al., 2009) and/or their children have chronic conditions (Barroso, Mendez, Graziano, \& Bagner, 2018; Craig et al., 2016; Golfenshtein, Srulovici, Medoff-Cooper, \& nursing, 2016; Pai et al., 2007).

Parents with elevated levels of psychopathology have been shown to engage in poorer parenting behaviors (Berg-Nielsen, Vikan, Dahl, \& psychiatry, 2002; Smith \& Work, 2004). For example, in a large study $(N=2838)$ of mother-child dyads, greater levels of maternal depression was associated with higher rates of neglect, psychological aggression, physical assault, and poorer engagement (Turney, 2011). Similar findings exist for mothers with anxiety, such that mothers of newborns high in anxiety reported low levels of warmth, involvement, and parenting satisfaction (Seymour, Giallo, Cooklin, Dunning, 2015). Of interest to the current study, recent work has shown that parents with high levels of ADHD symptoms themselves experience less gains in BPT (Chronis-Tuscano et al., 2011; Sonuga-Barke, Daley, \& Thompson, 2002). Taken together, it is not surprising that parents with elevated levels of psychopathology experience greater levels of stress. The constant need to manage their child's difficulties as well as their own cognitive and emotional impairments may be very overwhelming. Therefore, the variability in how parents manage their 
emotions during these stressful situations is emerging as a promising mechanism to understanding the association between parenting stress and child outcomes (ChronisTuscano, Wang, Woods, Strickland, \& Stein, 2017; Woods, Mazursky-Horowitz, Thomas, Dougherty, \& Chronis-Tuscano, 2019).

\section{Emotion Regulation}

ER is defined as the extrinsic and intrinsic processes responsible for the monitoring, evaluation, and modification of emotional reactions to achieve one's goals (Gross, 2011). Children with ADHD demonstrate deficits in four crucial domains of emotion dysregulation (ED): emotion recognition/understanding (ERU), emotional reactivity/negativity/lability (ERNL), emotion regulation (EREG), and empathy/callous-unemotional traits (ECUT; Graziano \& Garcia, 2016). For parents, a particularly important time to regulate one's emotions is in the context of managing their child's behavior, especially if children have difficulties regulating their own emotions. From an observational learning perspective, parents serve as models of emotional displays and these emotional behaviors are subsequently imitated by their children (Graziano, Keane, \& Calkins, 2010). Inappropriate parental displays of ER in turn have shown to contribute to poor emotional development in children and increased risk of psychopathologies (Kim, Capaldi, Pears, Kerr, \& Owen, 2009).

While factors such as stress play a large role in a parent's ability to modulate their emotions, parents with varying psychopathologies, specifically ADHD, tend to have greater levels of ER deficits (Mazursky-Horowitz et al., 2015). Additionally, mothers with greater ADHD symptoms tend to be less supportive in response to their child's negative emotions (Mokrova, O'Brien, Calkins, \& Keane, 2010), and engage 
in higher rates of negative parenting practices (Chronis-Tuscano et al., 2008). While most prior research examining parental ER strategies have relied heavily on selfreports or behavioral observations (Kim et al., 2009; Morelen, Shaffer, \& Suveg, 2016; Morris, Silk, Steinberg, Myers, \& Robinson, 2007), a growing body of research has focused on the study of biological markers of ER (Appelhans \& Luecken, 2006; Thayer, Åhs, Fredrikson, Sollers, \& Wager, 2012; S. R. Williams \& WoodruffBorden, 2015).

\section{Physiological Measurement of ER}

The parasympathetic nervous system (PNS) is a branch of the autonomic nervous system (ANS) which plays a critical role in the regulation of emotional responses (Kreibig, 2010; Thayer, Åhs, Fredrikson, Sollers, et al., 2012). From a topdown feedback or brain-behavior perspective, there is evidence to suggest that cortical areas such as the ventro-medial prefrontal cortex (vmPFC) and subcortical areas like the amygdala are associated with heart rate variability (HRV) during emotionally arousing tasks (Lane et al., 2009; Thayer, Åhs, Fredrikson, Sollers III, \& Wager, 2012). A measure of HRV, cardiac vagal tone, is an index of the PNS control of the heart via the vagus nerve (Grossman, Stemmler, \& Meinhardt, 1990). HRV can be non-invasively measured by respiratory sinus arrhythmia (RSA; Porges, 2007). Polyvagal Theory differentiates the role of the vagus nerve during a resting state versus a more challenging state. Resting or baseline measures of vagal tone represent an organism's ability to maintain homeostasis and the potential responsiveness of that organism. 
During such restful periods, the vagus nerve exerts an inhibitory influence on the heart acting as a "brake" by increasing vagal output to the sino-atrial (SA) node of the heart and limiting sympathetic influences, which contributes to a steady slow heart rate (HR). Indeed low baseline levels of RSA have been associated with numerous negative outcomes such as social impairments (Bornstein \& Suess, 2000) increased levels of internalizing and externalizing problems during childhood (Calkins, Graziano, \& Keane, 2007) and greater risk for depression into adulthood (Hamilton \& Alloy, 2016). During stressful periods, the vagal "brake" is disengaged resulting in a decrease in vagal output to the SA node of the heart as well as increased activity in the vmPFC (Thayer \& Lane, 2009; Thayer \& Sternberg, 2006a), and thus contributing to an increase in HR (S. W. Porges, Doussard-Roosevelt, Portales, \& Greenspan, 1996). Indeed, a greater change in RSA, or vagal withdrawal (RSA-W), has shown to aid an individual's capacity to cope with stressful events (Porges, 2003). For example, children with higher RSA withdrawal during challenging tasks exhibit better ER (Beauchaine, Gatzke-Kopp, \& Mead, 2007) and are less likely to exhibit externalizing and internalizing behavior problems (Graziano \& Derefinko, 2013).

Within the sympathetic nervous system (SNS), cardiac pre-ejection period (PEP) functions similarly to RSA as an index of sympathetic cardiac control on the heart via the beta-adrenal system (Berntson, Cacioppo, Binkley, et al., 1994). PEP is the time between the left ventricular depolarization to the onset of blood ejected into the aorta. Similarly to the measurement of RSA, PEP is examined during emotioninduction conditions in order to understand the SNS response via shortened PEP. Exposure to repeated stressors increases the allostatic load on physiological systems, 
such as PEP, that may contribute to increased sensitivity or dysfunction over time (Clark et al., 2014). PEP has been identified as an empirically supported measure of emotional reactivity (Kreibig, 2010; Kreibig, Wilhelm, Roth, \& Gross, 2007; Stifter, Dollar, \& Cipriano, 2011). Shortened PEP, or PEP reactivity (PEP-R), which is marked by greater reactivity and increased arousal to emotional stressors, has been associated with poorer social competence (Kalvin, Bierman, \& Gatzke-Kopp, 2016), increased levels of aggression (Beauchaine et al., 2013), and predictive of alcohol and other substance use (Brenner, Beauchaine, \& Sylvers, 2005).

Classic models of ANS functioning suggest reciprocal activation between the SNS and PNS branch as it relates to HR changes (Cannon, 1932). For example, as PNS activity increases, SNS activity decreases or vice versa. However, the "doctrine of autonomic space” (Berntson, Cacioppo, \& Quigley, 1991; Berntson, Cacioppo, Quigley, \& Fabro, 1994; Lenneman \& Backs, 2009) states the two branches of the ANS function in a multidimensional matter, rather than just reciprocally. Hence, under certain conditions an individual's PNS and SNS activity can both have excitatory or inhibitory influences on HR simultaneously (i.e., co-activation and coinhibition, respectively). Thus, it may be the case that synchronization between RSAW and PEP-R may be a proxy of a "core integration" system, in which individuals attempt to attend to their external environment and their physiological/homeostatic state (Thayer \& Lane, 2009). If this system is unbalanced or dysregulated, one's behavior will be disinhibited (Thayer \& Sternberg, 2006a). Despite this potential interaction between PNS and SNS activity, most studies have only examined these 
biological markers in isolation (Williams \& Woodruff-Borden, 2015) with no study to our knowledge examining these coupled systems in the context of parenting. Current Study

Despite the emergence of ER as being a key self-regulatory process across the lifespan (Diamond \& Aspinwall, 2003), the majority of the literature on ER has focused on the infant and early childhood period. Given the important role parents play in the development of children's ER skills via modeling of appropriate ER skills, it is imperative to examine underlying mechanisms associated with parent ER. Currently, the field relies heavily on traditional measures of ER such as self-reports and behavioral observations. Although studies with children have started to incorporate biomarkers of ER such as RSA and PEP, examination of the same constructs for parents is scant.

On the other hand, there is a very large body of research on stress. Individuals exposed to stress for extended periods have been shown to have poorer outcomes (Dube et al., 2009; Felitti \& Anda, 2010). From poor biological processes (i.e., cardiac problems; Dimsdale, 2008) to higher susceptibility for a mental health disorder (Felitti \& Anda, 2010; Kiecolt-Glaser et al., 2011), it is not surprising that most evidence-based interventions for children with behavior problems aim to reduce parenting stress. While various constructs such as parental psychopathology and parenting behaviors have been shown to play a role in treatment outcomes following interventions, little to no work has examined if ER skills differ between parents of TD developing children and children with ADHD. 
This is the first study to overcome these limitations by examining parent ER by integrating self-reports, behavioral observations, and psychophysiology to further understand maternal ER (Crandall, Deater-Deckard, \& Riley, 2015). The goal was to capture the heterogeneity of maternal ER by utilizing a latent profile approach. We hypothesized that distinct profiles of maternal ER would emerge, categorized as low, moderate, and high levels of ER across indicators. Using the profiles that emerged from the analyses, we then sought to examine how these distinct profiles were associated with various parental factors. For example, we hypothesized distinct measures of maternal ER would be uniquely associated with parent factors such as parental ADHD, parenting stress, and parenting behaviors. Furthermore, we hypothesized that mothers in the low maternal ER profile would have greater ADHD symptoms, more negative parenting, higher levels of stress, and lower levels of positive parenting compared to mothers in the moderate and high ER profiles. Lastly, given the novelty of these maternal ER profiles, we sought to take an exploratory approach to understanding how domains of child ER and child symptomology were uniquely associated with each profile of maternal ER. We hypothesized mothers in the low ER profile would also have children with the greater ER deficits and highest levels of ADHD symptoms, relative to mothers in the high ER profile. 


\section{METHOD}

\section{Participants and Recruitment}

The study was conducted at a large urban university in the southeastern region of the United States with a predominately Hispanic/Latino population. Families were recruited from local preschool and elementary schools, as well as mental health agencies through brochures, open houses/parent workshops. For the ADHD sample, if the mother (1) endorsed clinically significant levels of ADHD symptoms (six or more symptoms of either Inattention or Hyperactivity/Impulsivity according to the DSM-5 (Association, 2013) OR a previous diagnosis of ADHD), (2) indicated that the child was currently displaying clinically significant academic, behavioral, or social impairments as measured by a score of 3 or higher on a seven-point impairment rating scale (Fabiano et al., 2006), and (3) were not taking any psychotropic medication, the mother and child were invited to participate in an assessment to determine study eligibility. For the TD sample, if the parent (1) endorsed less than four ADHD symptoms (across either Inattention or Hyperactivity/Impulsivity according to the DSM-5), (2) less than four Oppositional Defiant Disorder (ODD) symptoms, and (3) indicated no clinically significant impairment (score below 3 on the impairment rating scale), the mother and child were invited to participate in an assessment to determine study eligibility. Exclusionary criteria included (1) a confirmed history of

an Autism Spectrum Disorder and/or Intellectual Disability, (2) not currently enrolled in school, (3) and inability to attend an 8-week summer treatment program (STPPreK; Graziano et al., 2014) prior to the start of the next school year (ADHD groups only). 
The final sample consisted of 182 parent-child dyads. Sixty-six children were in the TD group $($ Mean child age $=5.47, \mathrm{SD}=.90,74.2 \%$ males; Mean mother age $=$ 36.47, $\mathrm{SD}=5.70$;), and there were 116 children diagnosed with ADHD (Mean child age $=5.41, \mathrm{SD}=.75,80.2 \%$ males; Mean mother age $=36.14, \mathrm{SD}=6.21)$. As seen in table 2, there were no demographic differences between the ADHD and TD group. Within the ADHD group, 87 children met criteria for ADHD and ODD while 29 children met criteria for ADHD only. At intake, mothers provided informed consent to participate in the research study. Questionnaires were completed by the maternal caregiver in their preferred language (34 mothers completed questionnaires in Spanish).

\section{Data Collection Procedures}

All families participated in a one-time assessment prior to the start of the STPPreK (ADHD group only), which included completion of the ADHD, ODD, and CD modules on the C-DISC (Shaffer, Fisher, Lucas, Dulcan, \& Schwab-Stone, 2000) and various questionnaires regarding their children's behavioral, academic, and emotional functioning. Mothers completed a set of questionnaires based on their self-reported parenting strategies, ADHD symptomology, and ER strategies. Mother-child dyads also completed a series of tasks in the laboratory.

Mothers and child wore a total of seven electrodes that were attached to an ambulatory MindWare Mobile. For the baseline condition, children watched a 5minute neutral movie clip ("spot", a short story about a dog exploring a neighborhood). While this episode was not a true resting baseline given children's attention to the external stimulus, it was necessary to keep children sitting quietly as 
done in prior work (Calkins, Graziano, \& Keane, 2007). A research assistant remained in the room with the child to ensure the child was not touching the electrodes nor talking during the movie. Similarly, mothers completed a baseline task by sitting in a quiet room by themselves. They were instructed to avoid using their phones and falling asleep. A research assistant remained in the room to ensure these conditions were met.

Next, families were brought to a separate room with a two-way mirror. Mothers were informed that the research staff was on the other side of the mirror recording the interaction. Mothers were given a bug in the ear device through which the procedures would be communicated to her. Mothers and children were allowed to ambulate around the room as they pleased during the observation. At the end of the parent-child interaction, the mother was escorted back to her separate room to complete questionnaires while the child completed various tasks. Children were provided snack and coloring breaks between tasks. At the end of the clinic visit, children were allowed to select a toy from the treasure chest. All families received a \$100 gift card for completing the assessment.

\section{Measures}

\section{Pathophysiology Acquisition}

Respiratory Sinus Arrhythmia. RSA was indexed by extracting the high frequency component $(>0.15 \mathrm{~Hz})$ of $\mathrm{R}-\mathrm{R}$ peak time series. R-R waves were examined for artifacts and outliers using MindWare ${ }^{\circledR}$ Heart Rate Variability software V.3.1. RSA was derived by using spectral analysis in $30 \mathrm{~s}$ epochs. Time series were detrended and submitted to a Fourier transform. The high frequency band (in $\mathrm{ms}^{2}$ ) 
were set over the respiratory frequency band of .15 to $.40 \mathrm{~Hz}$, which is the recommended range for adults. Respiratory rates were derived from the impedance cardiogram (ICG; Z0) ensuring that the signals remained within analytical bandwidth.

Cardiac Pre-ejection Period. PEP was derived from ECG and ICG in 30s epochs, using MindWare Impedance Cardiography V.3.1. PEP was indexed as the time interval in milliseconds from the onset of the Q-wave to the B point of the $\mathrm{dZ} / \mathrm{dt}$ wave, using the methods delineated by Bernston and colleagues (2004). Artifacts were examined and removed using the MindWare Impedance Software. Less than $10 \%$ of parent data was not used due to hardware malfunction or excessive artifacts (more than $50 \%$ of segment was not useable).

Maternal Emotion Regulation (ER)

Psychophysiological ER. Mothers were asked to complete three tasks: a 5minute baseline task in which they sat quietly in a room by themselves (baseline physiological functioning), followed by a child lead play interaction, parent lead interaction, and a clean up task with their child (each task last for 5-minutes). Mothers and their children participated in a clean up situation using the Dyadic Parent-Child Interaction Coding System, 4th edition (DPICS-4; Eyberg, Nelson, Ginn, Bhuiyan, \& Boggs, 2013). Mothers instructed their child to put away three sets of toys (i.e., Mr. Potato Head, Legos, Play Food) without their help. The clean up task has been used in similar samples of young children with externalizing behavior problems (Bagner et al., 2009; Rodriguez et al., 2013) as an externally valid means of eliciting emotional reactions from the child. By creating a challenging situation for the child, we were able to examine mothers' reactions to their child. RSA and PEP 
were calculated by averaging the $30 \mathrm{~s}$ epochs together for a mean RSA and PEP score. RSA-W was calculated by subtracting the task score from the baseline (Baseline RSA - Clean up RSA). Greater RSA-W scores suggest a decrease in PNS influence on the heart. PEP-R was calculated by subtracting baseline PEP from task PEP (Clean up PEP - Baseline PEP). Lower PEP-R scores indicate shorting of PEP during the task, thus greater SNS reactivity.

Behavioral observation of ER. Mothers' participation in the clean up task was videotaped and coded for maternal duration of distress (total time in seconds mother was emotionally reactive) and emotion regulation (range from $0=$ dysregulated to $4=$ well-regulated), all of which have reported high reliability (Graziano, Slavec, Hart, Garcia, \& Pelham Jr, 2014). Twenty percent of the sample were coded by a second rater for reliability. Duration of distress during the task was highly correlated $(r=.86)$ and weighted kappa for the global code was in the almost perfect agreement range (.83).

Self-reported ER. Mothers completed the Difficulties in Emotion Regulation Scale-Short Form (DERS-SF; Kaufman et al., 2016). The DERS-SF is a validated 18item measure of emotional problems in adults (Victor \& Klonsky, 2016). The DERSSF yields 6 subscales (Awareness, Clarity, Goals, Impulse, Non-acceptance, Strategies) and an overall score. The overall score from the DERS-SF was used, $\alpha=$ .80 .

$\underline{\text { Parental Factors }}$

Parenting behaviors. Mother and child behaviors were coded during a 5minute clean-up situation using the Dyadic Parent-Child Interaction Coding System, 
4th edition (DPICS-4; Eyberg et al., 2013). Interactions were coded and categorized as "DO skills" (i.e., labeled/unlabeled praises, behavior descriptions, and reflections) and "DON'T skills" (i.e., commands, criticisms, and questions), and "Neutral Talk". Total "DO" and "DON'T" scores during the clean up task were computed, as well as a "Total Interactions" composite which was a sum of the "DO", "DON'T" and "Neutral Talk" behaviors. Finally, two proportion scores were computed 1) proportion of DO skills to Total Interactions and 2) proportion of DON'T skills to Total Interactions. An independent coder (blind to child diagnostic status) was assigned to code $20 \%$ of the observations a second time for reliability $(r \mathrm{~s}=.80-.90)$. Parenting Practices. Mothers also completed the Alabama Parenting Questionnaire (APQ; Shelton, Frick, \& Wooton, 1996), which is a 42-item measure of parenting practices across 5 domains: parental involvement, positive parenting, poor monitoring/supervision, inconsistent discipline, and corporal punishment. Consistent with prior work, two factors, Positive Parenting Composite $(\alpha=.82)$ and Inconsistent Discipline $(\alpha=.70)$ were examined in the current study (Hawes \& Dadds, 2006; Hinshaw et al., 2000). The APQ has been validated with young children (Clerkin, Halperin, Marks, \& Policaro, 2007).

ADHD Symptomology. The Adult ADHD Self-Report Scale (ASRS; Adler et al., 2006) in an 18-item measure used as a tool to identify impairing ADHD symptoms in adults (Van de Gild et al., 2013). Responses on the Adult ASRS vary from 0 - (never) to 4 (very often) when endorsing symptoms associated with ADHD within the past 6 months. A mean ADHD score was used, $\alpha=.94$. 
Parental Stress. The Parenting Stress Index- Short Form (PSI-SF) is a 36-item questionnaire that consists of 3 subscales (parental distress, parent-child dysfunctional interactions, and difficulty of the child), along with a total score. The total PSI-SF score was used in the current study, $\alpha=.94$.

\section{Child Factors}

$A D H D$ and $O D D$ Symptomology. Mothers and teachers completed the Disruptive Behavior Disorders (DBD) Rating Scale (Pelham, Gnagy, Greenslade, \& Milich, 1992), adapted for DSM-5 terminology. The DBD rating scale asks the respondent to rate on a 4-point scale ranging from 0 (not at all) to 3 (very much), the degree to which children display symptoms of ADHD, ODD, and CD. The DBD Rating Scale's responses range from 0 (not at all) to 3 (very much). Consistent with prior work (Hartman, Rhee, Willcutt, \& Pennington, 2007; Sibley et al., 2010), parent and teacher ratings were combined by taking the higher of the two ratings for each item to create composites: hyperactivity/impulsivity, inattention, and impulsivity. The mean score for each inattention, $(\alpha=.88)$, hyperactivity/impulsivity, $(\alpha=.92)$, and ODD symptoms were examined $(\alpha=.85)$.

\section{Emotion recognition/understanding (ERU). Children completed a} standardized emotion knowledge task (Denham, 1986) that required children to both expressively and receptively identify 8 different emotions (sad, happy, angry, afraid, surprised, disgusted, embarrassed, guilty) as presented visually via cartoon faces. Children scored 1 point for each correct expressive and subsequent receptive answer. A total of 16 points was possible with higher scores indicative of better emotional awareness/knowledge. 
Emotional regulation (EREG). Children completed two frustration tasks adapted from the Lab-TAB (Goldsmith \& Rothbart, 1996): I'm Not Sharing and Impossibly Perfect Circles. In the I'm Not Sharing task, an assistant brings a container of candy and tells the experimenter to share it equally with the child. The experimenter initially divides the candy equally. Eventually, the examiner takes more candy, eats a piece of the child's candy, then proceeds to take more candy, until they take all of the child's candy.

In the Impossibly Perfect Circles task, children were asked to draw circles repeatedly and were criticized (e.g., too large, too small) after each attempt. The tasks were discontinued if the child was highly distressed or cried for more than 30 s. If the child was not highly distressed, the tasks was terminated after 3 minutes and 30 seconds in which the child was praised for their effort and provided a small prize from a treasure chest (e.g., stickers, pencils, candy). The total amount of time the child was distressed was recorded and a proportion score (time distress/time in task) was used. Twenty percent of the sample was coded by a second rater for reliability. Duration of distress during the tasks was highly correlated $(r=.80)$. For data reduction purposes, the most severe rating of dysregulation between the two tasks was used for the current study.

Emotional reactivity/negativity/lability (ERNL). Mothers and teachers also completed the Emotion Regulation Checklist (ERC; Shields \& Cicchetti, 1997). The ERC is a 24-item questionnaire that uses a 4-point Likert scale (1=almost always to 4=never). The ERC and yields two subscales: Negativity/Lability scale (15 items), which represents negative affect/mood lability, and the Emotion Regulation scale 
(eight items), which assesses processes central to adaptive regulation. For the present study, the highest Negativity/Lability score between parent/teachers was used, with higher scores indicating greater levels of negativity/lability $(\alpha=.93)$.

Callous-unemotional behaviors (CU). Mothers and teachers completed an abbreviated version of the Inventory of Callous-Unemotional Traits (ICU; Frick, 2004) consisting of 12 items identified by Hawes and colleagues (2014) as showing psychometric properties similar to those of the full ICU. The items were rated on a four-point Likert scale ranging from 0 (not at all) to 3 (very much), and a CU composite was created by averaging these 12 items $(\alpha=.72)$. Once again, the highest score among parent and teacher reports was used.

\section{Data Analysis Plan}

All analyses were conducted using the Statistical Package for the Social Sciences version 20.0 (SPSS 20) and Mplus Version 7 (Muthen \& Muthen, 2012). For the maternal emotion regulation profiles, $80 \%$ of participants had complete psychophysiological data, 98\% behavioral data, and 100\% self-reported ER. During the psychophysiological data acquisition, excessive artifacts due to movement or hardware malfunction resulted in unusable data. Four maternal ER observations were lost due to camera malfunctioning. Little's Missing Completely at Random Test suggested there was no evidence that the missing data were not missing at random, $\chi^{2}$ $(48)=56.60, p=.19$. There was less than $5 \%$ missing data for maternal self-reports. According to Little's Missing Completely at Random Test, there was no evidence to suggest that the maternal questionnaires were not missing at random, $\chi^{2}(7)=10.93, p$ $=.14$. 
Latent profile analysis (LPA) was completed in Mplus using maximum likelihood estimation. Profiles of maternal emotion regulation comprised of selfreported (DERS) and observed (RSA/PEP and behavioral codes) measures of maternal emotion regulation as indicators. Multiple fit statistics were examined to evaluate each model. These indices included Akaike information criterion (AIC), Bayesian information criteria (BIC), Adjusted BIC, bootstrap likelihood ratio test (BLRT), and entropy. Following guidelines from Nylund, Asparouhov, and Muthen (2007), we began specifying two latent profiles and increased the number of latent profiles until the increase in model fit was no longer parsimonious. The best fit model consisted of the lowest BLRT, AIC, BIC, and highest entropy, compared to other models in conjunction with theory-based decisions and interpretability. The probability of profile membership was saved for each participant.

A series of univariate analysis of variance (ANOVA) tests were conducted to test the hypothesis that there were differences between profiles on measures of maternal ER (i.e., self-report, physiological, observed), parenting factors (i.e., behaviors, stress, ADHD symptoms) and child factors (i.e., ADHD and ODD symptoms, ER deficits). Lastly, linear regressions were conducted to examine the extent to which maternal and child factors were associated with the probability of membership to each maternal ER profile. 


\section{RESULTS}

Preliminary analyses

Prior to examining maternal emotion regulation profile, we examined if there were any differences between the ADHD and TD groups on various measures of maternal demographics. As seen in Table 1, there were no differences between maternal age, marital status, race, ethnicity, or maternal education.

\section{Maternal Emotion Regulation Latent Profile Analyses}

LPAs were conducted in Mplus. Seven variables were used as indicators to create profiles of maternal emotion regulation. Observational measures included behavioral (proportion of distress and global emotion regulation) and psychophysiological (baseline RSA, baseline PEP, RSA-W, PEP-R) indices of maternal emotion regulation. Mothers self-reported emotion dysregulation (DERS) was also used an indicator. See Table 4 for intercorrelations on maternal ER indicators and maternal factors. As seen in Table 3, post-hoc analyses revealed there were no differences between maternal demographic variables and ER profiles.

Fit indices for one-profile to five-profile solutions are presented in Table 2. Following Nylund and colleagues (2007) suggestions, profiles with less than 5\% of the total sample size should be interpreted with caution due to their low convergent probabilities, suggesting less than $50 \%$ of participants are correctly classified. Therefore, the five-profile solution was deemed uninterpretable since one profile only accounted for four participants $(2.2 \%$ of the sample). The bootstrapped likelihood ratio test revealed the four-profile model was significantly better than the three-

profile model $\chi^{2}(8)=38.20, p<.001$, with a lower adjusted BIC value of 3458.96 and 
AIC value of 3457.56. Although the two and three-profile solutions produced better entropy (.91 and .86 , respectively), the four-profile solution indicated a .74 entropy that appropriately estimated about three-fourths of the participants into appropriate profiles. Thus a four-profile solution was selected.

The profiles were conceptualized as a (a) behaviorally regulated yet physiologically distressed profile (Mixed ER; $n=64$ ), (b) moderate distress profile (Moderate ER; $n=49$ ), (c) high behavioral distress and average physiological regulation profile (Low ER; $n=12$ ), and (d) behaviorally regulated and physiologically regulated profile (High ER; $n=57$ ). As seen in Table 3 , there was a significant difference between diagnostic groups and membership to profiles, Pearson $\chi^{2}(3)=8.39, \mathrm{p}<.05$, such that there were more children with ADHD in the high behavioral distress and average physiological regulation profile. Figure 1 depicts the pattern of means across the four profiles. Scores were standardized so that positive values are above the mean while negative scores are below the mean.

Profile 1, or the Mixed ER, consisted of 35\% of the sample, 24 of which were in the ADHD group and 40 belonging in the TD group. As seen in Table 4, individuals in this group displayed low levels of distress during a 5-minute clean up task with their child (i.e., only spent $3 \%$ of the task time, 9 seconds, in distress). Additionally, individuals in this group engaged in effective emotion regulation strategies during the clean-up task with their child. However, parasympathetic influence, as measured by RSA-W, indicated an augmented response, suggesting individuals needed to increase their allostasis in order to attend to the task. This in 
part may also be due to the fact that individuals in this profile also had lower baseline RSA, which is associated with less parasympathetic control on cardiac output.

Profile 2, or Moderate ER, consisted of $27 \%$ of the sample, 35 of which were in the ADHD group and 14 belonging in the TD group. Table 4 demonstrates how individuals in this profile were distressed for $13 \%$ of the clean-up task (39 seconds) and were "somewhat" regulated during the task $($ mean $=2.80, S D=.46)$. Similarly to Mixed ER, membership to this group was associated with a lower baseline RSA and an augmented parasympathetic response (Mean RSA-W $=-.02, S D=.70)$

Profile 3, or Low ER, consisted of $7 \%$ of the sample, 11 of which were in the ADHD group and 1 in the TD group. As demonstrated in Table 4, individuals in the profile were distressed for 33\% (108 seconds) of the clean-up task as well as engaged in "somewhat" effective emotion regulation strategies. Compared to Mixed ER, individuals in this profile had significantly higher baseline RSA and RSA-W, suggesting a typical trend of parasympathetic withdrawal on the heart during a stressful situation.

Profile 4, or High ER, consisted of $31 \%$ of the sample, 30 of which were in the ADHD group and 27 in the TD group. Across behavioral and psychophysiological measures of maternal emotion regulation, individuals in this profile had low levels of distress (approximately 3\% of the clean-up task), mostly regulated levels of ER skills (mean global ER code $=3.69, S D=.47$ ), and the highest RSA-W. See Table 4 for all other mean comparisons. 
Comparison of Parenting Outcomes between Maternal ER Profiles

A series of ANOVAs were conducted to test the hypothesis that there would be one or more mean differences between maternal emotion regulation profiles and parenting outcomes, even after accounting for child symptomology (i.e., ADHD and ODD symptoms). Pairwise comparisons revealed differences between profiles of maternal ER and DON' $\mathrm{T}^{1}$ skills. Mothers in the Low ER profile displayed a significantly greater proportion of DON'T skills (Mean $=.70, s e=.04$ ) compared to mothers in the Mixed ER (Mean $=.52, s e=.02)$, Moderate ER $($ Mean $=.61, s e=$ .02 ), and High ER profiles (Mean $=.52, s e=.02) p s<.001$. Mothers in the Moderate ER profile (Mean $=.61, \mathrm{se}=.02)$ displayed a significantly greater amount of DON'T skills compared to mothers in the High ER profile, $p<.001$. There were no mean differences between mothers in Mixed ER and High ER profile on DON'T skills, $p>$ .05. Means for each parent outcome are reported in Table 5. There were no significant differences between profile membership and maternal ADHD symptoms, parenting stress, or positive and negative parenting practices, $p \mathrm{~s}>.05$.

Comparison of Child Outcomes between Maternal ER Profiles

A second series of ANOVAs were conducted to examine if there were differences in child factors between maternal ER profiles. We found no statistical differences across any child factors, Wilks lambda $=.88 F(21,471.47)=1.07, p=$ .38. Means for each child outcome are reported in Table 6 .

\footnotetext{
${ }^{1}$ In order to increase the generalizability and external validity of our findings, we utilized the proportion of DO and DON'T skills from the clean up task. It is important to note that all analyses were tested with total as well as CDI specific behaviors and there were no differences in our findings.
} 
Linear Regressions Examining Maternal and Child Factors Predicting Probability of Membership to Maternal ER Profiles

Maternal Factors. Linear regressions were conducted to examine the association between parenting and child outcomes and probability of membership to each profile. First, we examined the extent to which maternal factors were associated with the probability of membership to each profile (Table 7). In terms of the Mixed ER profile, no significant predictors emerged, $\mathrm{F}(9,166)=1.72, R^{2}=.09, \mathrm{p}>.05$; however, it is important to note a marginally significant association between the probability of membership to the Mixed ER profile and parenting stress, $\beta=-.18, p=$ .051 .

Proportion of DON'T skills was the only significant predictor of the probability of belonging in this Moderate ER profile, $\mathrm{F}(9,166)=2.70, R^{2}=.13, \mathrm{p}<$ .01 . There was a small effect $(\beta=.21, p<.05)$ of proportion of DON'T skills on membership to the Moderate ER profile, such that mothers tended to use more DON'T skills during the clean up task.

For the Low ER group, proportion of DON'T skills $(\beta=.28, p<.01)$ were associated with membership to this profile, $F(9,166)=2.42, R^{2}=.12, \mathrm{p}<.05$. Mothers in the Low ER group tended to use more DON'T skills during the clean up task.

Lastly, in terms of membership to the High ER profile, proportion of DON'T skills was the only significant predictor of the probability of belonging in this profile, $F(9,166)=2.62, R^{2}=.12, p<.01$. There was a small to moderate effect $(\beta=-.27, p<$ .01) of the proportion of DON'T skills on membership to the High ER profile, such 
that mothers tended to use less DON'T skills during the clean up task. Thus, proportion of DON'T skills and parenting stress were used in Table 14.

Child Factors. As seen in Table 13, child ER and symptomology were entered as predictors of the probability of membership to each maternal ER profile.

Consistently across profiles, the inclusion of all the child factors yielded nonsignificant models. However, significant individual effects are presented. Parent/teacher reports of child hyperactivity/impulsivity symptoms $(\beta=.44, p<.01)$ was significantly associated with membership to the Mixed ER profile, such that children in this group had greater levels of hyperactivity/impulsivity symptoms. There were no significant child predictors for the Low, Moderate, of High ER profiles. Subsequently, hyperactivity/impulsivity symptoms was the only child factor used in Table 13.

Maternal and Child Factors. Table 14 included the significant maternal and child factors presented above. Three significant variables emerged when predicting probability of belonging to the Mixed ER profile, $F(7,168)=4.95, R^{2}=.17, p<$ .001 . DON'T skills $(\beta=-.34, p<.001)$, parenting stress $(\beta=-.20, p<.01)$, and hyperactivity/impulsivity symptoms $(\beta=.19, p<.05)$, were significantly associated with the Mixed ER group. Mothers in the Mixed ER profile engaged in less DON'T skills during the clean up task, reported less parenting stress, yet their children tended to be more hyper/impulsive.

Next, we examined how maternal and child factors were associated with membership to the Moderate ER profile. DON'T skills $(\beta=.32, p<.001)$, was the only significant predictor of membership to the Moderate ER group, $F(7,168)=$ 
3.91, $R^{2}=.14, p<.001$. Mothers in the Moderate ER profile tended to engage in more DON'T skills during the clean up task.

When examining possible predictors of membership to the Low ER profile, only one maternal factor emerged, $F(7,168)=10.87, R^{2}=.31, p<.001$. Greater DON'T skills $(\beta=.55, p<.001)$ was significantly associated with a greater possibility of being in the Low ER profile. Of note, there was a trending association between DO skills and membership to the Low ER profile, $(\beta=-.13, p=.06)$.

Lastly, two significant predictors emerged for the High ER profile, $F(7,168)$ $=4.44, R^{2}=.16, p<.001$. DON'T skills $(\beta=-.32, p<.001)$ and child hyperactivity/impulsivity symptoms $(\beta=-.16, p<.05)$ were predictive of membership to the High ER profile. Mothers in this profile used less DON'T skills during the clean up task and their children have lower levels of hyperactivity/impulsivity. 


\section{DISCUSSION}

The purpose of the current study was to examine maternal ER from a multimodal perspective within a sample of mothers of children with and without ADHD. Given the emergence of emotion dysregulation as a core deficit in individuals with ADHD, our primary goal was to understand how various measurements of ER characterize the heterogeneity in maternal ER. Our secondary goal was to examine how differences in maternal ER were associated with parental factors such as ADHD symptomology, parenting stress, and parenting behaviors. Lastly, we were interested in examining how child factors, specifically ADHD symptomology and ER were associated with these maternal ER profiles. Results of the study revealed that maternal ER was characterized by four distinct profiles: mixed ER, low ER, moderate ER, and high ER. Additionally, we found that membership to the low and moderate ER profile was associated with greater levels of observable negative parenting behaviors while membership to the mixed ER profile was associated with selfreported levels of parenting stress. Lastly, we found that child hyperactivity/impulsivity symptoms were associated to the mixed and high maternal ER profiles, respectively. We elaborate on these findings below.

Partially consistent with our hypothesis, we found three profiles of maternal ER marked by low, moderate, and high levels of behavioral and physiological distress. Unexpectedly, a fourth profile emerged with high behavioral regulation but poor physiological reactivity. It is also important to note that self-reports of ER did not differentiate any profiles. While previous studies have found an association between self-reports on the DERS and HRV, it is important to note that the 
populations used in these studies were primarily college students (Visted et al., 2017; Williams et al., 2015). Additionally, the aforementioned studies were only able to examine state-levels of ER following an emotion-inducing task. On the contrary, our study employed a trait-level examination of maternal ER and did not pair the administration of the measure following the clean-up task. Therefore, the difference in sample demographics and study design may explain the mixed findings.

Both behavioral measures, proportion of distress and global regulation, were significantly associated with profile membership. For example, the low ER profile had a significantly higher proportion of distress and poorer global regulation during the clean-up task compared to mothers in the moderate, high, and mixed ER profiles. Mothers in the high and mixer ER profiles exhibited the least amount of distress and could be classified as "mostly regulated" to "well regulated" according to their scores on the global regulation code.

Within the physiological domain, greater baseline RSA as well as greater RSA-W was observed in high and low ER profiles relative to the moderate and mixed ER profiles. It is important to note that the difference in RSA-W between the low ER and high ER profiles was approaching significance, $p=.06$. Although it may be difficult to explain these null findings, we can cautiously speculate that there may be quantifiable differences in their parasympathetic response during the clean-up task. For example, previous work suggests that higher levels of RSA BL are associated with optimal physiological functioning in conjunction with RSA-W when dealing with stressful events (Hinnant \& El-Sheikh, 2009; Vasilev, Crowell, Beauchaine, Mead, \& Gatzke-Kopp, 2009; Cribbet, Williams, Gunn, \& Rau, 2011). Thus, it may 
be the case that mothers in the low ER profile demonstrate suboptimal parasympathetic withdrawal compared to mothers in the high ER profile.

There were also differences in sympathetic indices of maternal ER (i.e., PEP BL and PEP-R) between the mixed, moderate, and high ER groups. Our findings align with a review by Kreibig (2010) that found that PEP typically shortens when individuals experience anger, anxiety, and fear. While there no significant differences in PEP-R between the mothers in the low ER group compared to the other three groups, the directionality of this score is what we expected. Lastly, it is important to note the PEP-R standard error for the moderate ER group was twice as large compared to the other groups.

It is important to acknowledge the mixed ER profile. Mothers in this profile had the lowest RSA measures (i.e., RSA BL and RSA-W), significant PEP-R, yet had comparable levels of distress and global regulation relative to the high ER profile. While RSA and behavioral observations tend to be highly associated during the infancy period (Calkins et al., 2001), this association tends to taper off during the adolescent and adult periods (Beauchaine, 2001). It may be the case that mothers in the mixed ER profile have an imbalanced or co-activated autonomic response, causing them to be chronically hyper-aroused, especially during periods of rest (Thayer \& Sternberg, 2006b). Given this imbalance, mothers in the mixed ER profile seem to increase their allostatic load, as indexed by an augmented RSA response, or negative RSA-W score, during the clean-up task. As explained by Porges vagal brake theory (1996), vagal tone will decrease when the "brake" is removed, allowing the individual to respond or "fight" in order to respond to a situation. However, if an 
individual increases the vagal brake, this can prevent an individual from appropriately responding to their environment. Since the vagus nerve also innervates striated muscles in the face and neck area (Porges, 2001), it is not surprising that mothers in the mixed ER, who maintained high levels of RSA through tasks, demonstrated the least amount of changes in negative expressions and verbalizations. Similar to individuals with anxiety, it may be the case that mothers in this profile are in a constant state of "engagement" with their environment as indexed by their heightened PNS scores.

As it relates to our second goal, and after accounting for child ADHD and cooccurring ODD symptoms, the only significant difference across maternal ER profiles and maternal factors was on an observable measure of parenting, DON'T skills. Mothers in the high and mixed ER profiles were observed using approximately 6-7 DON'T skills per minute during the clean-up task. Next mothers in the moderate ER profile used approximately 10 DON'T skills per minute. Lastly, mothers in the low ER profile used nearly 17 DON'T skills per minute. When examining membership to each profile continuously, DON'T skills significantly predicted probability of membership to each of the profiles (see Table 12). Not surprisingly, mothers in the mixed and high ER profiles tended to have the least DON'T skills where as the low and moderate ER profiles tended to have mothers who engaged in more DON'T skills. It is important to note that our dimensional analysis, as reported in Table 4, also support these findings such that mothers with poor ER (self-reported and observed) also report less positive parenting ( $r \mathrm{~s}=-.37$ to $-.17, p \mathrm{~s}<.05)$. These findings were further supported by the finding that mothers in the low ER profile used 
less DO skills. Consistent with previous work, mothers who engage in greater rates of negative parenting behaviors also have poorer ER (Crandall et al., 2015; MazurskyHorowitz et al., 2015; Woods et al., 2019). Considering the salient findings associated with DON'T skills and maternal ER, future studies would benefit from incorporating a dyadic observational task to further elucidate the role of parent ER on maladaptive parenting skills.

Similar to other studies of maternal ADHD symptomology (Park, Hudec, \& Johnston, 2017) we found a large association between maternal ADHD symptomology and the DERS $(r=.60, p<.001)$. However, as seen in Table 10 , there were no differences across maternal ER profiles on self-reported ADHD symptoms. Thus, when examined dimensionally, it may be the case that maternal ER may partially explain the association between parental ADHD and negative parenting behaviors (Chronis-Tuscano et al., 2011; Mazursky-Horowitz et al., 2015). The underlying ER deficits in ADHD (Barkley, Fischer, \& Psychiatry, 2010) may better explain the difficulties parents with ADHD experience over and above the actual symptoms of ADHD. Thus, future work should examine if parent ER mediates the association between ADHD symptomology and parenting outcomes.

In regards to child factors, we found there was a significantly greater amount of children with ADHD in the low ER profile. It is important to note that approximately $83 \%(n=10)$ of the children in the low ER maternal profile had ADHD and co-occurring ODD. Given children with ADHD and co-occurring conduct problems tend to have more behavioral and emotional deficits (Caspi et al., 2008; Graziano \& Garcia, 2016), it is not surprising that mothers in this profile had the 
lowest ER skills given the co-occurring presentation may elicit more dysfunctional parenting behaviors. Next, we hypothesized that mothers in the low ER profile would also have children with greater ER deficits. While there were no differences across the four measures of ER, ADHD, or ODD symptoms (Table 6), only child hyperactivity/impulsivity symptoms were significantly predictive of membership to the mixed and high ER profile. Although cross-sectional in nature, our findings replicate previous work demonstrating parents of children with less behavioral and emotional problems have lower rates of parent psychopathology (Bagner et al., 2013; Han \& Shaffer, 2014). Interestingly, mothers in the mixed ER profile engaged in less DON'T skills, reported lower levels of parenting stress, yet their children tended to have higher levels of hyperactivity/impulsivity skills. Consistent with models suggesting continuous exposure to stressors increase an individuals' allostatic load (Goldstein \& McEwen, 2002; Sturge et al., 2011), the continuous "wear and tear" associated with managing a child's hyperactive/impulsive symptoms may be indexed by augmented RSA, or negative RSA-W scores. Considering the negative mental and physical sequelae associated with chronic exposure to stress, it is imperative to understand the bidirectional nature of ER problems between children and their parents over time.

Although we did not find significant differences across maternal profiles on measures of child ER, post-hoc analyses revealed that hyperactivity/impulsivity were strongly related to parent/teacher reported negativity $(r=.76, p<.001)$ and CUbehaviors $(r=.57, p<.001)$. Considering children with ADHD also have significant emotional impulsivity problems (Farone et al., 2019), it may be the case that 
hyperactive/impulsive symptoms may partially explain the link between ADHD and ED in young children.

The current study has several strengths. While previous studies of maternal ER have only examined self-reports (Woods et al., 2019), this is the first study to our knowledge, to use a multimodal approach to examine maternal ER. Aligned with RDoC (Insel et al., 2010), we examined maternal ER by using concurrent measurements of ER (i.e., behavioral and physiological) during a well-known and widely used parent-child paradigm (clean-up task; Eyberg, Nelson, Duke, \& Boggs, 2005) and included self-reported ER strategies. While some studies have examined the differences in young children's RSA during various tasks with their parent (Cooper-Vince et al., 2017; Richardson, Bocknek, McGoron, \& Trentacosta, 2019), findings from the current study elucidate the underlying processes that occur for parents during challenging parent-child interactions. We found that there were no differences across profiles on the self-report of ER (DERS), however there were significant differences on behavioral and physiological indices of maternal ER. Thus, future studies interested in examining the heterogeneity of maternal ER would benefit from observational and physiological data.

There were some limitations to the current study that need to be acknowledged. First, our measurement of self-reported ER (DERS) was not collected immediately after the clean-up task. The unique moment-to-moment nuances of the parenting "experience" may not of been captured in the same light as the observational (i.e., physiological and behavior coding) measures. Nonetheless, there is evidence to suggest that individuals will consistently use certain regulation 
strategies and can be conceptualized as a "trait-level" difference when conceptualizing ER (Gross \& John, 2003). Secondly, due to the design of the the current study, only mothers' reports and ER strategies were examined. While there is a growing literature on the influence of fathers on children's development (Jeynes, 2016), we were unable to examine any associations between mother and father emotion regulation. Future studies would benefit from understanding if differences exist between mother and fathers' reports of ER in the context of parenting. Lastly, approximately $6 \%$ of mothers reported having an ADHD diagnosis. Therefore, these results may not generalize to clinical samples of mothers who have an ADHD diagnosis.

Despite these limitations, the current study highlights the heterogeneity in maternal ER. The emergence of four profiles suggest that maternal ER is multidimensional and may be best conceptualized with various concurrent measures. The utility of using an ecological valid task, such as the clean-up scenario, allows these findings to generalize to parent-child interactions outside of a laboratory setting. Additionally, interventions for young children with behavior problems, such as behavioral parent training, focus on increasing positive parenting and decreasing negative parenting. Thus, focusing on negative parenting behaviors, such as the use of DON'T skills, is a key factor to consider when understanding the extent to which ER strategies impact a parents ability to engage effectively with their child.

Although this is the first study to examine maternal ER from a multi-modal perspective, there are various clinical implications. First, this study highlights the importance of examining parenting factors (i.e., ER, parenting stress, and parenting 
behaviors) when considering interventions for children with behavior problems, specifically ADHD. For example, as seen in Table 6, there were no significant differences in continuous measures of child symptomology (ADHD or ODD) or ED. However, from a diagnostic standpoint, we found children with ADHD and cooccurring ODD were more likely to have mothers with suboptimal ER strategies. Therefore, identifying if a child has "pure" ADHD or a co-occurring presentation will be helpful in identifying appropriate interventions considering mothers of children with the co-occurring presentation are at risk of having greater ER deficits themselves. Thus, interventions, which focus on improving parents' ER strategies, may be promising in attenuating mothers' ER problems.

While behavioral parent training programs such as Positive Parenting Program (Triple P; Sanders et al., 2000) and Parent-Child Interaction Therapy (PCIT; Eyberg et al., 2001) are effective in improving parenting and child behaviors, mothers with greater ADHD related impairments, such as poor ER, might benefit from alternative treatments. For example, mothers with ADHD may benefit from a combined treatment that is sequenced (Schoenfelder et al., 2019) to address their most impairing behaviors, such as poor ER strategies. We found there were no differences on selfreported ER (DERS); however, there were significant differences across physiological and behavioral indices of ER. While equipment for physiological acquisition may be limited to university-based settings, examining parents interacting with their children during challenging tasks can still yield helpful information on the parent-child dynamic and any dysfunctional behaviors. 
While there were no behavioral differences between mothers in the mixed and high ER groups, there were significant differences in their physiological reactions. One theory to support these differences in physiological functioning is the role cognitive reappraisal, which involves changing the meaning or thoughts about a stimulus/situation as a means to alter its change the emotional impact. Individuals who engage in cognitive reappraisal tend to demonstrate greater levels of emotion regulation (Gross 1998, 2015) as well as decreased likelihood of having psychopathology (Aldao, Nolen-Hoeskema, \& Schweizer, 2010). Deater-Decker and colleagues (2016) found that greater levels of ER and cognitive appraisal strategies during a challenging situation with their young child was associated with greater levels of positive affect and less negative affect. Thus, it may be the case that the largest difference between mothers in the mixed ER and high ER group is the physiologically taxing effect of cognitive reappraisal during the clean up task. It is also important to note that mothers in the mixed ER group were more likely to also have children with higher levels of hyperactivity/impulsivity symptoms, therefore requiring them to constantly upregulate their ER strategies (i.e.. physiological regulation [augmented RSA-W] and cognitive appraisal skills) in order to effective manage their own emotions as well as their child's behavior.

In summary, our multimodal assessment of maternal ER, which included physiological, behavioral, and self-reported ER strategies, yielded four distinct profiles: mixed, moderate, low, and high ER. By examining various indices of ER, we were able to further explain the heterogeneity in how mothers interact with their children during stressful situations. At a biological level, we found that mothers in the 
mixed ER group experience a unique ANS response in which there is a co-activation of the PNS and SNS branch. Most interestingly, mothers in the mixed ER profile were physiologically over aroused yet appeared behaviorally regulated. Behaviorally, mothers in the low ER profile experienced the most distress and were the least regulated during the clean up task. In regards to the moderate profile, mothers exhibited some co-activation of ANS, as indexed by a small augmented RSA score and a high PEP shortening (or PEP-R score), as well as some difficulties controlling their behavioral response. Lastly, the high ER profile was characterized as behaviorally regulated and predominantly PNS-controlled, as indexed by a greater RSA-W score and almost minimal shortening of PEP.

When examined continuously, the probability of pertaining to each of these maternal ER profiles was highly associated with DON'T skills. Not surprisingly, the probability of being in the high and mixed ER profile was greater for mothers with low DON'T skills and the inverse is was true for mothers in the low and moderate profiles. Interestingly, mothers in the mixed ER profile were less likely to have high levels of stress and mothers in the high ER profile reported having children with lower levels of hyperactivity/impulsivity symptoms.

While interventions may not be able to target a parent's physiological function directly, behavioral changes (i.e., improved ER during a challenging situation) may be associated with favorable outcomes for both parents and their children. Understanding ER functioning (Maliken \& Katz, 2013) prior to the start of treatment may be necessary in order to provide "precision medicine" (Insel, 2014) to parents whom may not benefit from the current traditional parent training programs. For 
example, the use of a dyad task, such as the clean-up task, could be a useful tool in identifying specific targets of treatment for parents. Additionally, future research studies can employ longitudinal approaches to understand the temporal precedence of ER problems in mothers and their children. Given the bidirectional nature of mental health problems in children and their parents (Bagner et al., 2013), future work should identify how and when these problematic ER strategies emerge. In doing so, treatments can be tailored to fit the developmental period (i.e., toddler, school age, adolescence) during which children and their parents are experiencing significant impairments due to their ER strategies. Theoretically speaking, addressing these significant parent ER problems may decrease stress levels associated with parenting and also decrease the probability on engaging in negative parenting behaviors. 


\section{LIST OF REFERENCES}

Adler, L. A., Spencer, T., Faraone, S. V., Kessler, R. C., Howes, M. J., Biederman, J., \& Secnik, K. (2006). Validity of pilot Adult ADHD Self-Report Scale (ASRS) to rate adult ADHD symptoms. Annals of Clinical Psychiatry, 18(3), 145-148.

Ansell, E. B., Rando, K., Tuit, K., Guarnaccia, J., \& Sinha, R. (2012). Cumulative adversity and smaller gray matter volume in medial prefrontal, anterior cingulate, and insula regions. 72(1), 57-64.

Appelhans, B. M., \& Luecken, L. J. (2006). Heart rate variability as an index of regulated emotional responding. Review of general psychology, 10(3), 229.

Attention-deficit, S. O. (2011). ADHD: clinical practice guideline for the diagnosis, evaluation, and treatment of attention-deficit/hyperactivity disorder in children and adolescents. Pediatrics, peds. 2011-2654.

Bagner, D. M., Fernandez, M. A., \& Eyberg, S. M. (2004). Parent-child interaction therapy and chronic illness: A case study. Journal of Clinical Psychology in Medical Settings, 11(1), 1-6.

Bagner, D. M., Pettit, J. W., Lewinsohn, P. M., Seeley, J. R., \& Jaccard, J. (2013). Disentangling the temporal relationship between parental depressive symptoms and early child behavior problems: A transactional framework. Journal of Clinical Child \& Adolescent Psychology, 42(1), 78-90.

Bagner, D. M., Sheinkopf, S. J., Miller-Loncar, C. L., Vohr, B. R., Hinckley, M., Eyberg, S. M., \& Lester, B. M. (2009). Parent-child interaction therapy for children born premature: A case study and illustration of vagal tone as a physiological measure of treatment outcome. Cognitive and Behavioral Practice, 16(4), 468-477.

Barbaresi, W. J., Colligan, R. C., Weaver, A. L., Voigt, R. G., Killian, J. M., \& Katusic, S. K. (2013). Mortality, ADHD, and psychosocial adversity in adults with childhood ADHD: a prospective study. Pediatrics, 131(4), 637-644.

Barkley, R. A. (1997). Behavioral inhibition, sustained attention, and executive functions: constructing a unifying theory of ADHD. Psychological bulletin, 121(1), 65 .

Barkley, R. A. (2014). Attention-deficit hyperactivity disorder: A handbook for diagnosis and treatment: Guilford Publications.

Barkley, R. A., \& Fischer, M. (2010). The unique contribution of emotional impulsiveness to impairment in major life activities in hyperactive children as adults. Journal of the American Academy of Child \& Adolescent Psychiatry, 49(5), 503-513. 
Barkley, R. A., \& Mash, E. J. (2003). Child psychopathology: Guilford Press.

Barroso, N. E., Mendez, L., Graziano, P. A., \& Bagner, D. M. (2018). Parenting stress through the lens of different clinical groups: A systematic review \& meta-analysis. Journal of abnormal child psychology, 46(3), 449-461.

Beauchaine, T. (2001). Vagal tone, development, and Gray's motivational theory: Toward an integrated model of autonomic nervous system functioning in psychopathology. Development and psychopathology, 13(2), 183-214.

Beauchaine, T. P., Gatzke-Kopp, L., \& Mead, H. K. (2007). Polyvagal theory and developmental psychopathology: Emotion dysregulation and conduct problems from preschool to adolescence. Biological psychology, 74(2), 174184.

Beauchaine, T. P., Gatzke-Kopp, L., Neuhaus, E., Chipman, J., Reid, M. J., \& Webster-Stratton, C. (2013). Sympathetic-and parasympathetic-linked cardiac function and prediction of externalizing behavior, emotion regulation, and prosocial behavior among preschoolers treated for ADHD. Journal of consulting and clinical psychology, 81(3), 481.

Berg-Nielsen, T. S., Vikan, A., \& Dahl, A. A. (2002). Parenting related to child and parental psychopathology: A descriptive review of the literature. Clinical child psychology and psychiatry, 7(4), 529-552.

Berntson, G. G., Cacioppo, J. T., Binkley, P. F., Uchino, B. N., Quigley, K. S., \& Fieldstone, A. (1994). Autonomic cardiac control. III. Psychological stress and cardiac response in autonomic space as revealed by pharmacological blockades. Psychophysiology, 31(6), 599-608.

Berntson, G. G., Cacioppo, J. T., \& Quigley, K. S. (1991). Autonomic determinism: the modes of autonomic control, the doctrine of autonomic space, and the laws of autonomic constraint. Psychological review, 98(4), 459.

Berntson, G. G., Cacioppo, J. T., Quigley, K. S., \& Fabro, V. T. (1994). Autonomic space and psychophysiological response. Psychophysiology, 31(1), 44-61.

Blair, C. (2002). School readiness. Integrating cognition and emotion in a neurobiological conceptualization of children's functioning at school entry. The American psychologist, 57(2), 111-127.

Bornstein, M. H., \& Suess, P. E. (2000). Child and mother cardiac vagal tone: Continuity, stability, and concordance across the first 5 years. Developmental Psychology, 36(1), 54. 
Brenner, S. L., Beauchaine, T. P., \& Sylvers, P. D. (2005). A comparison of psychophysiological and self-report measures of BAS and BIS activation. Psychophysiology, 42(1), 108-115.

Cacioppo, J. T., Berntson, G. G., Binkley, P. F., Quigley, K. S., Uchino, B. N., \& Fieldstone, A. (1994). Autonomic cardiac control. II. Noninvasive indices and basal response as revealed by autonomic blockades. Psychophysiology, 31(6), 586-598.

Calkins, S. D., Graziano, P. A., \& Keane, S. P. (2007). Cardiac vagal regulation differentiates among children at risk for behavior problems. Biol Psychol, 74(2), 144-153.

Cannon, W. B. (1932). The wisdom of the body.

Caspi, A., Langley, K., Milne, B., Moffitt, T. E., O’Donovan, M., Owen, M. J., ... \& Williams, B. (2008). A replicated molecular genetic basis for subtyping antisocial behavior in children with attention-deficit/hyperactivity disorder. Archives of general psychiatry, 65(2), 203-210.

Chronis-Tuscano, A., O’Brien, K. A., Johnston, C., Jones, H. A., Clarke, T. L., Raggi, V. L., . . Seymour, K. E. (2011). The relation between maternal adhd symptoms \& improvement in child behavior following brief behavioral parent training is mediated by change in negative parenting. Journal of Abnormal Child Psychology, 39(7), 1047-1057. doi:10.1007/s10802-011-9518-2

Chronis-Tuscano, A., Raggi, V. L., Clarke, T. L., Rooney, M. E., Diaz, Y., \& Pian, J. (2008). Associations between maternal attention-deficit/hyperactivity disorder symptoms and parenting. Journal of abnormal child psychology, 36(8), 1237.

Chronis-Tuscano, A., Wang, C. H., Woods, K. E., Strickland, J., \& Stein, M. A. (2017). Parent ADHD and evidence-based treatment for their children: review and directions for future research. Journal of abnormal child psychology, 45(3), 501-517.

Clark, A. J., Dich, N., Lange, T., Jennum, P., Hansen, Å. M., Lund, R., \& Rod, N. H. (2014). Impaired sleep and allostatic load: cross-sectional results from the Danish Copenhagen Aging and Midlife Biobank. Sleep medicine, 15(12), 1571-1578.

Clerkin, S. M., Halperin, J. M., Marks, D. J., \& Policaro, K. L. (2007). Psychometric properties of the alabama parenting questionnaire-preschool revision. Journal of Clinical Child and Adolescent Psychology, 36(1), 19-28.

Cooper-Vince, C. E., DeSerisy, M., Cornacchio, D., Sanchez, A., McLaughlin, K. A., \& Comer, J. S. (2017). Parasympathetic reactivity and disruptive behavior problems in young children during interactions with their mothers and other 
adults: A preliminary investigation. Developmental psychobiology, 59(4), 543-550.

Cormier, E. (2008). Attention deficit/hyperactivity disorder: a review and update. Journal of pediatric nursing, 23(5), 345-357.

Craig, F., Operto, F. F., De Giacomo, A., Margari, L., Frolli, A., Conson, M., .. . Margari, F. J. P. r. (2016). Parenting stress among parents of children with neurodevelopmental disorders. 242, 121-129.

Crandall, A., Deater-Deckard, K., \& Riley, A. W. (2015). Maternal emotion and cognitive control capacities and parenting: A conceptual framework. Developmental review, 36, 105-126.

Crnic, K. A., \& Greenberg, M. T. J. C. d. (1990). Minor parenting stresses with young children. 61(5), 1628-1637.

Deater-Deckard, K. (2008). Parenting stress: Yale University Press.

Denham, S. A. (1986). Social cognition, prosocial behavior, and emotion in preschoolers: Contextual validation. Child development, 194-201.

Diamond, L. M., \& Aspinwall, L. G. (2003). Emotion regulation across the life span: An integrative perspective emphasizing self-regulation, positive affect, and dyadic processes. Motivation and Emotion, 27(2), 125-156.

Dimsdale, J. E. (2008). Psychological stress and cardiovascular disease. Journal of the American College of Cardiology, 51(13), 1237-1246.

Dube, S. R., Fairweather, D., Pearson, W. S., Felitti, V. J., Anda, R. F., \& Croft, J. B. (2009). Cumulative childhood stress and autoimmune diseases in adults. Psychosomatic medicine, 71(2), 243.

Eiden, R. D., Colder, C., Edwards, E. P., \& Leonard, K. E. (2009). A longitudinal study of social competence among children of alcoholic and nonalcoholic parents: Role of parental psychopathology, parental warmth, and selfregulation. Psychology of addictive behaviors, 23(1), 36.

Eyberg, S., Nelson, M., Duke, M., \& Boggs, S. (2005). Manual for the dyadic parentchild interaction coding system. Retrieved July, 28, 2006.

Eyberg, S., Nelson, M., Ginn, N., Bhuiyan, N., \& Boggs, S. (2013). Dyadic parentchild interaction coding system: Comprehensive manual for research and training. Gainesville, FL: PCIT International. 
Felitti, V. J., \& Anda, R. F. (2010). The relationship of adverse childhood experiences to adult medical disease, psychiatric disorders, and sexual behavior: Implications for healthcare. The impact of early life trauma on health and disease: The hidden epidemic, 77-87.

Faraone, S. V., Rostain, A. L., Blader, J., Busch, B., Childress, A. C., Connor, D. F., \& Newcorn, J. H. (2019). Practitioner Review: Emotional dysregulation in attention-deficit/hyperactivity disorder-implications for clinical recognition and intervention. Journal of Child Psychology and Psychiatry, 60(2), 133-150.

Fontes, L. A. (2002). Child discipline and physical abuse in immigrant Latino families: Reducing violence and misunderstandings. Journal of Counseling \& Development, 80(1), 31-40.

Foster, E. M., Jensen, P. S., Schlander, M., Pelham, W. E., Jr., Hechtman, L., Arnold, L. E., .. . Wigal, T. (2007). Treatment for ADHD: is more complex treatment cost-effective for more complex cases? Health services research, 42(1 Pt 1), 165-182. doi:10.1111/j.1475-6773.2006.00599.x

Frick, P. J. (2004). The inventory of callous-unemotional traits. Unpublished rating scale.

Friedman, B. H., \& Thayer, J. F. (1998). Autonomic balance revisited: panic anxiety and heart rate variability. Journal of psychosomatic research, 44(1), 133-151.

Goldsmith, H., \& Rothbart, M. (1996). The Laboratory Temperament Assessment Battery (LabTAB): Locomotor version 3.0 technical manual. Madison, WI: Department of Psychology, University of Wisconsin.

Goldstein, D. S., \& McEwen, B. (2002). Allostasis, homeostats, and the nature of stress. Stress, 5(1), 55-58.

Golfenshtein, N., Srulovici, E., \& Medoff-Cooper, B. (2016). Investigating parenting stress across pediatric health conditions-a systematic review. Comprehensive child and adolescent nursing, 39(1), 41-79.

Graziano, P., \& Derefinko, K. (2013). Cardiac vagal control and children's adaptive functioning: A meta-analysis. Biological psychology, 94(1), 22-37.

Graziano, P. A., \& Garcia, A. (2016). Attention-deficit hyperactivity disorder and children's emotion dysregulation: A meta-analysis. Clinical psychology review, 46, 106-123.

Graziano, P. A., Keane, S. P., \& Calkins, S. D. (2010). Maternal Behavior and Children's Early Emotion Regulation Skills Differentially Predict Development of Children's Reactive Control and Later Effortful Control. Infant Child Dev, 19(4), 333-353. doi:10.1002/icd.670 
Graziano, P. A., Slavec, J., Hart, K., Garcia, A., \& Pelham Jr, W. E. (2014). Improving school readiness in preschoolers with behavior problems: Results from a summer treatment program. Journal of Psychopathology and Behavioral Assessment, 36(4), 555-569.

Gross, J. J. (2011). Handbook of emotion regulation: Guilford Press.

Gross, J. J., \& John, O. P. (2003). Individual differences in two emotion regulation processes: implications for affect, relationships, and well-being. Journal of Personality and Social Psychology, 85(2), 348.

Grossman, P., Stemmler, G., \& Meinhardt, E. (1990). Paced respiratory sinus arrhythmia as an index of cardiac parasympathetic tone during varying behavioral tasks. Psychophysiology, 27(4), 404-416.

Guelzow, B. T., Loya, F., \& Hinshaw, S. P. (2016). How persistent is ADHD into adulthood? Informant report and diagnostic thresholds in a female sample. Journal of abnormal child psychology, 1-12.

Hamilton, J. L., \& Alloy, L. B. (2016). Atypical reactivity of heart rate variability to stress and depression across development: Systematic review of the literature and directions for future research. Clinical Psychology Review, 50, 67-79.

Han, Z. R., Lei, X., Qian, J., Li, P., Wang, H., \& Zhang, X. (2016). Parent and child psychopathological symptoms: the mediating role of parental emotion dysregulation. Child and Adolescent Mental Health, 21(3), 161-168.

Han, Z. R., \& Shaffer, A. (2014). Maternal expressed emotion in relation to child behavior problems: Differential and mediating effects. Journal of Child and Family Studies, 23(8), 1491-1500.

Hartman, C. A., Rhee, S. H., Willcutt, E. G., \& Pennington, B. F. (2007). Modeling rater disagreement for ADHD: are parents or teachers biased? Journal of Abnormal Child Psychology, 35(4), 536-542.

Harvey, E. (1998). Parental employment and conduct problems among children with attention-deficit/hyperactivity disorder: An examination of child care workload and parenting well-being as mediating variables. Journal of Social and Clinical Psychology, 17(4), 476-490.

Hawes, D. J., \& Dadds, M. R. (2006). Assessing parenting practices through parentreport and direct observation during parent-training. Journal of Child and Family Studies, 15(5), 554-567. 
Hawes, S. W., Byrd, A. L., Henderson, C. E., Gazda, R. L., Burke, J. D., Loeber, R., $\&$ Pardini, D. A. (2014). Refining the parent-reported Inventory of CallousUnemotional Traits in boys with conduct problems. Psychological Assessment, 26(1), 256.

Hinshaw, S. P., Owens, E. B., Wells, K. C., Kraemer, H. C., Abikoff, H. B., Arnold, L. E., . . Hechtman, L. (2000). Family processes and treatment outcome in the MTA: Negative/ineffective parenting practices in relation to multimodal treatment. Journal of abnormal child psychology, 28(6), 555-568.

Hoffman, M. L. (2001). Empathy and moral development: Implications for caring and justice: Cambridge University Press.

Insel, T., Cuthbert, B., Garvey, M., Heinssen, R., Pine, D. S., Quinn, K., . . W Wang, P. (2010). Research domain criteria (RDoC): toward a new classification framework for research on mental disorders. In: Am Psychiatric Assoc.

Insel, T. R. (2014). The NIMH research domain criteria (RDoC) project: precision medicine for psychiatry. American Journal of Psychiatry, 171(4), 395-397.

Jackson, J. S., Knight, K. M., \& Rafferty, J. A. (2010). Race and unhealthy behaviors: chronic stress, the HPA axis, and physical and mental health disparities over the life course. American journal of public health, 100(5), 933-939.

Jeynes, W. H. (2016). Meta-analysis on the roles of fathers in parenting: Are they unique? Marriage \& Family Review, 52(7), 665-688.

Kaiser, N. M., McBurnett, K., \& Pfiffner, L. J. (2011). Child ADHD severity and positive and negative parenting as predictors of child social functioning: Evaluation of three theoretical models. Journal of Attention Disorders, 15(3), 193-203.

Kalvin, C. B., Bierman, K. L., \& Gatzke-Kopp, L. M. (2016). Emotional reactivity, behavior problems, and social adjustment at school entry in a high-risk sample. Journal of abnormal child psychology, 44(8), 1527-1541.

Kaminski, J. W., Valle, L. A., Filene, J. H., \& Boyle, C. L. (2008). A meta-analytic review of components associated with parent training program effectiveness. Journal of abnormal child psychology, 36(4), 567-589. doi:10.1007/s10802007-9201-9

Kaufman, E. A., Xia, M., Fosco, G., Yaptangco, M., Skidmore, C. R., \& Crowell, S. E. (2016). The Difficulties in Emotion Regulation Scale Short Form (DERSSF): validation and replication in adolescent and adult samples. Journal of Psychopathology and Behavioral Assessment, 38(3), 443-455. 
Kiecolt-Glaser, J. K., Gouin, J.-P., Weng, N.-p., Malarkey, W. B., Beversdorf, D. Q., \& Glaser, R. (2011). Childhood adversity heightens the impact of later-life caregiving stress on telomere length and inflammation. Psychosomatic medicine, 73(1), 16.

Kim, H. K., Capaldi, D. M., Pears, K. C., Kerr, D. C., \& Owen, L. D. (2009). Intergenerational transmission of internalising and externalising behaviours across three generations: Gender-specific pathways. Criminal Behaviour and Mental Health, 19(2), 125-141.

Knappe, S., Lieb, R., Beesdo, K., Fehm, L., Ping Low, N. C., Gloster, A. T., \& Wittchen, H. U. (2009). The role of parental psychopathology and family environment for social phobia in the first three decades of life. Depression and Anxiety, 26(4), 363-370.

Kreibig, S. D. (2010). Autonomic nervous system activity in emotion: A review. Biological psychology, 84(3), 394-421.

Kreibig, S. D., Wilhelm, F. H., Roth, W. T., \& Gross, J. J. (2007). Cardiovascular, electrodermal, and respiratory response patterns to fear-and sadness-inducing films. Psychophysiology, 44(5), 787-806.

Lane, R. D., McRae, K., Reiman, E. M., Chen, K., Ahern, G. L., \& Thayer, J. F. (2009). Neural correlates of heart rate variability during emotion. Neuroimage, 44(1), 213-222.

Larsson, H., Chang, Z., D'Onofrio, B. M., \& Lichtenstein, P. (2014). The heritability of clinically diagnosed attention deficit hyperactivity disorder across the lifespan. Psychological medicine, 44(10), 2223-2229.

Lenneman, J. K., \& Backs, R. W. (2009). Cardiac autonomic control during simulated driving with a concurrent verbal working memory task. Human factors, 5l(3), 404-418.

Maliken, A. C., \& Katz, L. F. (2013). Exploring the impact of parental psychopathology and emotion regulation on evidence-based parenting interventions: A transdiagnostic approach to improving treatment effectiveness. Clinical Child and Family Psychology Review, 16(2), 173-186.

Matza, L. S., Paramore, C., \& Prasad, M. (2005). A review of the economic burden of ADHD. Cost effectiveness and resource allocation, 3(1), 5.

Mazursky-Horowitz, H., Felton, J. W., MacPherson, L., Ehrlich, K. B., Cassidy, J., Lejuez, C., \& Chronis-Tuscano, A. (2015). Maternal emotion regulation mediates the association between adult attention-deficit/hyperactivity disorder 
symptoms and parenting. Journal of abnormal child psychology, 43(1), 121131.

Mennin, D. S., Heimberg, R. G., Turk, C. L., \& Fresco, D. M. (2005). Preliminary evidence for an emotion dysregulation model of generalized anxiety disorder. Behaviour Research and Therapy, 43(10), 1281-1310.

Merrill, B. M., Morrow, A. S., Altszuler, A. R., Macphee, F. L., Coxe, S., Molina, B. S., \& Pelham, W. E. (2016). 6.70. Young adults with childhood attentiondeficit/hyperactivity disorder: latent profiles of functional outcomes and impairment. Journal of the American Academy of Child \& Adolescent Psychiatry, 55(10), S227.

Miller, G. E., \& Blackwell, E. (2006). Turning up the heat: Inflammation as a mechanism linking chronic stress, depression, and heart disease. Current Directions in Psychological Science, 15(6), 269-272.

Mokrova, I., O'Brien, M., Calkins, S., \& Keane, S. (2010). Parental ADHD symptomology and ineffective parenting: The connecting link of home chaos. Parenting: Science and Practice, 10(2), 119-135.

Morelen, D., Shaffer, A., \& Suveg, C. (2016). Maternal emotion regulation: Links to emotion parenting and child emotion regulation. Journal of Family Issues, 37(13), 1891-1916.

Morris, A. S., Silk, J. S., Steinberg, L., Myers, S. S., \& Robinson, L. R. (2007). The role of the family context in the development of emotion regulation. Social development, 16(2), 361-388.

Neece, C. L., Green, S. A., \& Baker, B. L. (2012). Parenting stress and child behavior problems: A transactional relationship across time. American journal on intellectual and developmental disabilities, 117(1), 48-66.

O'Connor, T. G., Heron, J., Golding, J., Glover, V., \& Team, A. S. S. (2003). Maternal antenatal anxiety and behavioural/emotional problems in children: a test of a programming hypothesis. Journal of Child Psychology and Psychiatry, 44(7), 1025-1036.

Pai, A. L., Greenley, R. N., Lewandowski, A., Drotar, D., Youngstrom, E., \& Peterson, C. C. (2007). A meta-analytic review of the influence of pediatric cancer on parent and family functioning. Journal of Family Psychology, 21(3), 407.

Park, J. L., Hudec, K. L., \& Johnston, C. (2017). Parental ADHD symptoms and parenting behaviors: A meta-analytic review. Clinical Psychology Review, 56, 25-39. 
Pelham, \& Fabiano, G. A. (2008). Evidence-based psychosocial treatments for attention-deficit/hyperactivity disorder. Journal of Clinical Child and Adolescent Psychology, 37(1), 184-214. doi:10.1080/15374410701818681

Pelham, W. E., Gnagy, E. M., Greenslade, K. E., \& Milich, R. (1992). Teacher ratings of DSM-III-R symptoms for the disruptive behavior disorders. Journal of the American Academy of Child \& Adolescent Psychiatry, 31(2), 210-218.

Porges, S. W. (2001). The polyvagal theory: phylogenetic substrates of a social nervous system. International Journal of Psychophysiology, 42(2), 123-146.

Porges, S. W. (2003). The polyvagal theory: Phylogenetic contributions to social behavior. Physiology \& Behavior, 79(3), 503-513.

Porges, S. W. (2007). The polyvagal perspective. Biological psychology, 74(2), 116143.

Porges, S. W., Doussard-Roosevelt, J. A., Portales, A. L., \& Greenspan, S. I. (1996). Infant regulation of the vagal "brake" predicts child behavior problems: A psychobiological model of social behavior. Developmental psychobiology, 29(8), 697-712.

Quittner, A. L., Glueckauf, R. L., \& Jackson, D. N. (1990). Chronic parenting stress: Moderating versus mediating effects of social support. Journal of personality and social psychology, 59(6), 1266.

Richardson, P. A., Bocknek, E. L., McGoron, L., \& Trentacosta, C. J. (2019). Fathering across contexts: The moderating role of respiratory sinus arrhythmia in predicting toddler emotion regulation. Developmental psychobiology.

Rodríguez, G. M., Bagner, D. M., \& Graziano, P. A. (2014). Parent training for children born premature: A pilot study examining the moderating role of emotion regulation. Child Psychiatry \& Human Development, 45(2), 143-152.

Ryser, G. (2011). Fairness in testing and nonbiased assessment. Identifying gifted children: A practical guide, 63-74.

Schoenfelder, E. N., Chronis-Tuscano, A., Strickland, J., Almirall, D., \& Stein, M. A. (2019). Piloting a Sequential, Multiple Assignment, Randomized Trial for Mothers with Attention-Deficit/Hyperactivity Disorder and Their At-Risk Young Children. Journal of Child and Adolescent Psychopharmacology, 29(4), 256-267.

Seymour, M., Giallo, R., Cooklin, A., \& Dunning, M. (2015). Maternal anxiety, risk factors and parenting in the first post-natal year. Child: care, health and development, 41(2), 314-323. 
Shelton, K. K., Frick, P. J., \& Wootton, J. (1996). Assessment of parenting practices in families of elementary school-age children. Journal of clinical child psychology, 25(3), 317-329.

Sibley, M. H., Pelham, W. E., Molina, B. S., Waschbusch, D. A., Gnagy, E. M., Babinski, D. E., \& Biswas, A. (2010). Inconsistent self-report of delinquency by adolescents and young adults with ADHD. Journal of Abnormal Child Psychology, 38(5), 645-656.

Sjöwall, D., Roth, L., Lindqvist, S., \& Thorell, L. B. (2013). Multiple deficits in ADHD: executive dysfunction, delay aversion, reaction time variability, and emotional deficits. Journal of Child Psychology and Psychiatry, 54(6), 619627.

Smith, M. J. C., \& Work, F. S. (2004). Parental mental health: disruptions to parenting and outcomes for children. $9(1), 3-11$.

Sonuga-Barke, E. J., Daley, D., \& Thompson, M. (2002). Does maternal ADHD reduce the effectiveness of parent training for preschool children's ADHD? Journal of the American Academy of Child \& Adolescent Psychiatry, 41(6), 696-702.

Staufenbiel, S. M., Penninx, B. W., Spijker, A. T., Elzinga, B. M., \& van Rossum, E. F. J. P. (2013). Hair cortisol, stress exposure, and mental health in humans: a systematic review. 38(8), 1220-1235.

Stifter, C. A., Dollar, J. M., \& Cipriano, E. A. (2011). Temperament and emotion regulation: the role of autonomic nervous system reactivity. Developmental psychobiology, 53(3), 266-279.

Sturge-Apple, M. L., Skibo, M. A., Rogosch, F. A., Ignjatovic, Z., \& Heinzelman, W. (2011). The impact of allostatic load on maternal sympathovagal functioning in stressful child contexts: Implications for problematic parenting. Development and Psychopathology, 23(3), 831-844.

Thayer, J. F., Åhs, F., Fredrikson, M., Sollers III, J. J., \& Wager, T. D. (2012). A meta-analysis of heart rate variability and neuroimaging studies: implications for heart rate variability as a marker of stress and health. Neuroscience \& Biobehavioral Reviews, 36(2), 747-756.

Thayer, J. F., Åhs, F., Fredrikson, M., Sollers, J. J., \& Wager, T. D. (2012). A metaanalysis of heart rate variability and neuroimaging studies: implications for heart rate variability as a marker of stress and health. Neuroscience \& Biobehavioral Reviews, 36(2), 747-756. 
Thayer, J. F., \& Lane, R. D. (2009). Claude Bernard and the heart-brain connection: Further elaboration of a model of neurovisceral integration. Neuroscience \& Biobehavioral Reviews, 33(2), 81-88.

Thayer, J. F., \& Sternberg, E. (2006). Beyond heart rate variability: vagal regulation of allostatic systems. Annals of the New York Academy of Sciences, 1088(1), 361-372.

Turney, K. (2011). Labored love: Examining the link between maternal depression and parenting behaviors. Social Science Research, 40(1), 399-415.

Van de Glind, G., van den Brink, W., Koeter, M. W., Carpentier, P. J., van Emmerikvan Oortmerssen, K., Kaye, S., ... \& Moggi, F. (2013). Validity of the Adult ADHD Self-Report Scale (ASRS) as a screener for adult ADHD in treatment seeking substance use disorder patients. Drug and alcohol dependence, 132(3), 587-596.

Victor, S. E., \& Klonsky, E. D. (2016). Validation of a Brief Version of the Difficulties in Emotion Regulation Scale (DERS-18) in Five Samples. Journal of Psychopathology and Behavioral Assessment, 1-8.

Visted, E., Sørensen, L., Osnes, B., Svendsen, J. L., Binder, P.-E., \& Schanche, E. (2017). The association between self-reported difficulties in emotion regulation and heart rate variability: the salient role of not accepting negative emotions. Frontiers in Psychology, 8, 328.

Voeller, K. K. (2004). Attention-deficit hyperactivity disorder (ADHD). Journal of child neurology, 19(10), 798-814.

Webster-Stratton, Reid, M. J., \& Beauchaine, T. (2011). Combining parent and child training for young children with ADHD. Journal of clinical child and adolescent psychology, 40(2), 191-203. doi:10.1080/15374416.2011.546044

Williams, D. P., Cash, C., Rankin, C., Bernardi, A., Koenig, J., \& Thayer, J. F. (2015). Resting heart rate variability predicts self-reported difficulties in emotion regulation: a focus on different facets of emotion regulation. Frontiers in psychology, 6, 261.

Williams, S. R., \& Woodruff-Borden, J. (2015). Parent emotion socialization practices and child self-regulation as predictors of child anxiety: the mediating role of cardiac variability. Child Psychiatry \& Human Development, 46(4), 512-522.

Woods, K. E., Mazursky-Horowitz, H., Thomas, S. R., Dougherty, L. R., \& ChronisTuscano, A. The unique effects of maternal adhd symptoms and emotion 
dysregulation on parenting behavior. $O(0), 1087054719829820$.

doi: $10.1177 / 1087054719829820$

Wymbs, B. T., Wymbs, F. A., \& Dawson, A. E. (2015). Child ADHD and ODD behavior interacts with parent ADHD symptoms to worsen parenting and interparental communication. Journal of abnormal child psychology, 43(1), 107-119.

Yap, M. B., Schwartz, O. S., Byrne, M. L., Simmons, J. G., \& Allen, N. B. (2010). Maternal positive and negative interaction behaviors and early adolescents' depressive symptoms: Adolescent emotion regulation as a mediator. Journal of Research on Adolescence, 20(4), 1014-1043. 
Table 1. Maternal Demographics by Child Diagnostic Group

ADHD $\quad$ TD $\quad$ Full Sample

\begin{tabular}{llll}
\hline Maternal Age M (SD) & $35.92(6.05)$ & $36.08(5.43)$ & $35.98(5.79)$ \\
Marital Status (Married) & & & \\
Race/Ethnicity & $71.6 \%$ & $81.8 \%$ & $75.7 \%$ \\
White & & & \\
Black & $88.8 \%$ & $87.9 \%$ & $88.5 \%$ \\
Other & $10.3 \%$ & $9.1 \%$ & $9.9 \%$ \\
Hispanic & $.8 \%$ & $4.5 \%$ & $.5 \%$ \\
Education & $81.0 \%$ & $80.3 \%$ & $81.2 \%$ \\
Some high school & & & \\
High school diploma & $1.7 \%$ & $4.5 \%$ & $2.8 \%$ \\
Some college & $7.8 \%$ & $6.1 \%$ & $7.2 \%$ \\
Associate degree & $19.0 \%$ & $7.6 \%$ & $14.9 \%$ \\
College graduate & $7.8 \%$ & $15.2 \%$ & $10.5 \%$ \\
Advanced degree & $31.0 \%$ & $31.8 \%$ & $31.5 \%$ \\
\hline
\end{tabular}

Note. There were no demographic differences across 1) maternal profiles or 2) diagnostic groups, $\mathrm{ER}=$ emotion regulation, $\mathrm{ADHD}=$ Attention-deficit/hyperactivity disorder, TD = Typically developing; $\mathrm{a}=$ marital status as defined by living with partner/married or single; $b=$ "Other" race defined as Asian or Indian American/Native Alaskan. 
Table 2. Maternal ER by Child Diagnostic Group

\begin{tabular}{|c|c|c|c|c|}
\hline & Full Sample & ADHD & TD & $\mathbf{F}$ \\
\hline \multicolumn{5}{|l|}{ Variable } \\
\hline PEP BL (O) & $99.77(13.71)$ & $\begin{array}{l}100.74 \\
(14.87)\end{array}$ & $98.22(11.55)$ & 1.29 \\
\hline RSA BL (O) & $6.03(1.04)$ & $6.02(1.00)$ & $6.04(1.11)$ & .01 \\
\hline PEP-R (O) & $-4.73(13.32)$ & $-5.26(14.54)$ & $-3.88(11.18)$ & .35 \\
\hline RSA-W (O) & $-.04(.83)$ & $-.05(.85)$ & $-.01(.81)$ & .07 \\
\hline DERS (S) & $1.78(.55)$ & $1.85(.60)$ & $1.65(.41)$ & $6.10 \%$ \\
\hline Pro Distress (O) & $.08(.10)$ & $.10(.10)$ & $.05(.06)$ & $12.41 * * *$ \\
\hline Global Reg (O) & $3.32(.66)$ & $3.20(.65)$ & $3.53(.61)$ & $10.83 * * *$ \\
\hline $\begin{array}{l}\text { Parent ADHD } \\
\text { (S) }\end{array}$ & $1.23(.64)$ & $1.41(.62)$ & $.93(.53)$ & $27.64 * * *$ \\
\hline$(+)$ Parenting (S) & $69.16(6.74)$ & $67.81(7.19)$ & $71.55(5.09)$ & $13.92 * * *$ \\
\hline (-) Parenting (S) & $29.35(6.55)$ & $30.59(6.83)$ & $27.15(5.41)$ & $12.25 * * *$ \\
\hline Parent Stress (S) & $71.34(22.62)$ & $80.36(22.06)$ & $55.25(12.44)$ & $71.43 * * *$ \\
\hline DO Skills (O) & $.07(.08)$ & $.07(.09)$ & $.07(.06)$ & .44 \\
\hline $\begin{array}{l}\text { DON'T Skills } \\
(\mathrm{O})\end{array}$ & $.56(.14)$ & $.58(.14)$ & $.52(.12)$ & $7.91 * *$ \\
\hline
\end{tabular}

Note. Note. $\mathrm{BL}=$ Baseline; $\mathrm{PEP}=$ Pre-ejection period; $\mathrm{PEP} \mathrm{R}=$ PEP reactivity; $\mathrm{RSA}=$ respiratory sinus arrhythmia; RSA W $=$ RSA withdrawal; DERS $=$ Difficulties in Emotion Regulation Scale; $\mathrm{O}=$ Observation; $\mathrm{S}=$ Self-report; + = Positive parenting; - = Negative parenting 
Table 3. Child Symptomology and ER differences by Diagnostic Group

\begin{tabular}{|c|c|c|c|c|}
\hline & Full Sample & ADHD & TD & $X^{2} / F$ \\
\hline Age & $5.43(.80)$ & $5.41(.75)$ & $5.47(.90)$ & .27 \\
\hline Sex (male) & $78 \%$ & $80.2 \%$ & $74.2 \%$ & .86 \\
\hline IQ & $96.70(13.28)$ & $93.53(13.26)$ & $102.21(11.46)$ & $19.79^{* * *}$ \\
\hline \multicolumn{5}{|l|}{ Race/Ethnicity } \\
\hline White & $89.0 \%$ & $88.8 \%$ & $89.4 \%$ & .02 \\
\hline Black & $11.0 \%$ & $12.1 \%$ & $9.1 \%$ & .38 \\
\hline Other & $2.7 \%$ & .9 & $4.5 \%$ & 1.77 \\
\hline Hispanic & $85.2 \%$ & $85.3 \%$ & $84.8 \%$ & .05 \\
\hline $\begin{array}{l}\text { Symptomology/ ER } \\
\text { Domains } \\
\text { INATT symptoms } \\
\text { (C) }\end{array}$ & $1.54(.99)$ & $2.17(.58)$ & $.44(.43)$ & $452.51^{* * *}$ \\
\hline HI symptoms $(\mathrm{C})$ & $1.70(.97)$ & $2.30(.57)$ & $.64(.48)$ & $397.21^{* * *}$ \\
\hline ODD symptoms (C) & $1.16(.88)$ & $1.62(.72)$ & $.34(.41)$ & $180.98^{* * *}$ \\
\hline $\begin{array}{l}\text { Emotion } \\
\text { Knowledge (O) } \\
\text { Proportion of time } \\
\text { in distress (O) }\end{array}$ & $\begin{array}{l}10.03(2.13) \\
.52(.29)\end{array}$ & $\begin{array}{l}9.97(2.11) \\
.35(.21)\end{array}$ & $\begin{array}{l}10.16(2.18) \\
.79(.16)\end{array}$ & $\begin{array}{l}.33 \\
206.80^{* * *}\end{array}$ \\
\hline Negativity (C) & $2.27(.63)$ & $2.62(.46)$ & $1.67(.40)$ & $196.96^{* * *}$ \\
\hline CU-behaviors (C) & $1.08(.54)$ & $1.31(.52)$ & $.68(.27)$ & $81.33^{* * *}$ \\
\hline
\end{tabular}

Note. $\mathrm{O}=$ Observation; $\mathrm{C}=\mathrm{Combined}$ report, $\mathrm{ER}=$ Emotion regulation 
Table 4. Correlation Among Emotion Regulation Measures and Maternal Factors

\begin{tabular}{|c|c|c|c|c|c|c|c|c|c|c|c|c|c|}
\hline & 1 & 2 & 3 & 4 & 5 & 6 & 7 & 8 & 9 & 10 & 11 & 12 & 13 \\
\hline 1. PEP BL $(\mathrm{O})$ & - & & & & & & & & & & & & \\
\hline 2. RSA BL (O) & $.17^{*}$ & - & & & & & & & & & & & \\
\hline 3. PEP-R (O) & $-.45 * * *$ & -.04 & - & & & & & & & & & & \\
\hline 4. RSA-W (O) & $-.17^{*}$ & $.48 * * *$ & .13 & - & & & & & & & & & \\
\hline 5. DERS (S) & -.02 & -.02 & -.05 & .06 & - & & & & & & & & \\
\hline 6. Pro Distress $(\mathrm{O})$ & .10 & $.21^{* *}$ &.-.07 & .04 & .09 & - & & & & & & & \\
\hline 7. Global Reg (O) & -.09 & -.10 & .15 & .01 & -.09 & $-.69 * * *$ & - & & & & & & \\
\hline 8. Parent ADHD (S) & .08 & .08 & -.08 & .01 & $.60 * * *$ & .07 & -.01 & - & & & & & \\
\hline 9. $(+)$ Parenting $(\mathrm{S})$ & -.11 & -.10 & .16 & .001 & $-.37 * * *$ & $-.17 *$ & .13 & $-.34 * * *$ & - & & & & \\
\hline 10. (-) Parenting (S) & .13 & -.04 & .07 & -.07 & $.41^{* * *}$ & .09 & -.08 & $.28 * * *$ & $-.30 * * *$ & - & & & \\
\hline 11. Parent Stress (S) & -.10 & .07 & .01 & .06 & $.43 * * *$ & $.16^{*}$ & -.12 & $.42 * * *$ & $-.31 * * *$ & $.23 * *$ & - & & \\
\hline 12. DO Skills (O) & -.04 & -.07 & -.05 & -.04 & .03 & $-.22 * *$ & $.17 *$ & .04 & -.003 & $-.15^{*}$ & .04 & $\begin{array}{c}- \\
- \\
.47^{*}\end{array}$ & \\
\hline 13. DON'T Skills (O) & -.01 & .09 & .01 & .004 & .03 & $.40 * * *$ & $-.37 * * *$ & .07 & -.10 & .07 & .07 & $* *$ & - \\
\hline
\end{tabular}

Note. $\mathrm{BL}=$ Baseline; $\mathrm{PEP}=$ Pre-ejection period; PEP-R $=$ PEP reactivity; RSA = respiratory sinus arrhythmia; RSA-W $=\mathrm{RSA}$

withdrawal; DERS = Difficulties in Emotion Regulation Scale; $\mathrm{O}=$ Observation; $\mathrm{S}=$ Self-report; + = Positive parenting; - = Negative parenting 
Table 5. Maternal Demographics by ER profile

\begin{tabular}{llllll}
\hline & Mixed ER & Moderate ER & Low ER & High ER & Full Sample \\
\hline Maternal Age M (SD) & $37.75(5.48)$ & $34.98(5.75)$ & $35.72(5.62)$ & $34.98(5.85)$ & $35.98(5.79)$ \\
Marital Status (Married) & & & & & \\
Race/Ethnicity & $76.2 \%$ & $66.3 \%$ & $66.6 \%$ & $84.2 \%$ & $75.7 \%$ \\
White & & & & & \\
Black & $81.3 \%$ & $91.8 \%$ & $100 \%$ & $91.2 \%$ & $88.5 \%$ \\
Other & $15.6 \%$ & $6.1 \%$ & $0 \%$ & $8.8 \%$ & $9.9 \%$ \\
Hispanic & $3.1 \%$ & $2.0 \%$ & $0 \%$ & $1.8 \%$ & $.5 \%$ \\
Education & $71.4 \%$ & $85.7 \%$ & $83.3 \%$ & $87.7 \%$ & $81.2 \%$ \\
Some high school & $4.8 \%$ & & & & \\
High school diploma & $6.3 \%$ & $2 \%$ & $0 \%$ & $1.8 \%$ & $2.8 \%$ \\
Some college & $11.1 \%$ & $10.2 \%$ & $0 \%$ & $7.0 \%$ & $7.2 \%$ \\
Associate degree & $12.7 \%$ & $22.4 \%$ & $16.7 \%$ & $12.3 \%$ & $14.9 \%$ \\
College graduate & $36.5 \%$ & $6.1 \%$ & $8.3 \%$ & $12.3 \%$ & $10.5 \%$ \\
Advanced degree & $28.6 \%$ & $36.7 \%$ & $33.3 \%$ & $35.1 \%$ & $33.1 \%$ \\
\hline Note. There & & & & $31.6 \%$ & $3 \%$ \\
\hline
\end{tabular}

Note. There were no demographic differences across 1) maternal profiles or 2) diagnostic groups, ER = emotion regulation, $\mathrm{ADHD}=$ Attention-deficit/hyperactivity disorder, $\mathrm{TD}=$ Typically developing; $\mathrm{a}=$ marital status as defined by living with partner/married or single; $b=$ "Other" race defined as Asian or Indian American/Native Alaskan. 
Table 6. Fit Indices for Profile Solutions

\begin{tabular}{lrrrrr}
\hline Fit statistic & \multicolumn{5}{c}{ Number of profiles } \\
\hline AIC & 1 & 2 & 3 & 4 & 5 \\
BIC & 3667.35 & 3549.38 & 3479.76 & 3457.56 & 3415.36 \\
Adjusted BIC & 3712.2 & 3619.87 & 3575.88 & 3579.31 & 3562.74 \\
Bootstrapped LRT & 3667.86 & 3550.2 & 3480.87 & 3458.96 & 3417.06 \\
Entropy & & 133.96 & 85.62 & 38.2 & 62.63 \\
Smallest n & & 0.91 & 0.86 & 0.74 & 0.87 \\
Note. AIC Akakk & 182 & 24 & 11 & 12 & 4
\end{tabular}

Note. AIC $=$ Akaike information criterion; $\mathrm{BIC}=$ Bayesian information criterion;

LRT $=$ Likelihood ratio test 
Table 7. Maternal Emotion Regulation Profile Membership by Diagnostic Group

\begin{tabular}{llllll}
\hline & & Mixed ER & Moderate ER & Low ER* & High ER \\
\hline Control & Actual & 24 & 14 & 1 & 27 \\
& Expected & 23.2 & 17.8 & 4.4 & 20.7 \\
ADHD & Actual & 40 & 35 & 11 & 30 \\
& Expected & 40.8 & 31.2 & 7.6 & 36.3 \\
$\mathrm{~N}$ & & 64 & 49 & 12 & 57 \\
\hline
\end{tabular}

Note. $*$ Pearson $\chi^{2}(3)=8.39, \mathrm{p}<.05$. ER $=$ Emotion regulation. 
Table 8. Maternal Demographics by ER profile

\begin{tabular}{llllll}
\hline & Mixed ER & Moderate ER & Low ER & High ER & Full Sample \\
\hline Maternal Age M (SD) & $37.75(5.48)$ & $34.98(5.75)$ & $35.72(5.62)$ & $34.98(5.85)$ & $35.98(5.79)$ \\
Marital Status (Married) ${ }^{\mathrm{a}}$ & $76.2 \%$ & $66.3 \%$ & $66.6 \%$ & $84.2 \%$ & $75.7 \%$ \\
Race/Ethnicity & & & & \\
White & $81.3 \%$ & $91.8 \%$ & $100 \%$ & $91.2 \%$ & $88.5 \%$ \\
Black & $15.6 \%$ & $6.1 \%$ & $0 \%$ & $8.8 \%$ & $9.9 \%$ \\
Other & $3.1 \%$ & $2.0 \%$ & $0 \%$ & $1.8 \%$ & $.5 \%$ \\
Hispanic & $71.4 \%$ & $85.7 \%$ & $83.3 \%$ & $87.7 \%$ & $81.2 \%$ \\
Education & & & & $1.8 \%$ & $2.8 \%$ \\
Some high school & $4.8 \%$ & $2 \%$ & $0 \%$ & $7.0 \%$ & $7.2 \%$ \\
High school diploma & $6.3 \%$ & $10.2 \%$ & $0 \%$ & $12.3 \%$ & $14.9 \%$ \\
Some college & $11.1 \%$ & $22.4 \%$ & $16.7 \%$ & $12.3 \%$ & $10.5 \%$ \\
Associate degree & $12.7 \%$ & $6.1 \%$ & $8.3 \%$ & $31.6 \%$ & $31.5 \%$ \\
College graduate & $36.5 \%$ & $22.4 \%$ & $41.7 \%$ & $35.1 \%$ & $33.1 \%$ \\
Advanced degree & $28.6 \%$ & $36.7 \%$ & $33.3 \%$ & &
\end{tabular}

Note. There were no demographic differences across 1) maternal profiles or 2) diagnostic groups, ER = emotion regulation, $\mathrm{ADHD}=$ Attention-deficit/hyperactivity disorder, $\mathrm{TD}=$ Typically developing; $\mathrm{a}=$ marital status as defined by living with partner/married or single; $b=$ "Other" race defined as Asian or Indian American/Native Alaskan. 
Table 9. Comparison of Maternal Emotion Regulation Latent Profiles on Indicator Variables

\begin{tabular}{|c|c|c|c|c|c|c|}
\hline & Mixed ER ${ }^{a}$ & Moderate ER ${ }^{b}$ & Low ER ${ }^{c}$ & High ER $^{d}$ & & \\
\hline Raw Scores & $\mathrm{M}(\mathrm{SD})$ & $\mathrm{M}(\mathrm{SD})$ & $\mathrm{M}(\mathrm{SD})$ & $\mathrm{M}(\mathrm{SD})$ & $F$ & Cohen's $d$ \\
\hline PEP BL (O) & $99.37(12.71)$ & $101.94(14.16)$ & $104.32(11.38)$ & $97.51(14.67)$ & 1.17 & --- \\
\hline PEP Task (O) & $91.62(14.70)$ & $94.84(16.01)$ & 96.25 (12.09) & $95.07(13.51)$ & .68 & --- \\
\hline RSA BL (O) & $5.15(.76)$ & $6.22(.85)$ & $6.66(.64)$ & $6.71(.82)$ & $40.17 * * *$ & $\begin{array}{c}1.33^{\mathrm{ab} * * *}, 2.15^{\mathrm{ac} * * *} \\
1.97^{\mathrm{ad} * * *}, .59^{\mathrm{bd} *}\end{array}$ \\
\hline RSA Task (O) & $5.84(1.08)$ & $6.22(.89)$ & $6.42(.91)$ & $6.09(.91)$ & .12 & --- \\
\hline RSA W (O) & $-.70(.67)$ & $-.02(.70)$ & $.07(.62)$ & $.61(.55)$ & $39.23 * * *$ & $\begin{array}{c}.99^{\mathrm{ab} * * *}, 1.19^{\mathrm{ac} * * *} \\
2.14^{\mathrm{ad} * * *}, 1.00^{\mathrm{bd} * * *} \\
.92^{\mathrm{cd}}+\end{array}$ \\
\hline PEP R (O) & $-6.18(13.99)$ & $-7.29(14.71)$ & $-7.60(9.53)$ & $-.01(10.74)$ & $2.67 *$ & $.49^{\mathrm{ad} *}, .57^{\mathrm{bd} *}$ \\
\hline DERS (S) & $1.79(.52)$ & $1.84(.64)$ & $1.95(.53)$ & $1.68(.49)$ & 1.29 & --- \\
\hline $\begin{array}{l}\text { Proportion of } \\
\text { time in distress } \\
\text { (O) }\end{array}$ & $.03(.02)$ & $.13(.04)$ & $.36(.08)$ & $.03(.03)$ & $328.08 * * *$ & $\begin{array}{c}3.16^{\mathrm{ab} * * *}, 5.67^{\mathrm{ac} * * *} \\
3.64^{\mathrm{bc} * * *}, 2.83^{\mathrm{bd} * * *} \\
5.46^{\mathrm{cd} * * *}\end{array}$ \\
\hline $\begin{array}{l}\text { Global } \\
\text { regulation }(\mathrm{O})\end{array}$ & $3.60(.49)$ & $2.80(.46)$ & $2.33(.49)$ & $3.69(.47)$ & $55.29 * * *$ & $\begin{array}{c}1.68^{\mathrm{ab} * * *}, 2.59^{\mathrm{ac} * * *} \\
.99^{\mathrm{bc} *}, 1.91^{\mathrm{bd}_{* * *}} \\
2.83^{\mathrm{cd} * *}\end{array}$ \\
\hline
\end{tabular}

Note. $\mathrm{ER}=$ Emotion regulation, $\mathrm{BL}=$ Baseline; $\mathrm{PEP}=$ Pre-ejection period; $\mathrm{PEP} \mathrm{R}=\mathrm{PEP}$ reactivity; $\mathrm{RSA}=$ respiratory sinus arrhythmia; RSA W = RSA withdrawal; DERS = Difficulties in Emotion Regulation Scale; $\mathrm{O}=$ Observation; $\mathrm{S}=$ Self-report 
Table 10. Comparison of Maternal Factors and Profile Membership

\begin{tabular}{|c|c|c|c|c|c|c|}
\hline & Mixed ER ${ }^{\mathrm{a}}$ & Moderate ER & Low ER ${ }^{c}$ & $\operatorname{High} \mathrm{R}^{\mathrm{d}}$ & & \\
\hline Raw Scores & $\mathrm{M}(\mathrm{se})$ & $\mathrm{M}(\mathrm{se})$ & $\mathrm{M}(s e)$ & $\mathrm{M}(\mathrm{se})$ & $F$ & Cohen's $d$ \\
\hline $\begin{array}{l}\text { DO Skills: } \\
\text { Proportion Score }(\mathrm{O})\end{array}$ & $.09(.01)$ & $.05(.01)$ & $.02(02)$ & $.08(.01)$ & $3.70 *$ & $.58^{\mathrm{ac}}+$ \\
\hline $\begin{array}{l}\text { DON'T Skills: } \\
\text { Proportion Score }(\mathrm{O})\end{array}$ & $.52(.02)$ & $.61(.02)$ & $.70(.04)$ & $.52(.02)$ & $11.19 * * *$ & $\begin{array}{c}.71^{\mathrm{ab} * *}, 1.51^{\mathrm{ac} * * *}, .96^{\mathrm{bd} * *}, \\
1.67^{\mathrm{cd} * * *}\end{array}$ \\
\hline $\begin{array}{l}\text { Positive Parenting } \\
\text { (S) }\end{array}$ & $69.33(.85)$ & $68.32(.94)$ & $66.69(1.99)$ & $69.63(.89)$ & .82 & - \\
\hline $\begin{array}{l}\text { Negative Parenting } \\
\text { (S) }\end{array}$ & $29.25(.84)$ & $29.60(.93)$ & 30.75 (1.95) & $29.20(.88)$ & .20 & - \\
\hline $\begin{array}{l}\text { Mother ADHD Sx } \\
\text { (S) }\end{array}$ & $1.22(.07)$ & $1.19(.08)$ & $1.37(.17)$ & $1.24(.08)$ & .75 & - \\
\hline Parenting Stress (S) & $68.79(2.42)$ & $73.97(2.69)$ & $76.84(5.66)$ & $70.91(2.54)$ & 1.00 & - \\
\hline
\end{tabular}

Note. $+p<.10, * p<.05, * * p<.01, * * * p<.001$. All analyses controlled for parent/teacher reports of inattention, hyperactivity, and ODD symptoms. $\mathrm{O}=$ Observation; $\mathrm{S}=$ Self-report, $\mathrm{Sx}=$ symptoms 
Table 11. Comparison of Child Factors and Profile Membership

\begin{tabular}{|c|c|c|c|c|c|}
\hline & Mixed ER ${ }^{a}$ & Moderate $\mathrm{ER}^{\mathrm{b}}$ & Low $\mathrm{ER}^{\mathrm{c}}$ & High ER $^{d}$ & \\
\hline Raw Scores & $\mathrm{M}(\mathrm{se})$ & $\mathrm{M}(\mathrm{se})$ & $\mathrm{M}(\mathrm{se})$ & $\mathrm{M}(\mathrm{se})$ & $F$ \\
\hline INATT symptoms (C) & $1.55(.12)$ & $1.71(.14)$ & $1.93(.28)$ & $1.31(.13)$ & 2.12 \\
\hline HI symptoms (C) & $1.83(.12)$ & $1.76(.14)$ & $1.88(.28)$ & $1.46(.13)$ & 1.75 \\
\hline ODD symptoms (C) & $1.14(.11)$ & $1.29(.12)$ & $1.26(.26)$ & $1.04(.12)$ & .74 \\
\hline Emotion Knowledge (O) & $10.04(.24)$ & $10.00(.28)$ & $10.11(.56)$ & $10.04(.26)$ & .01 \\
\hline $\begin{array}{l}\text { Proportion of time } \\
\text { in distress }(\mathrm{O})\end{array}$ & $.54(.04)$ & $.50(.04)$ & $.38(.08)$ & $.54(.04)$ & .34 \\
\hline Negativity (C) & $2.31(.08)$ & $2.36(.09)$ & $2.24(.18)$ & $2.17(.08)$ & .87 \\
\hline CU-behaviors $(\mathrm{C})$ & $1.07(.07)$ & $1.16(.08)$ & $1.16(.16)$ & $1.01(.07)$ & .77 \\
\hline
\end{tabular}


Table 12. Regression Predicting Emotion Regulation Profile Membership from Maternal Factors

\begin{tabular}{lcccc}
\hline & $\beta$ & $T$-value & Model $R^{2}$ & $F$ \\
\hline Membership Probability in Mixed ER Profile & & & \\
Model 1. DO Skills (O) & .10 & 1.11 & .09 & $1.72+$ \\
DON'T Skills (O) & -.12 & -1.37 & & \\
Positive Parenting (S) & .05 & .58 & & \\
Negative Parenting (S) & .07 & .82 & & \\
Parenting Stress (S) & $-.18+$ & -1.84 & & \\
Parent ADHD Sx (S) & .01 & .10 & & \\
Membership Probability in Moderate ER Profile & & & \\
Model 1. DO Skills (O) & -.07 & -.81 & .13 & \\
DON'T Skills (O) & $.21^{*}$ & 2.42 & & \\
Positive Parenting (S) & -.10 & -1.20 & & \\
Negative Parenting (S) & -.04 & -.53 & & \\
Parenting Stress (S) & .12 & 1.24 & & \\
Parent ADHD Sx (S) & -.15 & -1.71 & & \\
Membership Probability in Low ER Profile & & & \\
Model 1. DO Skills (O) & -.04 & -.47 & .12 & \\
DON'T Skills (O) & $.28^{* *}$ & 3.21 & & \\
Positive Parenting (S) & -.06 & -.73 & & \\
Negative Parenting (S) & -.01 & -.15 & & \\
Parenting Stress (S) & .07 & .70 & & \\
Parent ADHD Sx (S) & .09 & 1.08 & & \\
Membership Probability in High ER Profile & & \\
Model 1. DO Skills (O) & -.004 & -.05 & .12 & \\
DON'T Skills (O) & $-.27^{* *}$ & -3.13 & & \\
Positive Parenting (S) & .09 & 1.10 & \\
Negative Parenting (S) & -.02 & -.23 & & \\
Parenting Stress (S) & .02 & .24 & & \\
Parent ADHD Sx (S) & .09 & 1.02 & & \\
\hline Note & & \\
\hline
\end{tabular}

Note. $* p<.05, * * p<.01, * * * p<.001$. All analyses controlled for child hyperactivity/impulsivity, inattention, and oppositional defiant disorder symptoms. $\mathrm{O}=$ Observation, $\mathrm{C}=$ Combined report, $\mathrm{S}=$ Self-report, $\mathrm{HI}=$ Hyperactive/impulsive, INATT $=$ Inattention. 
Table 13. Regression Predicting Emotion Regulation Profile Membership from Child Factors

\begin{tabular}{lcccc}
\hline & $\beta$ & $T$-value & Model $R^{2}$ & $F$ \\
\hline Membership Probability in Mixed ER Profile & & & \\
Model 1. Emotion Knowledge (O) & -.05 & -.54 & .08 & 1.48 \\
Distress (O) & .16 & 1.62 & & \\
Negativity (C) & -.002 & -.02 & & \\
CU-behaviors (C) & -.09 & -.84 & & \\
INATT Sxs (C) & -.19 & -1.30 & & \\
HI Sxs (C) & $.44 * *$ & 2.60 & & \\
ODD Sxs (C) & -.12 & -.75 & &
\end{tabular}

Membership Probability in Moderate ER Profile

$\begin{array}{lcccc}\text { Model 1. Emotion Knowledge (O) } & .02 & .79 & .07 & 1.20 \\ \text { Distress (O) } & -.04 & .72 & & \\ \text { Negativity (C) } & .13 & .40 & \\ \text { CU-behaviors (C) } & .06 & .57 & \\ \text { INATT Sxs (C) } & .19 & .19 & \\ \text { HI Sxs (C) } & -.26 & .13 & \\ \text { ODD Sxs (C) } & .07 & .67 & \end{array}$

Membership Probability in Low ER Profile

Model 1. Emotion Knowledge (O) $\quad 04$

Distress (O)

Negativity (C)

CU-behaviors $(\mathrm{C})$

INATT Sxs (C)

HI Sxs (C)

ODD Sxs (C)
.04

$-.13$

$-.17$

.01

.23

$-.13$

.04

Membership Probability in High ER Profile

Model 1. Emotion Knowledge (O) $\quad .001$

Distress (O)

$$
-.05
$$

Negativity (C)

$-.02$

CU-behaviors (C)

.03

INATT Sxs (C)

$-.15$

$\mathrm{HI} \operatorname{Sxs}(\mathrm{C})$

$-.11$

ODD Sxs (C)

.42

$-1.33$

$-1.16$

.06

1.56

$-.77$

.27
.02

$-.46$

$-.12$

.24

.08

1.39

$-1.05$

$-.63$

Note. $* p<.05, * * p<.01, * * * p<.001$. All analyses controlled for child age, sex, and IQ. $\mathrm{O}=$ Observation, $\mathrm{C}=$ Combined report, $\mathrm{CU}=$ Callous-unemotional, $\mathrm{HI}=$ Hyperactive/impulsive, INATT = Inattention, ODD = Oppositional defiant disorder, Sxs = symptoms. 
Table 14. Regression Predicting Emotion Regulation Profile Membership from Maternal and Child Factors

\begin{tabular}{|c|c|c|c|c|}
\hline & $\beta$ & $T$-value & Model $R^{2}$ & $F$ \\
\hline \multicolumn{5}{|c|}{ Membership Probability in Mixed ER Profile } \\
\hline Model 1. DON'T Skills & $-.17 *$ & -2.25 & .09 & $2.87 *$ \\
\hline Parenting Stress (S) & $-.21 * *$ & -2.62 & & \\
\hline HI Sxs (C) & $.18^{*}$ & 2.07 & & \\
\hline \multicolumn{5}{|c|}{ Membership Probability in Moderate ER Profile } \\
\hline Model 1. DON'T Skills & $.24 * * *$ & 3.30 & .12 & $3.79 * *$ \\
\hline Parenting Stress (S) & .16 & $1.94+$ & & \\
\hline HI Sxs (C) & -.01 & -.16 & & \\
\hline \multicolumn{5}{|c|}{ Membership Probability in Low ER Profile } \\
\hline Model 1. DON'T Skills & $.28 * * *$ & 3.82 & .13 & $4.12 * *$ \\
\hline Parenting Stress (S) & .08 & 1.04 & & \\
\hline HI Sxs (C) & -.03 & -.38 & & \\
\hline \multicolumn{5}{|c|}{ Membership Probability in High ER Profile } \\
\hline Model 1. DON'T Skills & $-.26 * * *$ & -3.55 & .14 & $4.49 * * *$ \\
\hline Parenting Stress (S) & .01 & .10 & & \\
\hline HI Sxs (C) & $-.15+$ & -1.83 & & \\
\hline
\end{tabular}


Figure 1. Maternal Emotion Regulation Profiles

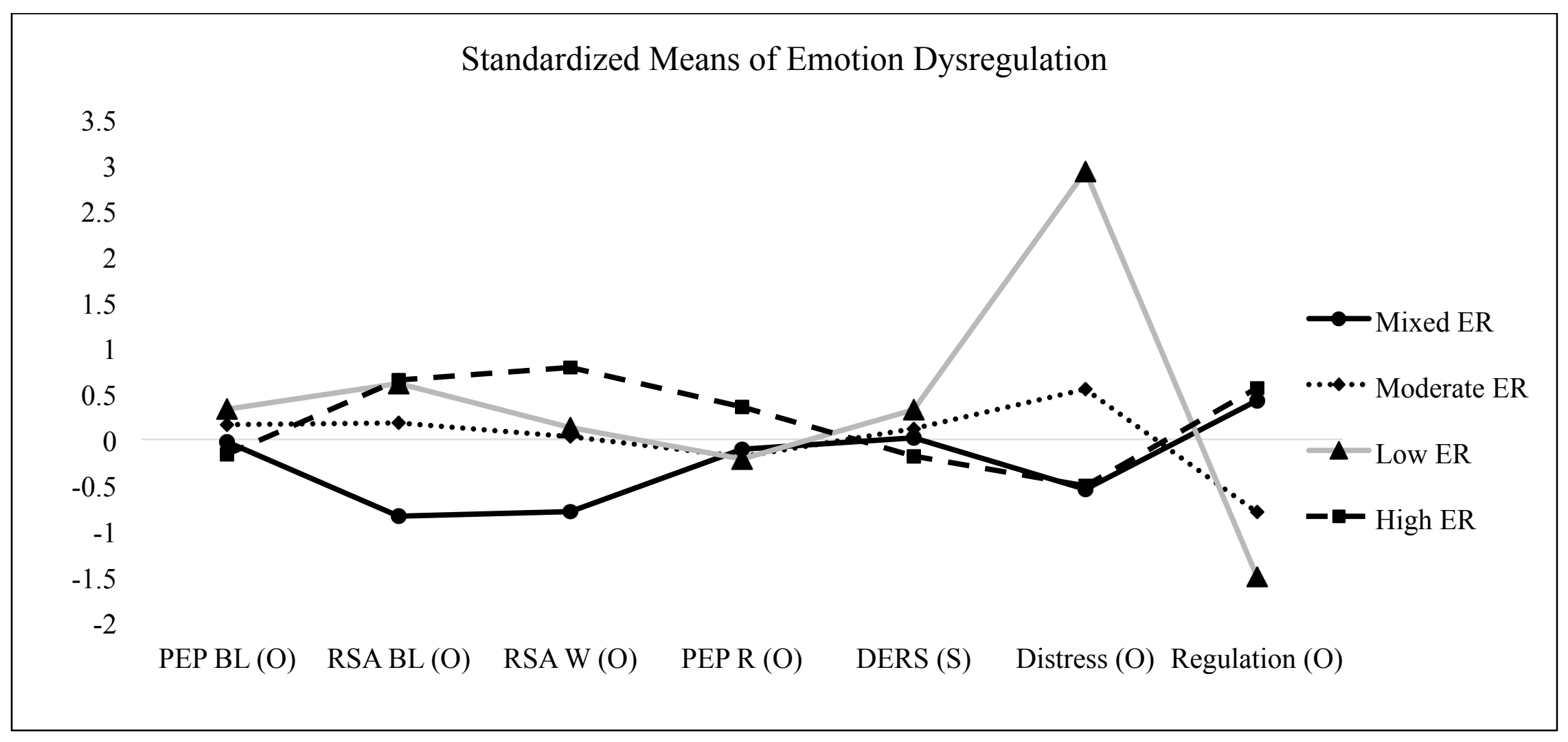

Note. $\mathrm{ER}=$ Emotion regulation, $\mathrm{BL}=$ Baseline; $\mathrm{PEP}=$ Pre-ejection period; $\mathrm{PEP} \mathrm{R}=\mathrm{PEP}$ reactivity; $\mathrm{RSA}=$ respiratory sinus arrhythmia; RSA W = RSA withdrawal; DERS = Difficulties in Emotion Regulation Scale; $\mathrm{O}=$ Observation; $\mathrm{S}=\mathrm{Self}-\mathrm{report}$ 


\section{APPENDICES}

A Multimodal Assessment of Emotion Dysregulation in Young Children with and without ADHD

This manuscript has been published in PsyrXiv Preprints and is under review in Journal of Child and Adolescent Clinical Psychology.

Garcia, A., Dick, A., \& Graziano, P. A. (2020, April 20). A Multimodal Assessment of Emotion Dysregulation in Young Children with and without ADHD. Retrieved from psyarxiv.com/z9emy 


\begin{abstract}
Objective: This study utilized a multimodal approach to examine emotion dysregulation (ED) in young children with attention-deficit/hyperactivity disorder (ADHD), ADHD + oppositional defiant disorder (ODD), and typically developing (TD) children. Methods: We sought to explore if specific domains of ED (emotion regulation [ER], negativity/lability [ERNL], emotion knowledge/understanding [ERU], and callous-unemotional [CU] behaviors) were uniquely associated with diagnostic classifications. The final sample consisted of 152 children ( $75 \%$ boys; mean age $=5.52, \mathrm{SD}=.84,83.4 \%$ Latinx) with the following group composition: ADHD- Only $(n=24)$, ADHD + ODD $(n=54)$, and TD $(n=74)$. Results: Higher levels of ADHD and ODD symptoms, measured continuously, were significantly associated with poorer EREG, greater ERNL, and higher levels of reported CU behaviors. There were no significant associations between ADHD or ODD symptoms on ERU. Using discriminant analyses, we found that parent/teacher reported EREG, ERNL, and CU were significant predictors of diagnostic classification. These ED domains correctly identified $84.7 \%$ of preschoolers. The model was most successful in classifying children with ADHD+ODD (92.3\%) and TD (93.2\%) children; however, the ADHD-Only group was correctly identified only $41.7 \%$ of the time. Conclusions: This is the first study to 1) examine multiple domains of ED in a clinical sample of preschool children with and without ADHD and 2) explore the clinical utility of considering ED when assessing for ADHD and ODD. Our findings suggest that measures of ED are particularly helpful for correctly diagnosing ADHD and co-occurring ODD but not necessarily children with ADHD-Only.
\end{abstract}


Keywords: emotion dysregulation; attention deficit/hyperactivity disorder; oppositional defiant disorder, preschoolers, discriminant analysis 


\section{A Multimodal Assessment of Emotion Dysregulation in Young Children With and Without ADHD}

Attention-deficit/hyperactivity disorder (ADHD) is a neurodevelopmental disorder which is marked by a triad of symptoms: inattention, hyperactivity, and impulsivity (Barkley, 2014). Impairments associated with ADHD are seen across various functional domains. It is well documented that symptoms of ADHD impair social functioning (Ros \& Graziano, 2018), academic performance (Loe \& Feldman, 2007), and increase familial problems (Barkley \& Mash, 2003). Aside from suboptimal outcomes at an individual level, ADHD carries a large financial burden ranging from $\$ 36$ billion to $\$ 52.4$ billion annually (W. E. Pelham, Foster, \& Robb, 2007). Given that ADHD is a chronic disorder associated with various consequences across the lifespan (Kuriyan et al., 2013; Malloy-Diniz, Fuentes, Leite, Correa, \& Bechara, 2007; Merrill et al., 2016), it is imperative to identify early indicators, or mechanisms, in early childhood. Of interest to the current study is emotion dysregulation (ED), which has gained significant attention as a contributor to these lifelong impairments in individuals with ADHD (Barkley \& Fischer, 2010; Bunford, Evans, \& Wymbs, 2015; Graziano \& Garcia, 2016; Shaw, Stringaris, Nigg, \& Leibenluft, 2014).

Emotion regulation (ER) is defined as the extrinsic and intrinsic processes responsible for the monitoring, evaluation, and modification of emotional reactions to meet situational demands and promote adaptive behaviors that are necessary for to achieving one's goals (Gross, 2011). Emotion dysregulation (ED) occurs when an individual has difficulty exercising any or all aspects of the ER process to such a 
degree that it results in the individual functioning below his or her baseline and failing to meet situational goals (Bunford et al., 2015). Children with ADHD who are emotionally dysregulated can be described as being emotionally impulsive, have a difficult time actively regulating their emotions, and can even display inappropriate emotions or moods (Bunford et al., 2015). Given the complex and multifaceted nature of emotions and the manner in which individuals process them (Gross, 1998), a recent meta-analysis (Graziano \& Garcia, 2016) identified four levels of ED that may account for the heterogeneous nature of ED-related impairments in youth with ADHD: emotion recognition/understanding (ERU), emotional reactivity/negativity/lability (ERNL), emotion regulation (EREG) and callousunemotional (CU) traits. The current study focused on examining the clinical utility of these ED dimensions as it relates to the diagnosis of ADHD and comorbid conduct problems (CP) such as Oppositional Defiant Disorder (ODD) among preschool children.

Emotion recognition/understanding (ERU). Aligned with Gross' model of emotion generation (1998), once an individual is exposed to an emotional stimulus, it is necessary for him or her to identify and process the specific emotion. Thus, the first domain of ED that may be impaired by ADHD is the youth's ability to identify a range of emotional cues (i.e., facial expressions, gestures, changes in speech prosody). Some studies have found that children with/at risk for ADHD have a limited emotion vocabulary (Kats-Gold \& Priel, 2009) and are worse at emotion recognition (Sjöwall, Roth, Lindqvist, \& Thorell, 2013). For young children, greater ERU is associated with improved academic (DuPaul et al., 2004) and social 
(Hinshaw, 1992) outcomes. A recent study found preschool children with ADHD performed worse on two emotional understanding tasks (matching expression and expression-situation matching); however, there were no differences between groups on labeling emotions (Lugo-Candelas, Flegenheimer, McDermott, \& Harvey, 2017). While most studies have examined differences in ERU between typically developing (TD) children and children with/at-risk for ADHD, Waller and colleagues examined differences in ERU among children with ADHD, ODD, and callous-unemotional (CU) behaviors (Waller et al., 2014). Findings from this study indicated that children with ADHD had poorer emotional knowledge compared to preschoolers with ODD and $\mathrm{CU}$ behaviors. Although many of these studies have provided useful information about ED in young children with and without ADHD, none to date have identified the clinical utility or diagnostic importance of ERU when diagnosing ADHD in preschoolers.

Emotion regulation (EREG). EREG refers to an individual's ability to modulate his or her emotional arousal (Bunford et al., 2015; Calkins, 2007, Gross, 2011) as well as generate and sustain emotions (Cole, Martin, \& Dennis, 2004). EREG problems are developmentally appropriate in young children (Eisenberg, Valiente, \& Eggum, 2010) and prevalent across childhood psychiatric disorders (Aldao et al., 2010; Graziano et al., 2019; Shaw et al., 2014; Zlomke \& Hahn, 2010). Across both observational tasks and parent/teacher ratings, studies have documented that children with ADHD experience significant EREG deficits, compared to TD children (Babb, Levine, \& Arseneault, 2010; Melnick \& Hinshaw, 2000). Such EREG deficits are particularly salient when measuring children's regulation of negative 
emotions or during tasks with a negative valence (i.e., frustrating, challenging, disappointing; (Nigg, 2006). Of note, some studies have documented that children with ADHD also have difficulty regulating positive emotions (Musser et al., 2011). Not only are EREG deficits more readily seen among children with ADHD, such deficits importantly contribute to other functional impairments within the social (Bunford, Evans, \& Langberg, 2018), cognitive (Berlin, Bohlin, Nyberg, \& Janols, 2004), and adaptive domains (Anastopoulos et al., 2011). Finally, while comorbid CP are also associated with EREG deficits (Nigg, Goldsmith, \& Sachek, 2004), they do not fully account for its link with ADHD (Graziano \& Garcia, 2016). Examining how EREG deficits relate to ADHD and comorbid $\mathrm{CP}$ with preschoolers would provide an important next step towards understanding its clinical utility for early intervention targets.

Emotional reactivity/negativity/lability (ERNL). The second domain of ED identified by Graziano and Garcia (2016) as being highly impaired among children with ADHD involves a child's ability to modulate the intensity or lability of their emotional response. Children with ADHD tend to exhibit higher levels of emotional excitability/exuberance or anger/irritability compared to TD (Barkley \& Fischer, 2010). In a large sample $(\mathrm{N}=1168)$ of children (ages 6-18) with ADHD, children with ADHD + ODD were reported by parents/teachers as having greater levels of emotional lability compared to children without the comorbid presentation (Sobanski et al., 2010). One of the few studies with a younger sample ( $\left.M^{\mathrm{age}}=6.51\right)$, also found that children with ADHD were rated by parents as being more emotionally labile relative to TD children (Lugo-Candelas et al., 2017). A significant limitation in the 
literature examining ERNL is the reliance on parent and/or teacher ratings (Graziano \& Garcia, 2016). One of the only studies with a younger sample, to our knowledge, to include an observational task found that children with ADHD exhibited more anger across suppression and reactivity tasks compared to TD children (Lugo-Candelas et al., 2017). Thus, more work is needed with younger samples examining multiple measures of ERNL to determine its association not only with ADHD, but importantly with comorbid CP. As pointed out by Overgaard and colleagues (2018) in a large (N $=495$ ) clinical sample of preschool children with and without ADHD, children with ADHD and greater ODD symptoms were rated by parents as being more emotionally labile compared to controls. Considering emotional reactivity/lability is a transdiagnostic feature in ADHD and ODD, it is crucial to understand how this domain of ED is clinically relevant and/or necessary when making diagnostic decisions.

Callous-unemotional traits $(C U)$. CU traits (or behaviors when considering young children) refers to low levels of empathy, guilt, and caring for others (Frick, Ray, Thornton, \& Kahn, 2014a). As recognized by the addition of a CU specifier to the DSM-5's diagnosis of conduct disorder ("with limited prosocial emotions"), this subset of children engage in the most pervasive, severe, and aggressive patterns of antisocial behavior (Frick et al., 2013). While CU traits are a cornerstone of psychopathic disorders (Blair, 2007), CU behaviors can be reliability identified in preschool and school-aged children (Bansal, Goh, Lee, \& Martel, 2020; Kimonis et al., 2006; Waller, Hyde, Grabell, Alves, \& Olson, 2015). Various studies have documented how the impairments associated with ADHD are amplified by the 
presence of CU behaviors (Graziano et al., 2016; Haas, Becker, Epstein, \& Frick, 2018; Waschbusch, Graziano, Willoughby, \& Pelham Jr, 2015). CU behaviors are also related to children's attenuated responses to evidence-based treatments (Bansal et al., 2019; Garcia, Graziano, \& Hart, 2018; Haas et al., 2011; Waschbusch et al., 2019). It is important to note that while children with ADHD and ODD are at increased risk for developing CP (Frick, Ray, Thornton, \& Kahn, 2014b), not all children with ADHD and/or ODD will exhibit problematic levels of CU (Frick et al., 2014b; Waller et al., 2015). As noted by Graziano \& Garcia (2016), while comorbid $\mathrm{CP}$ moderated the link between $\mathrm{ADHD}$ and $\mathrm{CU}$, a significant independent association between ADHD and CU $(d=.25)$ remained. Thus, it remains important to examine how $\mathrm{CU}$ behaviors along with the other ED dimensions contribute to the early identification of $\mathrm{ADHD}$ and/or comorbid $\mathrm{CP}$ in young children.

\section{Current study}

In summary, children with ADHD have significant impairments across four domains of ED; emotion recognition/understanding (ERU), emotional reactivity/lability/negativity (ERNL), emotion regulation (EREG), and callousunemotional traits (CU; Graziano \& Garcia, 2016). While there is ample evidence suggesting school-aged children with ADHD have higher levels of ED compared to their typically developing peers, less is known about ED in young children, specifically preschoolers with ADHD. There have been a few studies to explicitly examine ADHD and domains of ED in preschool samples (ages 3-5; Sjowall et al., 2015; Stringaris et al., 2015; Waller et al., 2014). From a developmental psychopathology perspective, preschool-aged children are the ideal population to start 
examining ADHD since 3-5\% of preschoolers carry an ADHD diagnosis (Lavigne, LeBailly, Hopkins, Gouze, \& Binns, 2009). Considering a large percentage of preschoolers with ADHD also carry a comorbid ODD diagnosis, it is crucial to understand how ODD symptoms are associated with the heterogeneity of ED in preschoolers with ADHD.

Thus, the current study attempts to address a significant gap in the literature by examining all four domains of ED within a preschool sample of children with and without ADHD. This is the first study, to our knowledge, to examine each domain of ED, in a clinical and non-clinical TD sample of preschool children. As documented by prior research, we also examined how comorbid CP related to ED. First, we sought to examine if diagnostic groups (i.e., TD, ADHD-only, ADHD+ODD) differed across domains of ED. Given the mixed literature associated with ERU in children with ADHD, especially in young children (Lugo-Candelas et al.,2017), we did not anticipate significant ERU differences across groups. In regard to ERNL and EREG we hypothesized that children in the ADHD-only and ADHD+ODD groups would have significantly greater levels of ERNL and poorer EREG compared to the TD groups. We also anticipated that preschoolers in the ADHD+ODD group would have significantly higher levels of CU behaviors compared to preschoolers in the TD and ADHD-only groups, given the higher levels of CU behaviors in children with cooccurring behavior problems (Waller et al., 2015). Lastly, given the transdiagnostic nature of ED, we sought to explore which domain(s) of ED had the best predictive value in correctly classifying children in their respective diagnostic groups. 
Considering that this is the first study to examine all four domains of ED in preschool children with and without ADHD, we took an exploratory approach to this aim.

\section{Methods}

\section{Participants and Recruitment}

Children and their caregivers were recruited from local schools and mental health agencies via brochures, radio and newspaper ads, and open houses/parent workshops. Legal guardians contacted the clinic and were directed to the study staff for screening questions to determine eligibility. For the ADHD sample, if the parent (1) endorsed clinically significant levels of ADHD symptoms (six or more symptoms of either Inattention or Hyperactivity/Impulsivity according to the DSM-

5 (Association, 2013) OR a previous diagnosis of ADHD), (2) indicated that the child is currently displaying clinically significant academic, behavioral, or social impairments as measured by a score of 3 or higher on a seven-point impairment rating scale (Fabiano et al., 2006), and (3) were not taking any psychotropic medication, the parent and child were invited to participate in an assessment to determine study eligibility. For the TD sample, if the parent (1) endorsed less than 4 ADHD symptoms (across either Inattention or Hyperactivity/Impulsivity according to the DSM-5), (2) less than 4 Oppositional Defiant Disorder (ODD) symptoms, and (3) indicated no clinically significant impairment (score below 3 on the impairment rating scale), the parent and child were invited to participate in an assessment to determine study eligibility. Participants were also required to be enrolled in school during the previous year, have an estimated IQ of 70 or higher $(M=98.69, S D=12.91)$, have no confirmed history of an Autism Spectrum Disorder, and be able to attend an 8-week 
summer treatment program (STP-PreK; Graziano et al., 2014) prior to the start of the next school year (ADHD groups only).

During intake, ADHD diagnosis (and comorbid disruptive behavior disorders) was assessed through a combination of parent structured interview (Computerized-Diagnostic Interview Schedule for Children; (Shaffer, Fisher, Lucas, Dulcan, \& Schwab-Stone, 2000) and parent and teacher ratings of symptoms and impairment (Disruptive Behavior Disorders Rating Scale, Impairment Rating Scale; Fabiano et al., 2006; Pelham, Gnagy, Greenslade, \& Milich, 1992), as is recommended practice (J. Pelham, William E, Fabiano, \& Massetti, 2005). Dual Ph.D. level clinician review was used to determine diagnosis and eligibility.

The final participating sample included 152 young children $(75 \%$ boys; mean age $=5.52, \mathrm{SD}=.84,83.4 \%$ Latinx $)$ with an equivalent distribution of children diagnosed with ADHD (51\%) and those characterized as TD (49\%). Additionally, within the ADHD group, $69 \%$ had a co-occurring ODD diagnosis. More than $60 \%$ of parents reported currently being married/living with the child's other biological parent. Although children in ADHD group were required to be medication naïve, 2 children $(2.5 \%)$ had a history of taking psychostimulants. However, at the time of recruitment, parents reported their child was no longer taking medications.

\section{Study Design and Procedure}

This study was approved by the university's Institutional Review Board. All families participated in a one-time assessment, which included completion of the ADHD, ODD, and Conduct Disorder (CD) modules on the C-DISC (Shaffer et al., 2000) and various questionnaires regarding their children's behavioral, academic, and 
emotional functioning. Children also completed a series of social-emotional tasks in the laboratory. Families of children with ADHD received the intervention (STPPreK) at either no cost via a federal grant or at a subsidized cost via a local grant, and all families received compensation (\$100 gift card for completing the assessment). Similar questionnaires were also obtained from children's teachers. Teachers also received compensation ( $\$ 50$ gift card) for completing the questionnaires. $A D H D$ and $O D D$ Symptomology

Parents and teachers completed the Disruptive Behavior Disorders (DBD) Rating Scale (W. E. Pelham, Gnagy, Greenslade, \& Milich, 1992), adapted for DSM5 terminology. The DBD rating scale asks the respondent to rate on a 4-point scale ranging from 0 (not at all) to 3 (very much), the degree to which children display symptoms of ADHD, ODD, and CD. The DBD Rating Scale's responses range from 0 (not at all) to 3 (very much). Consistent with prior work (Hartman, Rhee, Willcutt, \& Pennington, 2007; Sibley et al., 2010), parent and teacher ratings were combined by taking the higher of the two ratings for each item to create composites: hyperactivity/impulsivity, inattention, and impulsivity. The mean score for each inattention, $(\alpha=.88)$, hyperactivity/impulsivity, $(\alpha=.92)$, and ODD symptoms were examined $(\alpha=.85)$.

Emotion recognition/understanding (ERU)

Children completed a standardized emotion knowledge (EK) task (Denham, 1986) that required children to both expressively and receptively identify 8 different emotions (sad, happy, angry, afraid, surprised, disgusted, embarrassed, guilty) as presented visually via cartoon faces. Children scored 1 point for each correct 
expressive and subsequent receptive answer. A total of 16 points was possible with higher scores indicative of better emotional awareness/knowledge.

\section{Emotional regulation (EREG)}

Parents and teachers completed the Brief Rating Inventory of Executive Function (BRIEF; Gioia, Isquith, Retzlaff, \& Espy, 2002; Gioia, Espy, \& Isquith, 2003). The parent and teacher versions contain 63 items rated on a 3-point likert scale (never, sometimes, often) that provided five distinct but correlated clinical scales (inhibit, shift, emotional control, working memory, and plan/organize). For the purposes of the current study, the Emotional Control scale t-score was used $(\alpha=.92)$. Specifically, the highest t-score between parent and teacher reports was used, with higher scores indication poorer emotional control skills.

Children completed two frustration tasks adapted from the Lab-TAB (Goldsmith \& Rothbart, 1996): I'm Not Sharing and Impossibly Perfect Circles. In the I'm Not Sharing task, an assistant brings a container of candy and tells the experimenter to share it equally with the child. The experimenter initially divides the candy equally. Eventually, the examiner takes more candy, eats a piece of the child's candy, then proceeds to take more candy, until they take all of the child's candy. In the Impossibly Perfect Circles task, children were asked to draw circles repeatedly and were criticized (e.g., too large, too small) after each attempt. The tasks were discontinued if the child was highly distressed or cried for more than 30s. If the child was not highly distressed, the tasks was terminated after 3 minutes and 30 seconds in which the child was praised for their effort and provided a small prize from a treasure chest (e.g., stickers, pencils, candy). The Global Regulation measure was coded on a 
scale from 0 (dysregulated) to 4 (well regulated). For each code, $20 \%$ of the videos were coded for reliability. The reliability Kappas for global regulation codes in this study were all above .80 . For data reduction purposes, the most severe rating of dysregulation between the two tasks was used for the current study. Emotional reactivity/negativity/lability (ERNL)

During the I'm not sharing and Impossibly Perfect Circles tasks, research assistants coded affect lability. Affect lability was coded on a scale from $0=$ stable to $4=$ very unstable. Twenty percent of the observations were coded by a second rater for reliability purposes $(\mathrm{kappa}=.83)$.

Parents and teachers also completed the Emotion Regulation Checklist (ERC; Shields \& Cicchetti, 1997). The ERC is a 24-item questionnaire that uses a 4-point Likert scale ( $1=$ almost always to $4=$ never $)$. The ERC and yields two subscales: Negativity/Lability scale (15 items), which represents negative affect/mood lability, and the Emotion Regulation (ER) scale (eight items), which assesses processes central to adaptive regulation. For the present study, the highest Negativity/Lability score between parent/teachers was used, with higher scores indicating greater levels of negativity/lability $(\alpha=.93)$.

\section{Callous-unemotional behaviors (CU)}

Parents and teachers completed an abbreviated version of the Inventory of Callous-Unemotional Traits (ICU; (Frick, 2004) consisting of 12 items identified by Hawes et al. (2014) as showing psychometric properties similar to those of the full ICU. The items were rated on a four-point Likert scale ranging from 0 (not at all) to 
3 (very much), and a CU composite was created by averaging these 12 items ( $\alpha=$ .72). Once again, the highest score among parent and teacher reports was used.

\section{Data Analyses}

All analyses were conducted using SPSS Version 25. There was no missing data for any predictors or variables of interest. Pearson's correlations between study variables were examined. Within a general linear model framework, multivariate analyses of covariance (MANCOVA) were conducted to examine if there were significant differences across diagnostic groups (i.e., TD, ADHD-only, $\mathrm{ADHD}+\mathrm{ODD}$ ) on domains of $\mathrm{ED}$, while controlling for relevant demographic variables (i.e., age and sex) and cognitive functioning (Graziano \& Garcia, 2016). Lastly, a linear discriminant analysis (LDA) was conducted to examine which domains of ED were predictive of membership to each diagnostic group. LDA is a method used in machine learning analyses which allows for linear classifications which fit the data to best predict categorical group membership. Given we had three diagnostic groups (TD, ADHD-only, ADHD+ODD), a binary logistic regression was not used. LDA has been shown to be an effective strategy to correctly identifying children with and without ADHD (Duda, Ma, Haber, \& Wall, 2016; Pineda, Ardila, \& Rosselli, 1999; Sadatnezhad, Boostani, \& Ghanizadeh, 2011). Domains of ED that were significantly different across diagnostic groups were entered into the LDA along with relevant demographics variables as predictors of group membership.

\section{Results}

\section{Preliminary Analyses}

Descriptive statistics are presented in Table 1. Analyses of demographic variables revealed that child IQ was significantly associated with diagnostic group, 
such that TD children had higher IQs than children in the ADHD only and ADHD + ODD groups $F(2,146)=6.22, p<.01$. Additionally, age was significantly related to ERU, such that older children performed better on the emotion knowledge task, $r=$ $.49, p<.001$. Sex was significantly related to $\mathrm{CU}$, such that males were rated by parents and teachers as having greater levels of CU-behaviors, $r=-.19, p<.05$. There were no other demographic differences between diagnostic groups. Thus, all subsequent analyses controlled for child sex, age, and IQ.

\section{Examination of $A D H D$ and $O D D$ symptoms and domains of ED}

As seen in Table 2, severity of symptoms of ADHD (inattention and hyperactivity) and CP (ODD), measured continuously, were significantly associated with several domains of ED. Within the EREG domain, greater severity of inattention, hyperactivity, and ODD symptoms were associated with greater emotional control problems as reported by parents/teachers, $r=.67, r=.71, r=.83$, $p \mathrm{~s}<.001$, respectively. Similarly, greater severity of ODD, inattention, and hyperactivity symptoms were associated with poorer observed ER strategies, $r=-.19$, $r=-.25, r=-.26, p \mathrm{~s}<.05$, respectively. Overall, children with greater severity of ADHD and ODD symptoms had greater emotional control problems as reported by parents/teacher and had poorer emotion regulation skills during an emotionally eliciting laboratory task.

Within the ERNL domain, greater severity of inattention, hyperactivity, and ODD symptoms were associated with higher levels of negativity, as reported by parents/teacher, $r=.69, r=.82, r=.89, p \mathrm{~s}<.001$. Children with greater severity of ADHD and ODD symptoms were reported by their parents/teachers as being more 
emotionally labile and reactive. There were no significant associations between ADHD nor ODD symptoms on an observation of affect lability. Similarly, no significant associations emerged between ADHD nor ODD symptoms and children's performance on an ERU task. Lastly, ADHD and ODD symptoms were significantly associated with CU behaviors. Greater severity of inattention, hyperactivity, and ODD symptoms were related to greater levels of CU behaviors, $r=.60, r=.60$, and $r$ $=.67, p \mathrm{~s},<.001$, respectively.

\section{Primary Analyses: Group level differences on domains of ED}

As seen in Table 1, after accounting for sex, age, and IQ, there were no significant differences between groups on a measure of ERU, $F(2,145)=.45, p>.05$, or observed ERNL, $F(2,145)=.44, p>.05$. On the other hand, there were significant differences between parent reported ERNL, such that children in the ADHD+ODD group were rated as more emotionally negative and labile compared to children in the ADHD-Only (Cohen's $d=1.29, p<.001)$ and the TD groups $(d=2.70$, $p<.001)$. Children in the ADHD-Only group were rated as more emotionally negative and labile compared to children in the TD group $(d=1.46, p<.001)$.

Within the EREG domain, there was a significant difference between groups on the BRIEF-Emotional Control T-score, $F(2,145)=95.76, p<.001$. Specifically, children in the ADHD+ODD group were rated as having greater levels of emotional control problems relative to children in the ADHD-Only $(d=1.35, p<.001)$ and TD groups $(d=2.74, p<.001)$. Additionally, children in the ADHD-Only group were rated as having greater levels of emotional control problems relative to children in the TD group $(d=1.35, p<.001)$. We also found significant group differences on the 
observed global regulation code, $F(2,144)=5.46, p<.01$, such that children in the ADHD+ODD group displayed poorer EREG strategies relative to children in the TD group $(d=-.61, p<.01)$. There were no differences between the ADHD-Only and TD groups $(p=.32)$ or between the ADHD - Only and ADHD + ODD groups $(p=1.00)$.

Lastly, there was a significant group difference on parent/teacher reported CU behaviors between diagnostic groups, $F(2,145)=48.75, p>.001$. Specifically, children in the ADHD+ODD group were rated as having the highest levels of CUbehaviors compared to children in the ADHD-Only (Cohen's $d=.87, p<.001$ ) and TD groups (Cohen's $d=1.91, p>.001)$. Additionally, children in the ADHD-Only were rated as having higher levels of $\mathrm{CU}$ behaviors compared to children in the TD group (Cohen's $d=.95, p<.001)$.

Primary Analyses: Domains of ED predicting diagnostic group membership

A linear discriminant analysis (LDA) was performed to determine the capability of our selected ED variables to correctly classify children into the TD, ADHD-Only, and ADHD+ODD diagnostic groups. Only variables with significant ANOVA results from the previous analyses were used. This method increases a model's ability to optimize significant classifiers, or predictors, in order to effectively classify subjects (Yao, Lu, Li, Xu, \& Han, 2014). Tables 3 and 4 present the results from the LDA. The Wilks lambda (.14) for only the first function was significant ( $p$ $<.001$ ), suggesting the predictors in the model were statistically significant. As seen in Table 2, parent/teacher reported EREG, parent/teacher reported ERNL, and parent/teacher reported CU were moderately to largely associated with the function predicting group membership (standardized coefficients $=.45-.53$ ). On the other 
hand, observed EREG (global regulation) was negatively associated with the function, -.09. Taken together, parent/teacher reports of emotional control problems, negativity/lability, and CU behaviors (as well as the covariates; age, sex, IQ) accounted for $75 \%$ of the variance in the function predicting diagnostic group membership $($ canonical value $=.864)$. Overall, the model correctly classified $84.7 \%$ of the children in the study (see Table 3). The correct classifications for each group were: $94.6 \%$ for TD, $41.7 \%$ for ADHD-Only, and $90.4 \%$ for ADHD+ODD.

\section{Discussion}

This is the first study to our knowledge, to use a multi-informant and multimodal approach to examine differences in multiple domains of ED across young children with ADHD-Only, ADHD+ODD, as well as a TD comparison group. Once these differences were identified, we sought to understand how useful, or "clinically relevant" these differences in ED were in classifying children into their diagnostic groups. We found that children with ADHD+ODD were rated by their parents and teachers as having significantly greater impairments in EREG, ECUT, ERNL compared to both children with ADHD only and TD children. Children with ADHDOnly also had greater impairments in EREG, ECUT, and ERNL compared to TD children. In terms of observational tasks, young children in the ADHD+ODD group displayed poorer EREG skills compared to children in the ADHD-Only and TD groups. There were no differences across groups on a standardized ERU task or observed ERNL. Additionally, the significant domains of ED correctly classified $84.7 \%$ of children in the sample. The domains of ED most associated with the predictability of group membership were parent/teacher reported EREG, 
parent/teacher reported ERNL, and parent/teacher reports of CU behaviors. Almost $85 \%$ of participants were correctly classified. Implications from these findings are discussed in further detail below.

In domains of ED with multiple measurements (questionnaire and observation), we found several differences between groups across parent/teacher reports (EREG, ERNL, CU); however, when examining observed measures, we only found significant differences between groups on an observed measure of EREG. Aligned with previous work examining ERU differences in young children with and without ADHD, we did not find any difference between groups on an expressive and receptive task of emotion knowledge (Lugo-Candelas et al., 2017). Additionally, we did not find significant differences on behavioral observations of ERNL. These findings have been replicated across the literature, such that behavioral observations may represent the child's "best performance" at any given point, while parent/teacher ratings capture a general trend and/or pattern of functioning (Melnick \& Hinshaw, 2000; Toplak et al., 2013). Thus, the children's responses during the frustration tasks may not be an accurate depiction of their typical emotional functioning, specifically emotional reactivity/lability, across a longer period of time at school and/or at home. Additionally, the global code used in the current study to measure ERNL examined the number of changes in affect as opposed to the valence of their emotions (positive to negative). Some studies have found significant differences in the expression of positive emotions, more specifically, exuberance (Sjöwall \& Thorell, 2019) in children with ADHD compared to TD children. Given the heterogenous nature of ERNL, future studies should include observational tasks which allow for the 
examination of exuberance as well as negativity/lability to best classify children with and without ADHD and co-occurring $\mathrm{CP}$.

Aligned with findings from Graziano and Garcia (2016)'s meta-analysis of ED, it seems as though children with ADHD may be "less equipped" to respond (ERNL), modulate (EREG), and empathize (CU) following emotional events, compared to TD. Similarly, these strong findings were robust when examining ADHD symptoms (inattention and hyperactivity) continuously within our whole sample. Not surprisingly, when ODD symptoms and domains of ED were examined, we found even stronger associations between ODD symptoms and reports of EREG and parent/teacher reports of ERNL. These findings highlight the deficits in top-down emotional processing deficits in children with ADHD (Petrovic \& Castellanos, 2016). We also found that ED problems were exacerbated by the presence of other disruptive behavior disorders, such as ODD. In fact, children with ADHD+ODD were rated by their parents/teachers as having poorer EREG skills and higher levels of CU behaviors compared to both the ADHD only and TD groups. These increased ED problems in children with comorbid ADHD and ODD have been noted extensively in the literature (Factor, Reyes, \& Rosen, 2014; Graziano \& Garcia, 2016; Graziano et al., 2019; Sobanski et al., 2010). Our current study extends the literature by examining these highly co-occurring problems in an understudied sample of young children from a predominantly Latinx background (La Greca, Silverman, \& Lochman, 2009).

From a developmental psychopathology perspective, examining a transdiagnostic feature, such as ED, may serve as a useful risk factor related to the 
multiple pathways associated with the development of ADHD, ODD, and more serious conduct problems (Loeber, Burke, \& Pardini, 2009; Nigg et al., 2004). While there is evidence to suggest these pathways exist in school-aged children (Rowe, Costello, Angold, Copeland, \& Maughan, 2010; Viding \& McCrory, 2012), there is a significant gap in the literature which focuses on these early behavioral and emotional problems in preschool children. Thus, the findings of the current study suggest this is a crucial developmental period to examine when considering the onset of ADHD, ODD and other CPs.

In terms of the LDA, our predictors sub-optimally classified children in the ADHD-Only group. Gross' emotion generation model (1998) suggests cognitive abilities play a key role throughout multiple steps of ED. Although we controlled for cognitive functioning, we did not examine how differences in executive function (EF) were associated with ED. Recent work by Landis and colleagues (2020) have identified how EF and ED are highly associated with the symptoms of ADHD in a sample of preschool children. Thus, it may be the case that children with ADHDOnly had greater EF deficits, which were not captured in the classification analyses. However, these findings highlight the transdiagnostic nature of ED as well as the high ADHD/ODD comorbidity rate in preschoolers with ADHD. Future studies and clinical services would benefit from examining both EF and ED when determining if a child meets criteria for ADHD.

Some limitations need to be addressed. First, it is important to point out that of the 78 children with ADHD, the vast majority $(83 \%)$ met criteria for the combined type presentation. Thus, it was not possible to examine differences in ED according to 
ADHD presentation. Nonetheless, we did note via our continuous examination of ADHD symptoms and ED, with the whole sample, that both inattention and hyperactivity/impulsivity symptoms similarly related to ED deficits. Nevertheless, more work is needed examining ED within children with ADHD, predominantly inattentive type. Additionally, our observational frustration tasks were limited to an interaction with a confederate, thus making it difficult to assume their observed reaction would generalize to other individuals (e.g., parents) outside of the laboratory. It would also be important for future work to examine the utility of observing children's empathy/CU behaviors within the lab setting. Understanding the physiological reactivity associated with ED in children with ADHD may help elucidate the heterogeneity of ED in preschool children. For example, recent work by Morris (2019) and colleagues found significant differences in psychophysiological correlates (as measure by respiratory sinus arrhythmia [RSA] and electrodermal activity [EDA]) between school-aged children with and without ADHD. Lastly, while this may be a strength, our sample was predominately Latinx given the geographic location of the study. It is possible that these results may not generalize to other races/ethnic backgrounds. Nonetheless, these are rich findings about Latinx children, whom are part of the largest growing and understudied group in the United States (La Greca, Silverman, \& Lochman, 2009).

In sum, our findings suggest there are distinct ED differences between TD children, ADHD-Only, and ADHD+ODD. Specifically, preschool children with ADHD+ODD are having significantly higher levels of ED across multiple domains (ERNL, EREG, and CU behaviors) compared to children with ADHD-Only and TD 
children. Given the persistent and chronic nature of ADHD across the lifespan (Kuriyan et al., 2013; Malloy-Diniz et al., 2007; Merrill et al., 2016), identifying these emotional impairments during the preschool period can inform early intervention efforts targeting preschoolers with ADHD and comorbid ODD. The classification predictors used in our analyses suggests that most of the ED domains (EREG, ERNL, and CU behaviors) are excellent in correctly classifying children with ADHD+ODD (as well as TD) but not necessarily children with only ADHD. Given the important role of EF in both regulatory domains of ED (Blair \& Ursache, 2011) as well as its role within ADHD etiology (Antshel, Hier, \& Barkley, 2014; Barkley, 2000; Schoemaker et al., 2012), future work should examine the joint contributions of EF and ED as way to improve our classification of children with ADHD-Only versus those with comorbid CP. Finally, it will be important for future studies to incorporate biological correlates of ED and EF (i.e., heart rate variability during cognitive and emotional tasks, neural correlates) as a way to examine the heterogeneity of children with ADHD. 
Anastopoulos, A. D., Smith, T. F., Garrett, M. E., Morrissey-Kane, E., Schatz, N. K., Sommer, J. L., . . Ashley-Koch, A. (2011). Self-regulation of emotion, functional impairment, and comorbidity among childrenwith AD/HD. Journal of Attention Disorders, 15(7), 583-592.

Antshel, K. M., Hier, B. O., \& Barkley, R. A. (2014). Executive functioning theory and ADHD. In Handbook of executive functioning (pp. 107-120): Springer.

Association, A. P. (2013). Diagnostic and statistical manual of mental disorders (DSM-5®): American Psychiatric Pub.

Babb, K. A., Levine, L. J., \& Arseneault, J. M. (2010). Shifting gears: Coping flexibility in children with and without ADHD. International Journal of Behavioral Development, 34(1), 10-23.

Bansal, P. S., Goh, P. K., Lee, C. A., \& Martel, M. M. (2020). Conceptualizing Callous-Unemotional Traits in Preschool through Confirmatory Factor and Network Analysis. Journal of abnormal child psychology, 1-12.

Bansal, P. S., Haas, S. M., Willoughby, M. T., Coles, E. K., Pelham Jr, W. E., \& Waschbusch, D. A. (2019). A Pilot Study of Emotional Response to Time-Out in Children With Conduct Problems and Callous-Unemotional Traits. Psychological reports, 0033294119884014.

Barkley, R. A. (2000). Genetics of childhood disorders: XVII. ADHD, Part 1: The executive functions and ADHD. Journal of the American Academy of Child \& Adolescent Psychiatry.

Barkley, R. A. (2014). Attention-deficit hyperactivity disorder: A handbook for diagnosis and treatment: Guilford Publications.

Barkley, R. A., \& Fischer, M. (2010). The unique contribution of emotional impulsiveness to impairment in major life activities in hyperactive children as adults. Journal of the American Academy of Child \& Adolescent Psychiatry, 49(5), 503-513.

Barkley, R. A., \& Mash, E. J. (2003). Child psychopathology: Guilford Press. 
Berlin, L., Bohlin, G., Nyberg, L., \& Janols, L.-O. (2004). How well do measures of inhibition and other executive functions discriminate between children with ADHD and controls? Child Neuropsychology, 10(1), 1-13.

Blair, C., \& Ursache, A. (2011). A bidirectional model of executive functions and self-regulation.

Bunford, N., Evans, S. W., \& Langberg, J. M. (2018). Emotion dysregulation is associated with social impairment among young adolescents with ADHD. Journal of Attention Disorders, 22(1), 66-82.

Bunford, N., Evans, S. W., \& Wymbs, F. (2015). ADHD and emotion dysregulation among children and adolescents. Clinical child and family psychology review, $18(3), 185-217$.

Denham, S. A. (1986). Social cognition, prosocial behavior, and emotion in preschoolers: Contextual validation. Child development, 194-201.

Duda, M., Ma, R., Haber, N., \& Wall, D. (2016). Use of machine learning for behavioral distinction of autism and ADHD. Translational psychiatry, 6(2), e732-e732.

DuPaul, G. J., Volpe, R. J., Jitendra, A. K., Lutz, J. G., Lorah, K. S., \& Gruber, R. (2004). Elementary school students with AD/HD: Predictors of academic achievement. Journal of School Psychology, 42(4), 285-301.

Eisenberg, N., Valiente, C., \& Eggum, N. D. (2010). Self-Regulation and School Readiness. Early Education and Development, 21(5), 681-698. doi:10.1080/10409289.2010.497451

Fabiano, G. A., Pelham, J., William E, Waschbusch, D. A., Gnagy, E. M., Lahey, B. B., Chronis, A. M., . . B Burrows-MacLean, L. (2006). A practical measure of impairment: Psychometric properties of the impairment rating scale in samples of children with attention deficit hyperactivity disorder and two school-based samples. Journal of Clinical Child and Adolescent Psychology, 35(3), 369-385.

Factor, P. I., Reyes, R. A., \& Rosen, P. J. (2014). Emotional impulsivity in children with ADHD associated with comorbid — not ADHD—symptomatology. Journal of Psychopathology and Behavioral Assessment, 36(4), 530-541. 
Frick, P. J. (2004). The inventory of callous-unemotional traits. Unpublished rating scale.

Frick, P. J., Ray, J. V., Thornton, L. C., \& Kahn, R. E. (2014a). Annual research review: A developmental psychopathology approach to understanding callous unemotional traits in children and adolescents with serious conduct problems. Journal of Child Psychology and Psychiatry, 55(6), 532-548.

Frick, P. J., Ray, J. V., Thornton, L. C., \& Kahn, R. E. (2014b). Can callousunemotional traits enhance the understanding, diagnosis, and treatment of serious conduct problems in children and adolescents? A comprehensive review. Psychological bulletin, 140(1), 1.

Garcia, A. M., Graziano, P. A., \& Hart, K. C. (2018). Response to time-out among preschoolers with externalizing behavior problems: The role of callousunemotional traits. Child Psychiatry \& Human Development, 49(5), 699-708.

Goldsmith, H., \& Rothbart, M. (1996). The Laboratory Temperament Assessment Battery (LabTAB): Locomotor version 3.0 technical manual. Madison, WI: Department of Psychology, University of Wisconsin.

Graziano, P. A., \& Garcia, A. (2016). Attention-deficit hyperactivity disorder and children's emotion dysregulation: A meta-analysis. Clinical psychology review, 46, 106-123.

Graziano, P. A., Landis, T., Maharaj, A., Ros-Demarize, R., Hart, K. C., \& Garcia, A. (2019). Differentiating preschool children with conduct problems and callousunemotional behaviors through emotion regulation and executive functioning. Journal of Clinical Child \& Adolescent Psychology, 1-13.

Graziano, P. A., Ros, R., Haas, S., Hart, K., Slavec, J., Waschbusch, D., \& Garcia, A. (2016). Assessing callous-unemotional traits in preschool children with disruptive behavior problems using peer reports. Journal of Clinical Child \& Adolescent Psychology, 45(2), 201-214.

Gross, J. J. (1998). The emerging field of emotion regulation: An integrative review. Review of general psychology, 2(3), 271-299.

Gross, J. J. (2011). Handbook of emotion regulation: Guilford Press. 
Haas, S. M., Becker, S. P., Epstein, J. N., \& Frick, P. J. (2018). Callous-unemotional traits are uniquely associated with poorer peer functioning in school-aged children. Journal of abnormal child psychology, 46(4), 781-793.

Haas, S. M., Waschbusch, D. A., Pelham, W. E., King, S., Andrade, B. F., \& Carrey, N. J. (2011). Treatment response in CP/ADHD children with callous/unemotional traits. Journal of abnormal child psychology, 39(4), 541552.

Hartman, C. A., Rhee, S. H., Willcutt, E. G., \& Pennington, B. F. (2007). Modeling rater disagreement for ADHD: are parents or teachers biased? Journal of Abnormal Child Psychology, 35(4), 536-542.

Hawes, S. W., Byrd, A. L., Henderson, C. E., Gazda, R. L., Burke, J. D., Loeber, R., \& Pardini, D. A. (2014). Refining the parent-reported Inventory of CallousUnemotional Traits in boys with conduct problems. Psychological Assessment, 26(1), 256.

Kats-Gold, I., \& Priel, B. (2009). Emotion, understanding, and social skills among boys at risk of attention deficit hyperactivity disorder. Psychology in the Schools, 46(7), 658-678.

Kimonis, E. R., Frick, P. J., Boris, N. W., Smyke, A. T., Cornell, A. H., Farrell, J. M., \& Zeanah, C. H. (2006). Callous-unemotional features, behavioral inhibition, and parenting: independent predictors of aggression in a high-risk preschool sample. Journal of Child and Family Studies, 15(6), 741-752. doi:10.1007/s10826-006-9047-8

Kuriyan, A. B., Pelham, W. E., Molina, B. S., Waschbusch, D. A., Gnagy, E. M., Sibley, M. H., ... Yu, J. (2013). Young adult educational and vocational outcomes of children diagnosed with ADHD. Journal of Abnormal Child Psychology, 41(1), 27-41.

La Greca, A. M., Silverman, W. K., \& Lochman, J. E. (2009). Moving beyond efficacy and effectiveness in child and adolescent intervention research. Journal of consulting and clinical psychology, 77(3), 373.

Landis, T. D., Garcia, A. M., Hart, K. C., \& Graziano, P. A. Differentiating Symptoms of ADHD in Preschoolers: The Role of Emotion Regulation and 
Executive Function. Journal of Attention Disorders, $0(0)$, 1087054719896858. doi:10.1177/1087054719896858

Lavigne, J. V., LeBailly, S. A., Hopkins, J., Gouze, K. R., \& Binns, H. J. (2009). The prevalence of ADHD, ODD, depression, and anxiety in a community sample of 4-year-olds. Journal of Clinical Child \& Adolescent Psychology, 38(3), 315-328.

Loe, I. M., \& Feldman, H. M. (2007). Academic and educational outcomes of children with ADHD. Journal of pediatric psychology, 32(6), 643-654.

Loeber, R., Burke, J., \& Pardini, D. A. (2009). Perspectives on oppositional defiant disorder, conduct disorder, and psychopathic features. Journal of Child Psychology and Psychiatry, 50(1-2), 133-142.

Lugo-Candelas, C., Flegenheimer, C., McDermott, J. M., \& Harvey, E. (2017). Emotional understanding, reactivity, and regulation in young children with ADHD symptoms. Journal of abnormal child psychology, 45(7), 1297-1310.

Malloy-Diniz, L., Fuentes, D., Leite, W. B., Correa, H., \& Bechara, A. (2007). Impulsive behavior in adults with attention deficit/hyperactivity disorder: characterization of attentional, motor and cognitive impulsiveness. Journal of the International Neuropsychological Society, 13(4), 693-698.

Melnick, S. M., \& Hinshaw, S. P. (2000). Emotion regulation and parenting in $\mathrm{AD} / \mathrm{HD}$ and comparison boys: Linkages with social behaviors and peer preference. Journal of abnormal child psychology, 28(1), 73-86.

Merrill, B. M., Morrow, A. S., Altszuler, A. R., Macphee, F. L., Coxe, S., Molina, B. S., \& Pelham, W. E. (2016). 6.70 Young adults with childhood attentiondeficit/hyperactivity disorder: Latent profiles of functional outcomes and impairment. Journal of the American Academy of Child \& Adolescent Psychiatry, 55(10), S227.

Morris, S. S., Musser, E. D., Tenenbaum, R. B., Ward, A. R., Martinez, J., Raiker, J. S., ... Riopelle, C. (2019). Emotion regulation via the autonomic nervous system in children with attention-deficit/hyperactivity disorder (ADHD): replication and extension. Journal of abnormal child psychology, 1-13. 
Musser, E. D., Backs, R. W., Schmitt, C. F., Ablow, J. C., Measelle, J. R., \& Nigg, J. T. (2011). Emotion regulation via the autonomic nervous system in children with attention-deficit/hyperactivity disorder (ADHD). Journal of abnormal child psychology, 39(6), 841-852.

Nigg, J. T. (2006). Temperament and developmental psychopathology. Journal of Child Psychology and Psychiatry, 47(3-4), 395-422.

Nigg, J. T., Goldsmith, H. H., \& Sachek, J. (2004). Temperament and attention deficit hyperactivity disorder: The development of a multiple pathway model. Journal of Clinical Child and Adolescent Psychology, 33(1), 42-53.

Overgaard, K. R., Oerbeck, B., Aase, H., Torgersen, S., Reichborn-Kjennerud, T., \& Zeiner, P. (2018). Emotional lability in preschoolers with symptoms of ADHD. Journal of Attention Disorders, 22(8), 787-795.

Pelham, J., William E, Fabiano, G. A., \& Massetti, G. M. (2005). Evidence-based assessment of attention deficit hyperactivity disorder in children and adolescents. Journal of Clinical Child and Adolescent Psychology, 34(3), 449476.

Pelham, W. E., Foster, E. M., \& Robb, J. A. (2007). The economic impact of attention-deficit/hyperactivity disorder in children and adolescents. Journal of Pediatric Psychology, 32(6), 711-727.

Pelham, W. E., Gnagy, E. M., Greenslade, K. E., \& Milich, R. (1992). Teacher ratings of DSM-III-R symptoms for the disruptive behavior disorders. Journal of the American Academy of Child \& Adolescent Psychiatry, 31(2), 210-218.

Petrovic, P., \& Castellanos, F. X. (2016). Top-down dysregulation-from ADHD to emotional instability. Frontiers in Behavioral Neuroscience, 10, 70.

Pineda, D., Ardila, A., \& Rosselli, M. (1999). Neuropsychological and behavioral assessment of ADHD in seven-to twelve-year-old children: A discriminant analysis. Journal of Learning Disabilities, 32(2), 159-173.

Ros, R., \& Graziano, P. A. (2018). Social functioning in children with or at risk for attention deficit/hyperactivity disorder: a meta-analytic review. Journal of Clinical Child \& Adolescent Psychology, 47(2), 213-235. 
Rowe, R., Costello, E. J., Angold, A., Copeland, W. E., \& Maughan, B. (2010).

Developmental pathways in oppositional defiant disorder and conduct disorder. Journal of abnormal psychology, 119(4), 726.

Sadatnezhad, K., Boostani, R., \& Ghanizadeh, A. (2011). Classification of BMD and ADHD patients using their EEG signals. Expert Systems with Applications, 38(3), 1956-1963.

Schoemaker, K., Bunte, T., Wiebe, S. A., Espy, K. A., Deković, M., \& Matthys, W. (2012). Executive function deficits in preschool children with ADHD and DBD. Journal of Child Psychology and Psychiatry, 53(2), 111-119.

Shaffer, D., Fisher, P., Lucas, C. P., Dulcan, M. K., \& Schwab-Stone, M. E. (2000). NIMH Diagnostic Interview Schedule for Children Version IV (NIMH DISCIV): description, differences from previous versions, and reliability of some common diagnoses. Journal of the American Academy of Child \& Adolescent Psychiatry, 39(1), 28-38.

Shaw, P., Stringaris, A., Nigg, J., \& Leibenluft, E. (2014). Emotion dysregulation in attention deficit hyperactivity disorder. American Journal of Psychiatry, 171(3), 276-293.

Shields, A., \& Cicchetti, D. (1997). Emotion regulation among school-age children: The development and validation of a new criterion Q-sort scale. Developmental psychology, 33(6), 906.

Sibley, M. H., Pelham, W. E., Molina, B. S., Waschbusch, D. A., Gnagy, E. M., Babinski, D. E., \& Biswas, A. (2010). Inconsistent self-report of delinquency by adolescents and young adults with ADHD. Journal of Abnormal Child Psychology, 38(5), 645-656.

Sjöwall, D., Roth, L., Lindqvist, S., \& Thorell, L. B. (2013). Multiple deficits in ADHD: executive dysfunction, delay aversion, reaction time variability, and emotional deficits. Journal of Child Psychology and Psychiatry, 54(6), 619627.

Sjöwall, D., \& Thorell, L. B. (2019). A critical appraisal of the role of neuropsychological deficits in preschool ADHD. Child Neuropsychology, $25(1), 60-80$. 
Sobanski, E., Banaschewski, T., Asherson, P., Buitelaar, J., Chen, W., Franke, B., . . Sonuga-Barke, E. (2010). Emotional lability in children and adolescents with attention deficit/hyperactivity disorder (ADHD): clinical correlates and familial prevalence. Journal of Child Psychology and Psychiatry, 51(8), 915923.

Sutton, J. (2004). ToM goes to school: Social cognition and social values in bullying. In

Individual differences in theory of mind (pp. 109-131). Psychology Press.

Viding, E., \& McCrory, E. J. (2012). Genetic and neurocognitive contributions to the development of psychopathy. Development and Psychopathology, 24(3), 969983.

Waller, R., Gardner, F., Viding, E., Shaw, D. S., Dishion, T. J., Wilson, M. N., \& Hyde, L. W. (2014). Bidirectional associations between parental warmth, callous unemotional behavior, and behavior problems in high-risk preschoolers. Journal of abnormal child psychology, 42(8), 1275-1285.

Waller, R., Hyde, L. W., Grabell, A. S., Alves, M. L., \& Olson, S. L. (2015). Differential associations of early callous-unemotional, oppositional, and ADHD behaviors: multiple domains within early-starting conduct problems? Journal of Child Psychology and Psychiatry, 56(6), 657-666.

Waschbusch, D. A., Graziano, P. A., Willoughby, M. T., \& Pelham Jr, W. E. (2015). Classroom rule violations in elementary school students with callousunemotional traits. Journal of Emotional and Behavioral Disorders, 23(3), 180-192.

Waschbusch, D. A., Willoughby, M. T., Haas, S. M., Ridenour, T., Helseth, S., Crum, K. I., . . Pelham, W. E. (2019). Effects of behavioral treatment modified to fit children with conduct problems and callous-unemotional (CU) traits. Journal of Clinical Child \& Adolescent Psychology, 1-12. 


\section{Table 1}

Descriptive Statistics and Outcomes.

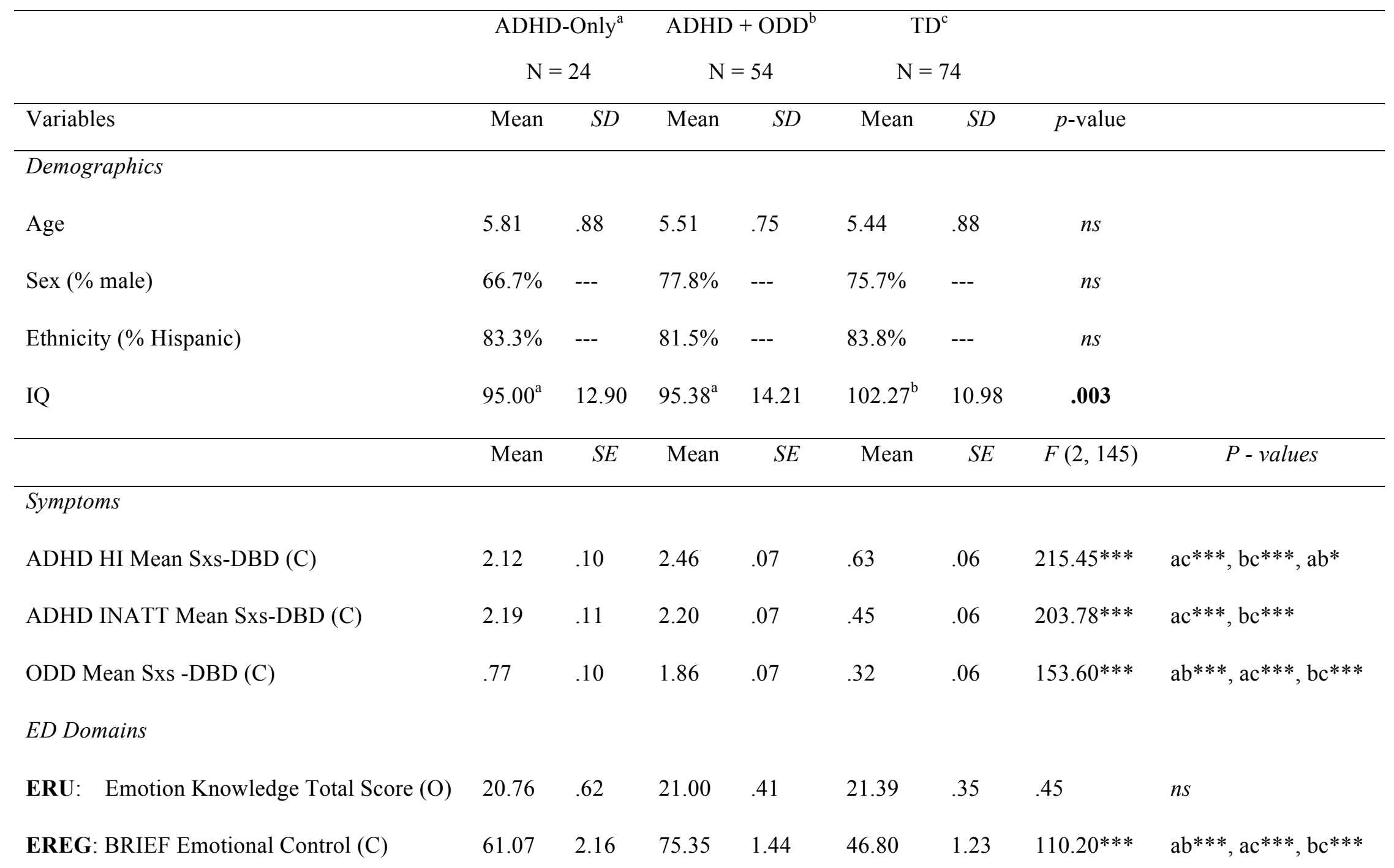


ERNL: ERC-Negativity Subscale (C)

Affect Lability (O)

.04

2.78

.05

1.62

.04

$155.74 * * *$

$a b^{* * *}, \mathrm{ac}^{* * *}, \mathrm{bc}^{* * *}$

CU: ICU Mean Item Score (C)

* $p<.05, * * p<.01, * * * p<.001, \mathrm{~ns}=$ no significance. All analyses controlled for sex, age, and IQ. C = Combined parent and teacher report, $\mathrm{O}=$ Observation, $\mathrm{ADHD}=$ Attention-deficit/hyperactivity disorder, $\mathrm{HI}=$ Hyperactivity/Impulsivity, INATT $=\mathrm{Inattention}, \mathrm{ODD}=$ Oppositional Defiant Disorder, Sxs = Symptoms, DBD = Disruptive Behavior Disorders Rating Scale, TD = Typically Developing, BRIEF $=$ Behavior Rating Inventory of Executive Functioning, ERC = Emotion Regulation Checklist (Shields \& Cicchetti, 1997), ERU= Emotion Understanding, EREG= Emotion Regulation, ERNL= Emotional reactivity/negativity/lability, $\mathrm{CU}=$ Callous-unemotional behaviors 
Table 2

Partial Correlations Between Study Variables.

\begin{tabular}{|c|c|c|c|c|c|c|c|c|c|}
\hline & 1 & 2 & 3 & 4 & 5 & 6 & 7 & 8 & 9 \\
\hline $\begin{array}{l}A D H D \text { and } C P \text { Sxs } \\
\text { 1. Inattention }(\mathrm{C})\end{array}$ & - & & & & & & & & \\
\hline 2. Hyperactivity/Impulsivity (C) & $.84 * * *$ & - & & & & & & & \\
\hline 3. ODD $(\mathrm{C})$ & $.66^{* * *}$ & $.77 * * *$ & - & & & & & & \\
\hline $\begin{array}{l}E R U \\
\text { 4. Emotion Knowledge }(\mathrm{O})\end{array}$ & .07 & .07 & .05 & - & & & & & \\
\hline $\begin{array}{l}\text { EREG } \\
\text { 5. BRIEF-Emotion Control (C) }\end{array}$ & $.67 * * *$ & $.71 * * *$ & $.83 * * *$ & .08 & - & & & & \\
\hline 6. Global Regulation (O) & $-.25 * *$ & $-.26 * *$ & $-.19 *$ & $-.14^{*}$ & $-.33 * * *$ & - & & & \\
\hline $\begin{array}{l}E R N L \\
\text { 7. Negativity (C) }\end{array}$ & $.69 * * *$ & $.82 * * *$ & $.89 * * *$ & .03 & $.85 * * *$ & $-0.24 * *$ & - & & \\
\hline 8. Affect Lability (O) & -.01 & .07 & .10 & .10 & .15 & $-.42 * * *$ & .12 & - & \\
\hline $\begin{array}{l}C U \\
\text { 9. } \mathrm{CU} \text { behaviors }(\mathrm{C})\end{array}$ & $.60 * * *$ & $.60 * * *$ & $.67 * * *$ & .00 & $.49 * * *$ & -.08 & $.66 * * *$ & -.01 & - \\
\hline
\end{tabular}

Note. $* * * p<.001, * * p<.01, * p<.05$. Partial correlations controlling for age, sex, and IQ. ADHD = Attention-deficit/hyperactivity disorder, $\mathrm{ODD}=$ Oppositional Defiant Disorder, $\mathrm{Sxs}=$ Symptoms, $\mathrm{C}=$ Combined parent and teacher report, $\mathrm{O}=$ observed measure, BRIEF $=$ Behavior Rating Inventory of Executive Functioning, ERU = Emotion Understanding, EREG= Emotion Regulation, ERNL= Emotional reactivity/negativity/lability, $\mathrm{CU}=$ Callous-unemotional behavior 
Table 3

Discriminant Function Coefficients for Emotion Dysregulation Domains.

Variable

Standardized Coefficients

EREG: BRIEF-Emotional Control T-Score (C)

.43

Global Regulation $(\mathrm{O})$ $-.09$

ERNL: ERC- Negativity Subscale (C) .54

CU: ICU Mean Item Score (C)

Note. $\mathrm{C}=$ Combined parent and teacher report, $\mathrm{O}=$ Observation, $\mathrm{BRIEF}=$ Behavior Rating Inventory of Executive Functioning, EREG= Emotion Regulation, ERNL= Emotional reactivity/negativity/lability, $\mathrm{CU}=$ Callous-unemotional behaviors, $\mathrm{ERC}=$ Emotion Regulation Checklist (Shields \& Cicchetti, 1997), ICU = Inventory of Callous-Unemotional Traits (Frick, 2004) 
Table 4

Classification Results for ED Domains Predicting Diagnostic Groups.

\begin{tabular}{lllll}
\hline \multicolumn{5}{c}{ Predicted (\%) } \\
\hline Group & TD & ADHD-Only & ADHD + ODD & Centroid \\
\hline TD $(n=74)$ & 93.2 & 5.4 & 1.4 & -1.62 \\
ADHD Only $(n=24)$ & 33.3 & 41.7 & 25.0 & .36 \\
ADHD + ODD $(n=$ & 3.8 & 3.8 & 92.3 & 2.14
\end{tabular}

54)

Note. $84.7 \%$ of original cases correctly classified. ED = Emotion dysregulation, $\mathrm{TD}=$ Typically developing, ADHD = Attention-deficit/hyperactivity disorder, ODD = Oppositional Defiant Disorder 
Response to Time-Out Among Preschoolers with Externalizing Behavior Problems: The Role of Callous-Unemotional Traits

This was published in Child Psychiatry and Human Development

Garcia, A. M., Graziano, P. A., \& Hart, K. C. (2018). Response to time-out among preschoolers with externalizing behavior problems: The role of callous-unemotional traits. Child Psychiatry \& Human Development, 49(5), 699-708. 


\title{
Response to Time-Out Among Preschoolers with Externalizing Behavior Problems: The Role of Callous-Unemotional Traits
}

\author{
Alexis M. Garcla' 1 - Paulo A. Grazlano' - Katle C. Hart ${ }^{1}$ \\ Publishod online: 19 Fobruary 2018 \\ oSpringer Sdence+ Eueiness Modla, UC, part of Spinger Natuv 2018
}

\section{Abstract}

This study ex amined the role of callous-unemotional (CU) traits in preschoolers with externalizing behavior problems (EBP) and their response to time out (TO). One hundred ninety paschoolers (76\% boys, $\mathrm{M}^{20}=4.92$ ) with at-risk/flinically elevated kevels of EBP participated in an 8-woek summer treatment program (STP-PreK). Total number of minutes spent deily in TO for intenticnal aggression (LA) and reperted non- compliancx (RNC) were recorded during the initial (T1) and final (T2) phases of the STP-PreK. After accounting for severity of EBP and levels of TO at T1, hipher kevels of CU traits predicted greater total levels of TO at T2. An interaction also emerped betwexn symptoms of oppositional defiant disorike (ODD) and CU traits in podicting LA. Specifically, greater ODD symptrms predicted fewer number of LA $x$ lated TO at T2, but only for children with low CU traits. Implications for treatment are discussed.

Keywords Behavional treatment - Callous -unemotional traits - Conduct problems · Preschoolers · Time-out

\section{Introduction}

Externalizing behavior problems (EBP) such as attentiondeficit/hypenactivity disorder (ADHD), oppositional defiant disorder (ODD), and conduct disorder (CD) affect 5-10\% of children and sdolescents and reporsent the most common referrals to mental health clinics [1, 2]. EBP areeven more cormmon in preschoolers, with prevalencr rates ranging frum 14 to $52 \%$ [3]. A percentage of these children, ranging from 7 to $25 \%[4,5]$, also display a range of conduct problems (CP) such as aggressive, defiant, and anti-social behavions (AB) that are known to violate the rights of others and major societal norms [6]. Multiple longitudinal studies show that at least half of preschool children with moderate to severe CP continue to show similar behaviors at school age [7-9]. Given the stability $[10]$ and detrimental outcomes (i.e, cognitive impairments, ageression, delinquency, and emotional impairments) [11] associated with early CP, it is important to consider risk factors that influxnce the course of early CP.

Callous-unemotional (CU) traits have emrerped as important factor in understanding the heterogeneity in emotion

Paulo A.Gruizo

perziandiuedu

1 Depertment of Pygchology, Florida International University, Miani, FL. $331 \%$, USA dysx gulation for children with EBP [12], and of particular interest to the current study, CP [13]. Children displaying CU traits are typically defined as having low levels of guilt, empathy, and caring for others. The subgroup of children with $\mathrm{CP}$ that display CU traits experience the most pervasive, sever, and aggressive patterns of antispcial behavior [14]. For example, children with CP exhibiting CU traits have higher rates of property delinquency (i.e, destruction of property), violent delinquency (ie., physical altercations), and police contact than children who only have $\mathrm{CP}$ or $\mathrm{CU}$ alone [15]. Children with $\mathbf{C P}$ and $\mathrm{CU}$ traits have been shown to exhibit impairments across domains (e.g., academic, social, and behavioral) in the classroom setting [16]. Additionally, the stability of CU traits has been documented during the preschool [17], earty childhood [18], and adolescent years $[19,20]$. Given the relafively high stability of CU traits from childhood to adolescence [21], it is imperative to examine CU traits among younger children.

\section{CUTraits in Preschoolers}

As highlighted by Waller et al. [22], there ax relatively few studies investigating CU traits in preschoolers with emerging evidence suggesting that $\mathrm{CU}$ traits can be identified as early as age three [23]. Early CU traits have been found to predict laker ODD and CD diagnoses [24]. Even fewer studies have 
examined the role of CU traits among preschoolers with CP in terms of impeirment across domains (e.q- social function, academics). For example, with regard to social functioning. Grveiano et al. [25] neported that preschool children with CP. can correctly identify perrs whoengage in behaviors indicative of CU traits and are more likely to dislike and socially zeject them. In the academic domain, preschool children with CU have been found to be more likely to experience academic underachievement [26, 27]. Due to the stability and array of impairments children with CU traits experiencr across domains, it is crucial to intervene early to help attenuate somr of their behavioral and emotional deficits.

\section{Treatment of CP in Preschoolers}

Evidence-based treatments (EBT) have been shown to be an effective way to reducx the severity of CP [28-30]. Eyberg et al. [28] proposed when selecting EBT for young children (ages 2-5), behavioral parent training (BPT) should be the finst line of approach nather than medication. In BPT, negative behavions are decreased through two key phases, which include increasing positive interactions between the parent and child, and providing consistent consequences for negative behaviors $[29,31,32]$. Acconding to a metaanalysis conducted by Kaminski et al. [29], the first phase of treatment primarily focuses on positive interactions that are zward driven, while the second phase uses consequences or punishments, like time-out (TO), to address negative behavion. However, relatively few studies have examined the extent to which young children with $\mathrm{CU}$ traits $\mathrm{x}$ spond to specific treatment components like TO.

The few studies to date that have ex amined the treatment response of children with CU traits have yielded mixed findings. For example, one study showed that parents found TO to be less effective for boys who had higher CU traits [33], suggesting the boys in the study were less sensitive to punishment, regandless of parenting strak gies. This may be related to emerging evidence suggesting that children with CU traits are insensitive to punishment and may be more sensitive to reward related goals $[34,35]$. However, a systematic review by Waller et al. [36], found that parentfocused interventions appeared to $b$ effective in $x$ ducing CU traits in children. For example, in the context of a behavioral farmily intervention based on Sanders and Dadds [37]. BPT was found to be an effective treatment on roducing the level of CU traits and CP in young children [18].

In addition to BPT, multimodal interventions that target childxen and paxents separately have also been effective in improving CP [38, 39]. For example, the Summer Treatment Program (STP) [40] is effective in zeducing CPs such as aggression [41] as well as improving children's social functioning [42]. Yet it is important to note the effect of the SIP on reducing CP was significantly lower among children displaying CU traits [35, 43]. On the other hand, an abbreviated version of Coping Ptwer [44], which is another multimodal program tarpeting aggression, was effective in reducing children's CP, $\pi$ gardless of CU traits [45]. Given the mixed findings in school-aged children with $C_{\mathrm{s}}$, the ex tent to which CU traits attenuate the effectiveness of such multimodal interventions in young children, primarily posschoolers, remains unclear.

\section{Current Study}

In summary, emerging evidence points to the stability of early CU traits during the preschool period $[46,47]$ and significant behavicral, acadernic, social, and familial impairment [24-26, 36]. Very few studies have examined preschookrs with CU traits' response to established EBT for CP [48]. Given evidencx with older children suggesting that CU traits are associated with a deficit in punishment $\mathrm{s}$ nsitivity $[34,35]$, a clinically relevant question becomes the extent to which preschoolers with CU traits are responsive to a widely used therapeutic component, TO. Ex amining young children's response to TO is crucial given that TO is part of almost every EBT for CP [28, 29]. Most notably, the Ew studies that have examined the link between children's response to treatment in the form of TO and CU traits were done with older samples $[35,43,46]$.

Hencr, the current study is the first to our knowledge to examine the role of CU traits in preschoolers with $\mathrm{CP}$ and their response to TO. Within the context of a comprehensive multimodal Summer Treatment Program for Pre-K indergarteners (STP-PreK) [49] in a sample of preschoolers with EBP, we examined the extent to which CU traits (as rated by parents/porschool teachers) at pre-treatment predicted (a) baseline levels of TO during the initial phase of the STP-PrK (Time 1) and (b) change in the levels of TO from the initial to final phase of the STP.PreK (Time 2). TO was examined both in terms of tntal number of daily minutes during the SIP.PreK as well as the number of TO due to either intentional aggression (IA) or reprated noncompliance (RNC). After accounting for demographic variables that may relate to CU traits (e.g- sex) $[50,51]$ as well as severity of CP [52,53], we hy pothesind that preschookers with higher levels of CU traits would spend more minutes in TO during the initial and final phases of the SIP-PreK.

\section{Methods}

\section{Participants and Recrultment}

Children and their caxgivers were recruiled from local pre. school and mental health apencies via brochures, radio and newspaper ads, and open houses/parent workshops. Legal 
guardians contacted the clinic and were directed to the study staff for screening questions to determine eligibility. Participants were required to (a) have an externalizing problems composite t-scome of 60 or above on the parent $M=64.30$, $S D=13.17)$ or tearher $(M=65.31, S D=13.41)$ BASC-2 [54], (b) be enrolled in preschool during the previous year, (c) have an estimated IQ of 70 or higher (M-94.13), (d) have no confirmed history of an Autism Spectrum or Prychotic Disoriker, and (e) be able to attend an 8-week summer treatment program (SIP) prior to the start of the next preschool or kindergarten year.

The final participating sample consisted of 190 preschool children (76\% boys) with at risk or clinically elevated levels of EBP whose parents provided consent to participate in the study. The mean age of the participating children was 4.92 years and more than half of the parents reported curzently being married/living with the child's other biological parent $(60 \%)$. Acoording to the C-DISC [55], which was conducted by mental health graduate students under the supervision of a licensed psychologist, $42 \%$ pervent of children met DSM-IV criteria for both ADHD and ODD while an additional $24 \%$ met criteria for ADHD-only.

\section{Study Design and Procedure}

This study was approved by the university's Institutional Review Board. Children were recruited across 2 years and participated in the STP-PnK [49]. All families participated in a pre-treatment assessment prior to the start of the SIPPreK, which included completicn of the ADHD, ODD, and CD modules on the C-DISC [55] and various questionnaires zgarding their children's behavioral, academic, and emotional functioning. Other than moceiving the intervention at either no cost via a federal grant or at a subsidized cost via a local grant, families did not recrive compensation for completing the pre-treatment assessment. Similar questionnaires were also obtained from children's preschool teachers.

For this study, we were interested in examining the extent to which initial levels of pasent and teacher ratings of children's CU traits were uniquely related to children's nesponse to a component of the multimodal intervention, TO. Number of minutes spent in TO were recorded by a counselor in the STP-PreK [49]. Briefly, children were assigned TOs for the following three reasons: LA, intenticnal destruction of property (IDP), and RNC. Counselors followed the TO sequence used in Parent-Child Interaction Therapy (PCIT) [56].

A child would receive aTO for LA for instances of aggressive behaviors directed towards other children or staff mermbers (e.g., hitting, spitting, biting). TOs for IDP were given for destructive behaviors towards the child's own belongings, the belonging of another person, or objects in the classroom (e.g., baxaking pencil during seatwork, ripping up a classmates dras ing flipping a desk). TOs for IDP were not ex amined in the following study given the low frequency of such behaviors. Finally, RNC TOs wex assigned when the child friled to comply with a command after being prompted two times by a counselor or $\mathbf{k}$ acher. Regardless of the reason for which the TO was assigned, children were expected to serve their TO appropriately for a total of $3 \mathrm{~min}$ followed by a 5 s moment of silence. Serving a TO appropriately was described to the child as staying on the TO chair in the ocrner of the classoom, quietly. If a child's behavior did not meet the criteria necessary to end the TO (being seated and silent after the $3 \mathrm{~min}$ and $5 \mathrm{~s}$ period), the counselar monitoring the TO would actively ignore these behavions until the child was serving the final 5 s appropriakly.

\section{Measures}

\section{CP and ADHD Symptoms}

Parents and teachers completed the Disruptive Behavior Dis. orders (DBD) Rating Scale [57]. The DBD rating scale axks the respondent to rate on a 4-point scale ranging from 0 (not ar all) to 3 (very much), the degree to which children dis play symptoms of $A D H D, O D D$, and CD. The DBD Rating Scale's responses range from 0 (nor ar all) to 3 (very much). Consistent with prior work [58, 59], parent and teacher nat. ings were combined by taking the higher of the two ratings for each itern to creale composites. Of note we did notexam. ine CD given our preschool sample. Rather, our $C P$ me asure was the mean scoure acroos the ODD symptoms ( $\alpha-85$ ). The me an score across the ADHD symptoms was also examined $(\mathrm{a}-92)$

\section{cuTralts}

Parents and preschool teachers completed an abbreviated version of the inventrory of callous-unemotional traits (KCU) [60] consisting of 12 iterns identified by Haves et al. [48] as showing similar prychometric properties to those of the full ICU. The items were rated on a 4-point Likert scak ranging from 0 (not ar all) to 3 (very much) and included: seems to enjoy being mean; is cold or uncaring; lacks remorse for misbehsvior, does not sexm to respond or care about punishment; and uses or cons other people to get what hed she wants. Consistent with pricr work examining CU traits [19], parent and teacher ratings were combined by taking the higher of the two ratings for each itm ( $\alpha-84)$. This method is useful when one is attempting to avoid underreporting [15] behaviors that may occur across several settings.

\section{Measurement of Minutes in TO}

Consistent with previous work [61], counselars zeconded the start and end time of each TO, the reason it was assigned 
(LA, RNC), and the number of minutes spent in TO for the day. For the purposes of the curnent study, the first 2 wexks, Time 1 (T1) were used to exarnine initial levels of TO. The purpose of examining TO acruss the first 2 werks was to account for the "honeymoon effect." The "honeymooneffect" suggests that clinically elevated behavions may decline or "disappear" at the beginning of treatment, only to zemerge shortly thexaffer. Toexamine the extent to which children responded to the TO component of the STP-PreK, we examined TO during the last 2 wexks of the STP-PreK, Time 2 (T2).

\section{Data Analytic Plan}

All analyses were conducted using the Statistical Package for Social Sciences, version 20 (SPSS 20). Missing values analyses revealed that only one child was missing data across TO domains at week 8 . The lack of data for this child was due to absences during the last 2 weeks of the STPPreK. Little's Missing Completely at Random (MCA R) test zevealed the data was missing at random, $\chi^{2}=1.26, p=.74$. Preliminary data analyses wex conducted to examine ary associations between demographic variables and any outcome variables. Given the dependent variables in the current study were count variables, several assumptions for ordinary least squares (OLS) analyses were violated. First, all the outcomes had a right-skewed distribution (kurtosis ranpe $5.50-23.04)$, violating the first assumption of OLS, conditional normality. Secondly, the variance for each outcome violated the assumption of homoscedasticity, such that the variances increased at different values of the predictors.

According to Cose et al. [62], Poisson regressions are optimal for analyses involving count data. Predicted outcomes are transformed with a link function (natural log), that allow the dependent and independent variables to have different metric properties. For example, for every one-unit change in our predicturs (i.e, ADHD, CP, CU traits), we expected a multiplicative $\left(e^{\mathrm{b} 1+\mathrm{b} 2+b 3}\right.$...) change in the outcomes (i.e., IA, RNC). The current study used nested overdisperikd Poisson regressions to predicted T2 TO. Finst, we ran an intercept only model (model 1). Model 2 included age and $\mathrm{T} 1$ as covariates. The following model (model 3) included ADHD, CP, and CU traits as predictors. Finally, model 4 examined interactions between ADHD, CP, and CU traits.

\section{Results}

\section{Preliminary Analyses}

Descriptive statistics for all dernographic variables are presented in Table 1. Preliminary analyses revealed a small
Table 1 Deseripthe variables

\begin{tabular}{|c|c|c|c|c|}
\hline & $M$ & $\mathbf{D D}$ & Range & $\mathrm{N}$ \\
\hline \multicolumn{5}{|l|}{ Demognaphic variaties } \\
\hline Chad sex (\%, mak) & 76 & - & - & 190 \\
\hline Chad nace (s: Hispanic) & 82 & - & - & 190 \\
\hline Chad ape & 4.92 & 53 & $3.50-6.24$ & 190 \\
\hline Marital status (o, marriad) & 60 & - & - & 190 \\
\hline \multicolumn{5}{|l|}{ Hehs icral mexurs } \\
\hline DHD:ADHD & 1.94 & 56 & $.28-294$ & 190 \\
\hline DAD:CP & $13 \pi$ & .68 & $0-3$ & 190 \\
\hline ICU:CU & 108 & .42 & $.08-217$ & 190 \\
\hline \multicolumn{5}{|l|}{ Mean count (per dy) } \\
\hline IA: $\operatorname{Tin} 1$ & .64 & .97 & $0.62 n$ & 190 \\
\hline IA: $\operatorname{Tim} 2$ & 52 & .98 & 0.8 .2 & 189 \\
\hline RNC: Time 1 & 1.54 & 1.93 & 0.11 .33 & 190 \\
\hline RNC: Tine 2 & 94 & 1.48 & $0.0 \%$ & 189 \\
\hline Total number of & 9.85 & 1609 & Q- DEDO & 190 \\
\hline Total number of minules Time 2 & 4.15 & 454 & $0-32.00$ & 189 \\
\hline
\end{tabular}

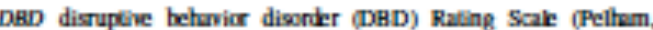
et al. 1998), $K C U$ imenisoy of callots unemolicanal inits (CCU; Frick DO4), CP conduct probiems, CU callous unemotional trits, ADFD attenson-deficiVhypenctivity-impultwe discnite. 70 Eime-out, IA intentional aegression, R.NC eprated non-conpliance

association between age and symptoms of ADHD, $r=.15$, $p<.05$, such that older children were exhibiting more behwions associated with ADHD. Age was also negatively associakd with tntal number of minutes at T2, such that older children were in TO for less time than younger children, $r=-.15, p<.05$. There were no statistically significant associations between sex and our outoome variables, ps $>05$. Regarding our variables of interest, there was a small association between $\mathrm{CU}$ traits and all three domains of $\mathrm{TO}$ at $\mathrm{T} 2$ $r s=.14-.17, p s<.05$. A small association between ADHD symptorns and RNC at T1 suggest that childen nated as having greater symptoms of ADHD recxived more TO for RNC at the beginning of the STP-PreK, $r=.15, p<.05$. Lastly, children rated as having greater levels of $\mathrm{CP}$ were more likely to receive a TO for $\mathrm{LA}$ at $\mathrm{T} 1, r=.23, p<.05$.

\section{Baseline Levels of TO}

On averape, children spent 9.85 minutes in TO per day during T1, $M=9.85, S D=16.09$. Paired $t$ tests indicated that children were assigned a significant greater number of TO for RNC $(M-1.54, S D-1.93)$ compared to LA $(M-.64$, $S D=.97), u(189)-7.12$, Cohen's $d-.59, p<.001$. After accounting for age, $C P$ was significantly related to total number of LA at T1, Wald's $\chi^{2}(1)-4.13, p<.05$, suggest. ing children rated by pasents/eachers as having higher levels of CP received more TO for LA at T1. Levels of ADHD prior to the start of the STP-P $x$ K significantly poedicted the 
number of RNC TO at $\mathrm{T} 1, \chi^{2}(1)-4.50, p<05$. Children rated by their parents/teachers as having higher levels of ADHD symptoms reciived a grester number of RNC TO at T1. ADHD, $C$, nor CU traits were associated with the total number of minutes childnen were in $\mathrm{TO}$ at $\mathrm{T} 1, p s>05$ (Table 2).

\section{Intervention Effects on TO}

After controlling for age and $\mathrm{T} 1$, there were significant changes across TO domains. The average number of minutes spent in TO during T2 decreased significantly, $F(2$, $186)-36.14, p<.001$, Cohen's $d=-.49$. The average number of TO assigned for RNC and IA also decreased significantly, $F(2,186)-36.42, p<.001$, Cohen's $d=-.35, F(2$, $187)=78.73, p<.001$, Cohen's $d=-.12$, respectively.

\section{Overdlspered Polsson Regression Analyses}

As seen in Table 3, four overdispered Poisson regression analyses (model 1-model 4) were tested to examine the association between CU traits and TO at T2 for LA, RNC, and total number of minutes in TO. Wald's $\chi^{2}$ and pseudo $\mathrm{R}^{2}$ change for the additional predictors in each model are xported in Table 2. T1 TO (model 2) were significantly associaled with T2 across all TO domains ( $\mathrm{ps}<001)$. When $A D H D, C P$, and CU traits were added to the analyses (model 3), CP and CU traits were uniquely associated with IA, RNC, and total number of minutes in TO. ADHD was not zelated to any of the outcomes in the current study $(p s>05)$.

\section{IA at T2}

The addition of ADHD, CP, and CU traits (model 3) while controlling for IA and age at $T 1$ (model 2) acoounted for $42 \%$ of the devianc. However, Wald's test revealed that only CU traits was a significant predictor of $\mathrm{LA}$ at $\mathrm{T} 2$, Wald $\chi^{2}$ (1) $-4.20, p<.05$. Children with higher levels of CU traits received greater amounts of TO for IA at T2. This main effect was qualified by a significant interaction (model 4) between $C P$ and $C U$ traits, Wald $\chi^{2}(1)-4.68, p<.05$. Probing of the interaction revealed that CU traits moderated the association between levels of CP and TO for IA at T2, such that association between $\mathrm{CP}$ and number of $\mathrm{LA}$ TO at $\mathrm{T} 2$ was only present for children with low CU traits, Wald $\chi^{2}$ (1) $-7.48, p<.01$; see Fig. 1. For every one-unit increase in $\mathrm{CP}$, there was a .24 multiplicative decrease in the number of TO assigned for IA at T2. This association did not hold for children with high CU traits, Wald $\chi^{2}(1)-05, p<.82$

\section{RNC at T2}

After controlling for $\mathrm{T} 1$ and age (model 2), ADHD, CP, and CU traits accounted for $32 \%$ of the deviance. There was a main effect for CP and CU traits, Wald $\chi^{2}(1)-8.96, p<.01$, Wald $\chi^{2}(1)-6.03, p<.05$, respectively. Children nated by parents/teachers as having higher kvels of CP before starting the STP-PreK rexived less TO for RNC at T2 On the other hand, children with higher levels of CU traits before the start of the SIP. PreK received more TO for RNC at T2. These main effects were then probed (model 4), however there were no interaction effects ( $p s>05$ ).

Table 2 Correlations beween study variables

\begin{tabular}{|c|c|c|c|c|c|c|c|c|c|c|c|}
\hline & 1 & 2 & 3 & 4 & 5 & 6 & 7 & 8 & 9 & 10 & 11 \\
\hline \multicolumn{12}{|l|}{ 1. Age } \\
\hline $2 \operatorname{sex}$ & -104 & & & & & & & & & & \\
\hline 3. DHD $A D H D(C)$ & $.15^{\circ}$ & -.11 & & & & & & & & & \\
\hline 4. $\mathrm{DHD}(\mathrm{P}(\mathrm{C})$ & Do & -.03 & $33 * *$ & & & & & & & & \\
\hline 5. $\mathrm{xCU}: \mathrm{CU}(\mathrm{C})$ & -02 & D3 & $28 * \cdots$ & $45 * \cdots$ & & & & & & & \\
\hline 6. Tobals Mins in TO: Tine 10 ) & -108 & -.04 & .14 & .13 & 05 & & & & & & \\
\hline 7. Tobla Mirs in TO: Time $2(0)$ & $-.15^{*}$ & -11 & $\mathscr{l n}$ & $\infty$ & $.16^{\circ}$ & $52 * * 0$ & & & & & \\
\hline 8. Number of RNC TO: Time 1 (O) & -.12 & -05 & $.15^{*}$ & .06 & .13 & 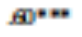 & $46^{20 *}$ & & & & \\
\hline 9. Number of RNC TO: Time 2 (O) & -108 & D1 & .03 & $-\infty$ & $.14^{*}$ & $.18^{*}$ & $A 4=0$ & $53 * *$ & & & \\
\hline 1. Numbr of LA TO: Time 1 (O) & -.05 & -.08 & .12 & $23 \%$ & $.18^{*}$ & $A 2 * \cdots$ & $\pi m$ & 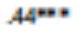 & $28 \cdots$ & & \\
\hline 11. Nunher of LA TO: Time 2 (D) & $-\infty 2$ & -.14 & .13 & .12 & $.17 *$ & $24 * 5$ & $46^{2 * *}$ & $36 m$ & $-42 * *$ & $66=2$ & \\
\hline
\end{tabular}

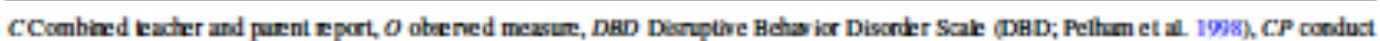

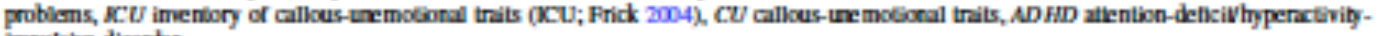
impulshe disonder

$* *_{p}<001, * p<01, * p<05$ 
Table 3 Models sor predicting bily TO oulocenes at Tine 2 (LA, R.NC, Total)

\begin{tabular}{|c|c|c|c|c|c|c|}
\hline & $b$ & 五 & $95 \% \mathrm{Cl}$ & Wadd's $\chi^{2}$ & Devianx & Pscudo $\mathrm{R}^{2}$ \\
\hline \multicolumn{7}{|l|}{ Number of iA at Tine $2(\mathrm{O})$} \\
\hline Model 1: intercept model & 1.55 & 471 & $(1.28,1.82)$ & $12954 \mathrm{kn}$ & 1875.62 & - \\
\hline Model 2 aye & -06 & .94 & $(-40,28)$ & .12 & 1144.61 & 39 \\
\hline LA: Time $1(0)$ & D6 & 106 & $(05,07)$ & $15174 \mathrm{mon}$ & - & - \\
\hline Model 3: ADHD (C) & 33 & 139 & $(-0.0,72)$ & 205 & 1034.98 & $A 2$ \\
\hline $\mathrm{CP}(\mathrm{C})$ & -.22 & 20 & $(-56, .12)$ & 1.66 & - & - \\
\hline Cu traits (C) & $A 8$ & 162 & $(.02, .95)$ & 4.20 & - & - \\
\hline Model 4: ADHD xCU & -.12 & 89 & $(-100, .76)$ & .00 & 1051.49 & 44 \\
\hline ADHD $\times C P$ & DQ & 109 & $(-.49, .67)$ & .10 & - & - \\
\hline $\mathrm{ODD} \times \mathrm{Cu}$ & 65 & 1.92 & $(06,1.25)$ & 4.68 & - & - \\
\hline \multicolumn{7}{|c|}{ Numbr of RNC at Time $2(0)$} \\
\hline Model 1: intercept model & 2.14 & 8.50 & $(1.92,2.36)$ & $340.81=0$. & 2826.44 & - \\
\hline Model 2 age & $D 2$ & 102 & $(-33,33)$ & .02 & 2002.38 & 26 \\
\hline LA: Time $1(0)$ & 03 & 103 & $(.21,04)$ & $6274 * \cdots$ & - & - \\
\hline Model 3: ADHD (C) & -02 & 98 & $(-38,35)$ & .01 & 1933.14 & 32 \\
\hline $\mathrm{CP}(\mathrm{C})$ & -.47 & 63 & $(-.78,-.16)$ & $8.98 \%$ & - & - \\
\hline Cu traits (C) & 59 & 1.80 & $(.12,1.06)$ & 603 & - & - \\
\hline Model 4: ADHD xCU & -.39 & 68 & $(-1.26,48)$ & $\pi$ & 1881.75 & 33 \\
\hline$A D H D \times C P$ & A6 & 158 & $(-12,1.04)$ & 2.42 & - & - \\
\hline $\mathrm{ODD} \times \mathrm{CU}$ & $A 1$ & 152 & $(-24.1 .05)$ & 1.53 & - & - \\
\hline \multicolumn{7}{|c|}{ Tobal number of minutes in TO at Tine $2(0)$} \\
\hline Model 1: intercept model & 3.62 & 37.34 & $(3.46,3.78)$ & $6917.75 \%$ & 6917.5 & - \\
\hline Model 2 age & -.24 & .79 & $(-A D,-01)$ & 402 & 5361.19 & .23 \\
\hline LA:Time $1(0)$ & $D 02$ & 100 & $\left(\infty_{2}, \infty_{3}\right)$ & $66.15 * \cdots$ & - & - \\
\hline Mode1 3: ADHD (C) & -05 & .95 & $(-30,20)$ & .16 & 519827 & 25 \\
\hline $\mathrm{CP}(\mathrm{C})$ & -02 & 98 & $(-24,20)$ & .05 & - & - \\
\hline Cu traits (C) & 38 & 1.46 & $(05,72)$ & 508 & - & - \\
\hline Model 4: ADHD $\times C U$ & 32 & 138 & $(-20, .85)$ & 1.45 & 4965.88 & 28 \\
\hline$A D H D \times C P$ & -07 & 93 & $(-.44,31)$ & .121 & - & - \\
\hline $\mathrm{ODD} \times \mathrm{CU}$ & 46 & 1.58 & $(05,87)$ & 473 & - & - \\
\hline
\end{tabular}

$P$ parent report, $C$ conbined purent and eacher repoet, $O$ obernation, $O$ conduct problems, $C U$ callous-

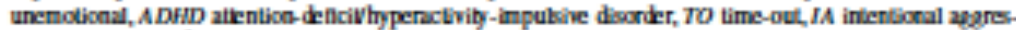
sion, $R . X$ : rpeated non-compliance

"p<05, $\cdots p<01, * \cdots p e \infty 1$

\section{Total Number of Minutes in to at T2}

Unlike the aforementioned analyses, age significantly predicted the number of minutes children were in TO at T2, Wald $\chi^{2}(1)-4.02, p<.05$, suggesting that younger children spent more minutes in TO at T2 compared to older children. Model 3 acoounted for $25 \%$ of the deviance in the model. There was a main effect for CU traits, such that higher levels of CU traits predicted more minutes in TO at T2, Wald $\chi^{2}(1)-5.06, p<.05$. This main effect was qualified by a significant interaction between $\mathrm{CP}$ and $\mathrm{CU}$ traits, Wald $\chi^{2}(1)-4.73, p<.05$. However, there were no differences between the simple slopes for ODD at any level of CU traits, ps $>.05$.

\section{Discussion}

Within the context of a comprehensive multimodal STP for preschoolers with EBP, we examined the extent to which CU traits predicted TO levels during the initial and final phases of the STP-PreK. First, it is important to note that children's overall kevels of TO significantly decreased from T1 to T2 of the STP-PreK. Second, CU traits did not predict initial levels of TO during the STP-PreK. Rather, $\mathrm{CU}$ traits was associated with greater kvels of TO at T2 for total number of minutes, number of LA TO, and RNC TO. We elaborate on these findings below. 


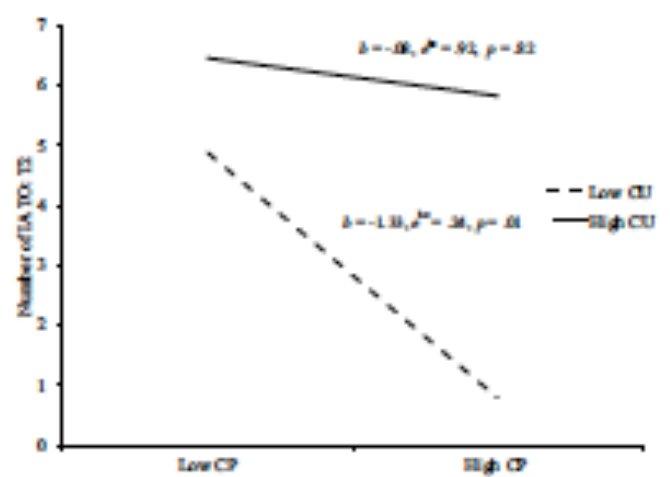

Pig $1 \mathrm{CP}$ by CU ca number of IA TO assigned at T2 Analyses con. toolkd for age, T1, LA, and ADHD. IS intentional apgresion, TO Eime-out, 77 Time 1,72 Time $2, \sigma$ conduct peoblems, $C U$ callots:

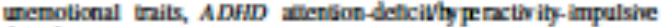
discriter

At $\mathrm{T} 1$, children spent an average of $9.85 \mathrm{~min}$ in $\mathrm{TO}$ a day. However, by the end of the STP-PreK, T2, there was appraximately a $58 \%$ meduction in daily number of minutes spent in TO $(M=4.15, S D=4.54)$. This significant reduetion speaks to the effectiveness of multimodal behavioral programs targeting children with EBP. Past studies have traditionally relied on post-treatment parent and teacher mports $[63,64]$ to measure treatment outcomrs. For example, Hawes and Dadds [33] used parent reports to measure children's emotional reaction during TO. Additionally, classroum-based interventions have been shown to decrease externalizing and internalizing behavions in the classroom, as reported by teachers [65]. Significantly less work has examined moor objective behavioral measures within the contex t of treatment. To our knowledge, this is the finst study that has examined more objective measures of preschoolers' disruptive behaviors by examining the amount of time they spent in TO. Due to the fact that the STP-PreK mimics the school setting, measuring the number of minutes spent in TO provides an ecologically valid me asure of $\pi$ sponse to an important component of treatment, TO. By doing so, it allowed us to more accuntely measure childnen's ageression and non-compliance within a classroom setting.

Consistent with our hypothesis, preschoolers with higher levels of CU traits, as meported by parents/preschool teachers, were less responsive to the use of TO during the STP. PreK. Specifically, even after accounting for initial levels of TO, CU traits predicted overall TO and RNC during the final phase of the SIP-ProK. While there were overall decreases: in the number of 'TO and the total number of minutes spent in TO, prior work that dichotomizes CU traits also found that children with higher CU traits did not respond to a multimodal treatment, compared to children with nollow CU traits $[66,67]$. Several mechanisms may explain the reascon why children with higher levels of $\mathrm{CU}$ traits do not respond as well to a behavional intervention.

Previous research shows that children and adolescents with CU traits differ in their responses to emotional cues and the possibility of consequences for their actions [68, $69]$. Furthermore, research by Pardini and Byrd [70] found that children with CU traits had "deviant social schemas" that increaved instrumental aggression. More importantly, significant associations $z$ vealed that children with more CU traits were less fearful towards punishment. The current study shows that even within ayoung preschool sample, CU traits may suggest not only an inherent oppositionality [71], but perhaps a lack of emotional reactivity $[15,72]$ in terms of their lack of response to thre at/punishment (e.q., recxiving a TO warning for RNC).

It is also important to note that an interaxtion emerged between CP and CU traits as it relates to LA TO. Specifically, at high kvels of CU traits, co-occurring $C P$ had no impact on number of LA TO at T2 However, at low levels of CU traits, high CP was associaled with fewer IA TO whereas low CP was associated with greater IA TO at T2. This find. ing suggests that children with higher levels of CP (without CU traits) $\pi$ sponded more positively to the intervention. Indexd children with ODD do quite well in PT programs like PCIT where TO is a major component $[73,74]$. On the other hand, our low $C^{P}$ group, which ended up with higher LA TO, may be more indicative of a group of children who engage in more covert acts of $C P$ (which would explain their lower CP rating according to parents and teachers). Indeed, studies have distinguished children with early CU traits engape in more proactive versus ractive forms of aggressicn [23] with some studies indicating that proactive arts of apgression have worse catromes in life $[21,75]$. Future work examining the heterogeneity in young children with EBP's tre alment response may want to examine different forms of aggression to determine which ones may be more amenable to the use of TO.

There were some limitations to the current study that need to be acknowledped. First, a TO was assigned based on a hierarchy such that a child could ex hibit two behavions, but only the most severe would be moonded as the reavon for the TO. For example, if a child was instructed to return to his or her seat and received a TO warning for not complying, but then pinched a child as he or she was running around, he or she would be assigned a TO for LA, rather than RNC. This system could potentially redux the average number of daily minutes a child spent in TO for non-compliant behaviors; however, it was very successful in capturing aggressive behavions trow ards pers and staff. Second, although all teachers and counselurs in the SIP-PreK were trained in the operational procedures of assigning TO and were supervised 
co a daily basis, it was not feasible to video record the classrocen to moor accurately capture the recordings of the TO. The in-vivo nature of the TO data collection may have also zesulked in some childzen exhibiting behaviors which should have bern resulted in TOs but were missed by a counselor (although given the high number staff to student ratio (1:3) in each classroom this is unlikely to have happened at significant rate). Lastly, another limitation was the cultural homogeneity of the current sample (82\% Hispanie/Latino), due to the geographical location. Although such cultural homogeneity may be a strength due to the fact that Hispanid Latino children are the fastest growing group of children in the Unikd Staks [76], it is important to be cautious when generalizing the current study's findings to other cultural racial groups.

In sum, total number of TO for ageressive and non- oompliant behaviors significantly decreased over the course of our multimodal summer treatment intervention. However. our findings highlight that children with higher kvels of $\mathrm{CU}$ traits experienoed lower reductions in TO across the intervention. This is the finst study, to our knowledge, to directly observe preschooler's response to a widely used treatment component (ie, TO) and is consistent with past work showing that children with CU traits are less sensitive to punish. ment $[14,67]$. In temms of implications, it is first important to note that most schools do not have the personnel and training to conduct TOs in the classroom. When viewed in conjunetion with our finding that children with higher levels of CU traits did not respond as well to TO, alternative behavical management strategies should be considered. Taking into account children with EBP's reward sensitivity [77, 78], several school-baved intervention programs have bern sueassful in reducing CP in the classroom, $\pi$ gardless of $\mathrm{CU}$ traits [79, 80]. Lastly, future intervention studies should examine the extent to which existing behavicral management and socialemotional curriculum are effective in not simply mducing $C P$ but also in promoting children'semputhetic and prosocial behaviors

\section{Summary}

Externalizing behavior problems (EBP) such as attentiondeficii/hyperactivity disonter (ADHD), $O D D$, and $C D$ affect a substantial number of children and adolescents. EBP are even more present in preschool children. More recently, a subset of children with EBP have been identified as having CU traits. Children with CU traits ax typically defined as having low kevels of guilt, empathy, and caring for others. Several studies have identified these early antisocial behaviors in children as young as 3 years old. Longitudinal studies have found that children with CP and early CU traits continue to exhibit various functional impairments (i.e., acadernic, social, and behavional) acruss developement. For example, children with $C P$ and $C U$ traits have higher rates of aggressive behaviors as well as juvenile delinquency into sdolescrnoe.

While several EBT have shown to be successful in the reduction of $\mathrm{CP}$, there is still mixed evidence at the effectiveness of these EBTs for children with $C P$ and $C U$ traits. More specifically, several studies have examined which components of treatment may be associated with behavional improvements in children with CP and CU traits. Therefure, the current study sought to examine the role of CU traits, as reported by parents/preschool teachers, on the levels of time. out (TO) during an 8-week compohensive multimodal STP for Pre-Kindergarteners (STPPreK). TO is a crucial treat. ment component that is found in almost every EBT for CP. The current study examined TO at the initial phaso $/ 1$ ime 1 (first 2 weeks; T1) and the final phase/Time 2 (last 2 wexks; T2) of the SIP.PreK. Weexamined the total number of minutes children spent in TO, the number of IA, and RNC TO children recoived during the initial and final phase of the STP-PreK.

This study found that even after accounting for initial kvels of EBP, CU traits were not associated with any TO outcomes at T1. However, CU traits and CP were significant predictors of IA at T2 After probing a significant interaction, we found that low CU traits moderated the associa tion betwexn CP and number of LA at T2. CU traits were also positively associated with the number of RNC as well as the total number of minutes spent in TO at T2. These findings suggest that pos schoolers with a more pure ADHD or CP presentation sorms to be more responsive to the TO component of treatment compured to preschoolers with a more comorhid ADHD/CP +CU traits presentation. Future work should examine other behavioral management stratgies (newards versus TO) that may help neduce impairments associated with $\mathrm{CP}$ and $\mathrm{CU}$ traits, while increasing prosocial and empathetic behaviors.

Acknowlodgements The research reported here was supporied by the Inditute of Education Sciences, U.S. Depurtment of Eiducation, through Grant R324A 120136 as well as a local prant from The Children's Trust (1329-7290) bo the second author. The opinions expressed arr those of the authors and bo not mpresent vicws of the Instituke of the U.S. Department of Education or The Chindren's Trust.

\section{References}

1. Perou $R$ es al (2013) Merial health suneillanx anong childenUniled States, 2005-2011. MMWR Surveill Summ 62(Suppl 2): $1-35$

2. Carborneau $R$ et al (2016) Comocted deve lopment of dioruptive behs ioes from age 14 to 5 years in a population birth cobort and association with school adjutement in tirst gnade.J Ahnome Child Prychol 44(4):67)-620 
3. Huaqing QiC, Kaiser AP (2003) Behavior problems of preschool children from low-incone familics neview of the likerz. tur. Top Farty Child Spec Eidue 23(4):188-216

4. Campbell $S B$ (1995) Heharior problems in parshool children: a review of recrnt mesearch. I Child Psychol Psychiatry 36(1):113-149

5. Wehster-Stratbon C, Hammond M (1998) Conduct problens and kevel of sociall conptence in Head Start children parvalence. pervasiveness, and associaled risk factors. Clin Chisd Fam Prychol Rer 1(2):101-124

6. Association AP (2013) Diagnostic and statiotical manual of mental disoeders (DSM-5w). Anerican Psychiatric, Washing. ton, DC

7. Camplell SB (1991) Longiludinal stbdies of actine and aymes sine preschookrs individual diflerences in earty behasor and outcorn. In: Rochesier symposiun on deve lopenental prychopz tholog. Firheum, Hillialak

3. Cole PM, Teti LO,Zahn-Waxker C (2DOB) Mutualemolion rpuls. tion and the stabiliny of conduct peoblems between presthool and earty school are. Dex Psychopachol 15(1):1-18

9. Keenan K. Wakschlag i.s (2000) More than the terrible twos: the nature and severity of behasior peoblens in clinic-reterred preschool children. J A bnorm Child Prychol 23(1)-33-46

10. Keenan K ef al (2011) Prodictivevalidity of DSM-TV opposilional defant and conduct disoriers in elinically melerred prexhookrs. J Child Psychol Psychiaty 52(1):47-55

11. Kirs Cohen J et all (2009) Five-ye r prodictine validity ofDSM-IV condect disonder recearch diapoosis in $4 \%-5$-year-old children. Fur Child Adokse Psychiatry 13(5):284-291

12. GrazinoPA, Groria A (2016) Attention-defeit bypetivify dis onder and childen'semotion dyse pulation: a meta-analysis. Clin Psychol Rev 46:106-123

13. Frick PJ, Harry CT, B odin SD (200) Applying the concept of paychopathy to children implications for the assesment of anti. social youth. The clinical and forenoic asoesment of psychopath: a practitioner's guit. L.awrenx Eribum, Malwah, PP 3-24

14. Frick PJ et all (2003) Callots-unemotional traits and conduct problems in the prediction of conduct peoblem semeriby, 2agrs. sion, and selir-mport of delinquency. I Abaorm Child Psychol $31(4) \cdot 457-470$

15. Fridk PJ et all (2005) Callous-unemotical traits in predicting the geverity and stability of conduct peoblems and delinqxing. I

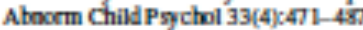

16. Waschbusch DA, Wilioughty MT (208)Aatention-deficilfyper activ ity disonder and callots unemotional inits as moderaloes of conduct peoblems whener anining inpairnent and apgression in elemenlary sthool children. A geress Behs 34(2):132-153

17. Dadts MR et al (2005) Disntangling the underty ing dimensions of psychopalty and conduct peoblens in childhood: acummunity study.J Consult Clin Prychol 73(3) ca00

18. Hrwes DJ, Dadts MR (DON) Stality and malkability of calloes: unemotional traits during treatnent for childhood conduct peob. lens. JClin Child A dolese Prychol 36(3) -347-355

19. Pandini DA, Lochman JE, Powell N (2000) The development of callous unemobonal tnits and antisocial behrior in children: ax: there shared andor unique prediciors? I Clin Child Adolese Psychol $36(3)-312-333$

2. MunouLLC, Frick PJ (2007) The reliability, stahellify, and pedictie utility of the self-mport version of the antisocial procsss screening devix. Scand J Psychol 48(4):292-312

21. Frick PJ, While SF (2008) Research review: the importanx of callous-unemotical thits for dvelopnental models of apareswive and antisoc al behas ior.J Child Prychol Prychiatry 49(4):352-375

22. Walkr R et al (2014) B idirectional asocialions between parcilal warnth, callous uremoGonal trhas ior, and behs ior probliens in high risk poeschockr. I A morm Chad Pagchol 42(8):1275-1225
23. Kimonis ER ef al (2006) Callous uremobiond Laurs, hehrvical inhibition, and parenting: independent predictirs of appresion in a high-risk parschool sample. I Child Fun Stud 15(6):741-752

24. Eprekta Let al (2013) Imeniary of callots unemobond trils in a conmunity sample of presthookr. J Clin Child Adolese Pychol 42(1):91-105

25. Graiano PA et al (2016) A sqessing callots unemotional traits in preschool chilidren with diaruptive bhaior problens wing peer reports. JClin Child Adoles Prychol 45(2)-201-214

26. Ciucci Ei et al (2014) Th association hetween callous unemo. tional traits and hehrional and academic adjustment in children: further validation of the imentirny of callots unemotional trats. I Parchopathol Behrs A ssess 36/2):130-200

27. Vaugha MCG et al (2011) Jurenile psychopathic personallity traits are associaled with poor reading achievenent. Psychiatr $\mathrm{O}$ 82(3): $77-190$

28. Eyberg SM, Nelioon MM, Hopgs SR (2003) Evidence-bozed porthosocial trazments sor childen and adokscrents with diaruptive behrevior.J Clin Chisd Adolese Psychol 37(1):215-237

29. Kamindi JW et al (DOS) A neta anah bic nevicw of components associaled with parent trainine prouram eflectieness. I Áboom Chind Psychol 36(4):567-589

30. Pelham WE, Fibiano GA (2008) Evidence-based psychosocial

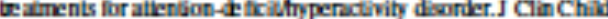
Adolex Prychol 30(1) $184-214$

31. Eybers $S$ (1938) Parent-chisd interaction thrapy: integntion of inditional and behwional concrers. Child Fam Behas Thr $10(1): 33-46$

32. Webster-Stration C (1989) Systemalic comparison of consumer alisfaction of three cooteffective parent tnining peoprans for conduct problem children. Behs Ther 20(1) $103-115$

33. Haves DJ, Dodds MR (2006) The treatment of oonduct probtems in chadren with callous unemotional traits. J Cunsult Clin Prychol 73(4):737

34. Dadts MR, Sylnon K (2003) Punithnent insensitivity and parent. iny tempenment and leaming as interxcting rids for antisociol behrvior. Clin Child Fam Psychol Rer 6(2):69-86

35. Miner NV \& al (2014) Hehwior thenpy and callous unemobon2 tritsreffects of a pilot study examining modified hehrsionl contingencies on chald behrvior. Behas Ther 45(5) $6006-618$

36. Waller R, Gardrer F, Hyde LW (2013) What are the associations between parenting, calnous-unemotional traits, and antisocial behs ior in youth? A systematic rvicw of eridenx. Clin Pychol Rev 33(4):593-603

37. Sanders MR, Dodds MR (1993) Behrrional fanlily interention. Allyn $\&$ Hacon, Boston

33. Famner EM et al (2002) Review of the evidence base for treatment of childhood poychopatholog:er iemallining disoetsr. J Curcult Clin Prychol 70(6):1260

39. Kolkn DJ et al (DON) Community va. clinic-based modular trax. ment of childen witherty-onet toDD oe CD: a clinical trial with 3-year follow-up. I Abnom Child Pychol 37(5) D91-600

40. Pelhan WE, Creiner AR, Gnaey EM (1998) Childrer's sumner treatment progran manal

41. Pelhan $W$ et al (2010) Summer tratment prognms for atterison deficiVhypenstivity discrater Er id Based Psychother Child Ado. ksc 2207-292

42. FahisnoGA, Schate NK, Pe ham WE Jr (2014) Summer tratmen! Frograns for youth with A DHD. Child Adolesc Pyychiatr Clin N Am 23(4),757-7)3

43. Hass SM et al (2011) Treatment response in CPVADHD chil dren with callous'unemotional traits. J Abnoem Child Psychol 3)(4):541-552

44. Powe lil NP ef al. (2017) The Coping power peognem sor aperesise behs iar in childten. Evidenx-besed psychothenpies for children and adolescents. Guillori, New York 
45. Lochman III et all (2014) Does a booder intervention aupnent the preventive eflects of an abbrevialed version of the coping power progran for apgessive chiliden2s Abnom Child Psychol $42(3) \times 367-331$

46. Hawes DJ et al (2011) Do childhood callous-unemotional trits drive change in parenting poratians? I Clin Child Adolexe Psychol $40(4) \times 307-518$

47. Waller $\mathbb{R}$ et al (2012) Do harsh and positive parenting pedict parent mports of dexrictul-callows behrvior inearty childhood? J Child Pychol Psychiatry 53(\%):846-953

48. Hawes DJ, Prix MU, Dadts MR (2014) Callous-unemolional triits and the treatment of conduct problems in childhood and adolescence: a comprehnsive review. Clin Chald Fan Prychol Rev 17(3)-24s-261

42. Grziano PAet al (2014) Inpruving school readiness in preschool. ers with behas iar prublems: results trum a summer treainent pro. gran J Prychopathol Hehr A seess 36(4):555-567)

5. Fism CA, Siragrwa S, Frick PJ (2006) Callous-unemolicnal traits in a conmenity semple of adolexcents. A seesment 13/4):454 4f

51. Stickle TR, Kirkpatrick NM, Brush LN (DOP) Callous unemo. Eonal trails and social information processing: multiple risk-factor models for understanding angrsshe behs ior in antisocial youth Lav Hum Behw 33(6) -515-529

52. Fanti KA (2013) Individual, social, and behrvicenl faciors asoci. aled with co-occurning conduct problems and callots-umemobonal trits. J A brom Chisd Psychol 41(5):811-824

53. Has SM et al (2015) Examining the rok of callots-unemotional trails in the attributional syles and $\mathbf{x}$ if compenar evaluation: of children with condact problems and ADHD. JPsychopathol Helss A sves 37(2) $196-206$

54. Reynolds $\mathrm{CR}$, Kamphaus $\mathrm{KW}$ (2004) BASC-2 Behasior ases. ment system sor children. Wiky, Hoboken

55. Shafler D et al $(200)$ NMH Dlannodic Interview Schedule for Children Version IV (NIMH DISC-IV) C description, difnenences from previous versicas, and rliability of some common diagno. ses. I An Acrd Child Adokes Psychiatry 39(1):23-38

56. Eytreg SM, Bops SR, AlrinaJ (1905) Parent-child interation thrapy: a psychosocial model for the irsiment of young children with condact peoblen behs ior and their taniles. Pychopharma. col B un 31(1):83-91

5. Peltem WFet al (1992) Teacher ratings orDSM-III- $\mathbb{R}$ smploces for the diaruptive behas ior disonden. I Am Acad Chisd Adoks Psychiatry 3i(2)-210-218

58. Hartman $\mathrm{CA}$ et all (2007) Modeling nier disagrexment for ADHD: anc parents or teachers biased? I A boom Chaid Psychol $35(4) \cdot 536-54 ?$

52. Sibley MH et al (2010) Inconesistent ali-mpoet of delinquency by adolescrnts and young adults with ADHD. I Abaorm Child Psychol 35(5):645-656

a. Frick PJ (2004) The imentony of callous-unemolicall trails. Urpublished rating scale

61. Fabiano GA et al (2004) An evaluation of thres time-out procedures for children with altention at ficilly peractivity disceder. Behs Ther $35(3)(449-469)$

62. Coxe S, West SG, Alen LS (200) Thr andusis of count data: a gentre introduction bo Poisson renression and its alternaties. J Persunal A scess 91(2):121-136

63. Absout HB et al (2015) Parent training for preschool A DHD: : randomined controlled trial of specialined and peneric proerams. JChad Psychol Psychiaty 56(6) 6 618-631
64. Van Den Hoodthker BJ et al (2007) Eiffectheness of h has ionil purent training for children with ADHD in routine clinical pras. lice: a randonined conitrolled staby. I Am Acad Child Adoles: Psychiairy 46(10)-1263-12)1

65. Stetan CA (2012) socialemotional presention program for pr: school childerr: an analysis of a high risk sample. Cogn Creic ComporiCogn H rin Behrs 16(3) 2012

66. MasiG et al (2013) Response to tratments in youth with disruptwe behas ior discrtex. Conpr Psychiairy 54(7):1002-1015

67. Wilkinson S, Walkr R, Viding E (2016) Pnctitioner review: imolving young people with callots unemoticasl traits in tre:tment-does it work? A gromatic neview. J Child Psychol Pychizto $57(5) 552-565$

68. Barker ED et al (2011) The impact of prenatal natemal risk, Earless temprament and earty purnting on adolescrnt callow: uremoticnal trats: a 14-year iongifudinal inestigation. J Child Pyychol Pychiaty 52(8):878-88s

6. Kimonis ER et al (2008) Callows unenotional traits and theemo. lional proarssing of distress cues in detained boys esting the moderiting role of agression, exposure bo conmunity violence, and histories of abuse. Der Psychopathol 20(2):569-589

70. Pardini DA, Byrd AL. (2012) Perxptions of agressive condicts and others diodress in children with callous-unenotional traits:'T'I show you who's boss, even ar you suffer and 1 get in trouble'. J Chad Psychol Pychiary 53(3):283-291

71. Hart SD, Hare WD (1997) Psychoparh: assessment and associeLion with criminal conduct. Wiley, Hoboken

72 Loncy BR ef al (2003) Callous unemobonal traits, inpulsivily. and emobonal proarssing in adolescents with antioncial behs ioc problems. JClin Chind Adoks Psychol 32(1) c66-50

73. Z Zoxer A, Eyberg SM (D10)Parent-child interaction thraps and the treatnent of disuptive behs ior disonien In Evidenar-bered prychohenpies for children and abolessents, 2nd ed. Guillond, New York, PP 172-193

74. Hoges $S R$ ef all (2005) Outocenes of parent-child interaction ther-

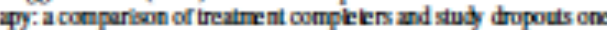
in three years liser. Child Fam Hehrs Ther 26(4): 1-2

75. Find PJ,Dickens $C(2006)$ Current perspectives on conduct ds. arder. Curr Paychiatry Rep \&(1):58-72

76. La Greca A M, Sibernan WK, Lochman $\mathbb{E}$ (2009) Moving beyond effacy and effectiveress in child and sdoksornt iniervertion research. J Consult: Clin Pychol 77(3) [ 373

77. Beauchaine TP, Gatzke-Kopp L., Mead HK (2007) Polyvagal theory and developmental prychopathoboy: emobon dysmepula Lion and conduct problems from prexhool to sdoksarna. B iol Psychol 742(2):174-184

78. Barry CT et al (2000) The importance of callous-unemotional traits for extending the conapt of psychopathy to chisiren. J Absorm Psychol 10902 r 335-340

79. Webster-Sintion C, Reid M, Hanmond M (2001) Preventing condact poobkms, promoting sociall competence: a porrent and eacher trining partinenhip in Head start. J Clin Child Psychoi 30(3): $283-302$

80. Webster-Stnalon C,Jamila Reid M, Sioolmiller M (200) Preient. ing condect peoblens and impeoving school readiness: evalua tion of the increditte years teacher and child training proenms in high-risk schools. I Child Pychol Psychiatry 49(5) C4 1-498 
Conflict between Parents and Adolescents with ADHD: Situational Triggers and the Role of Comorbidity

This was published in Journal of Child and Family Studies

Garcia, A. M., Medina, D., \& Sibley, M. H. (2019). Conflict between Parents and Adolescents with ADHD: Situational Triggers and the Role of Comorbidity. Journal of Child and Family Studies, 28(12), 3338-3345. 


\title{
Conflict between Parents and Adolescents with ADHD: Situational Triggers and the Role of Comorbidity
}

\author{
Nexis M. Garcia (5) - Dassiell Medina ${ }^{1}$ - Margaret H. Sibley ${ }^{1,2}$ \\ Rubished anise: 27 Juy 2019 \\ o Sainger Sciend + Bushess Modla, UC, part of Springer Nanse 2019
}

\section{Mbstract}

Objectives Little is known thout factos that contribute to conflict between purents and adolescents with ADHD. The aurrent staty examines the frequency and in tencity of rgumen ts between alolescents with ADHD and their parents with anten fion to situational triggers and alolescent and parent chracteris bes that predict oonflict.

Method Adolescents and parents $(N-128)$ completed a battery of ating scales $a$ baseline intake into a nndomized clinical trial.

Results The most frequent and clinially significant argumant topics identified by parent were homework problems, peasonal hygiene, and bedtime. Similarly, homework problems were nied by purents as the most intense scurces of arguments. Adolescents with ADHD who displayed higher comorbid depressive or aggresive symptoms hal the most frequent rguments with their parents.

Condusions Intavention and prevention progams targeting conffict between teens with ADHD and their parents might consider concursent trentment of rgument sources (i.e, divorganization, homework problems). Comorbid mood and behavior problems should also be adtressed.

Keywords Adolescence - ADHD - Familial conflict - Comothidity - Parenting

For typically developing youth, adolescence represents a time of increased prent-child conflict as teens strive to increase atonomy in the face of prental limits (Larson a al. 1996; Larrensen et al. 1998; Steinberg and Morris 2001). This conffict is purticulrrly elevated for adolescents with Atention DefiaitHyperactivity Disorder (ADHD; Bdwrods et al. 2001), who display low frustration tolennce and poor interpeasonal and conflict resolution skills (Anderson et al. 1987; Petcher et al. 1996; Sobunshi et al. 2010; Wohmeier et al. 2010). These defidts can promi. nently emage during arguments with parents (Shok 1998; Shek and $\mathrm{Ma}$ 2001) making dysfunctional purent-adolescent relationships one of the mont impaired

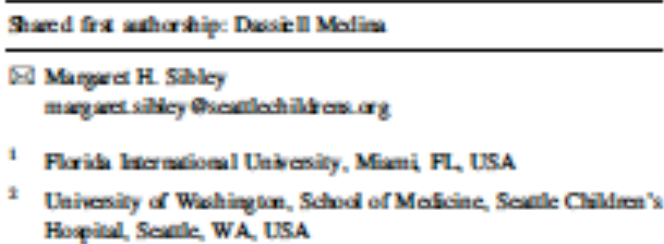

פิ Springer domins for adolescents with ADHD (Brikley et al. 1992; Bdwands at al. 2001; Montemayor and Huson 1985).

Adolescents who have frequent conflicts with parnts are at elevised nisk for a range of subsequent prychological problems (Bulnda and Mujumdar 2009; Ruever at al. 1999; Shot 1998). As a result of family difficulties, youth may feel withdrawn and develop mood disorders such as depression, which can in turn exacerhate family problems and increase risky behaviors (Averhach et al. 2007; Fendrich et al. 1990; Ptessen et al. 1993; Semajin a al. 2015). Moreover, parentadolescent conflict is associnted with poorer school adjustment, wellheing, and prychological adjastment (Shok 1997; 1998). As a result, to prevent escalution of ommortid prychopthology in adolescents with $A D H D$, the prentseen relationchip is a pressing intervention domain for these youth.

Only a small amount of information is known about risk factors for conflids between parents and adolescents with ADHD. Crifying common siturional and behrvioral antecedents to conflict could be useful to conflict. reduction efforts. For example, it is unclear whether adolescents with $A D H D$ argue wout the same topics as typically develoging teens (talking hack to parents, use of 
drags/akohol, and school problems, helping around the house, cleaning up; Allison 2000) or if there are disorderspecific argument topics (i.e, homework problems, nule breaking) that require spexific dinical attention. Knowing typical topical antecedents to conflicts would aid intervention efforts.

Addifionally, prents and adolescents with ADHD mxy experience more frequent and intense arguments when the prent or teen pos sesses cartain characteristics. For instance, it is well extablished thrt adolescents with ADHD who display omorbid oppositional or aggressive behavios are more likely to display purentizen conffict than those without these comorhidities (Edwrds et al. 2001). However, less attention has focused on the increase prevalence mes of $\mathrm{ADHD}$ and cooccuring depression in adolescence (Kessler et al. 2012; Larson et al. 2011). Some evidence suggests thrt prent child relubonship problams may crente nisk for depression among children and adolescents with ADHD Gohncton and Mash 2001; Humphreys et al. 2013; Ostander and Hemm 2006). However, it is unclex if depression in tum exacabutes purent teen mlationchip problems (though there is evidence that adolescents with depression display incressed intapeanonal aggrescion; Shecher et al. 2000 ). It is important to note that while prent. ten conflict may bea risk fuctor associated with both $A D H D$ and depression, casul associtions have yet to be found.

It is also posible thrt parent teen conflict is exacerbuted by parent prychological problems. For example, psychoputhology is devated among parents of ADHD youth and may land to inconsistent or negative purenting (Burke et al. 2008; Chronis et al. 2003; Johnshon and Mach 2001), Adolescents with ADHD may be most likely to displaying negrive demeanor in response to a parent with their own mood or behnvioal difficulies (Semeijn et al. 2015; Gottib and Whiffen 1989). Understanding how adolescent and purent psychological chractaristics contribute to onffict could al so sid intervention efforts.

In conclusion, maximally effective onflict redaction interventions for adolescents with ADHD likely must turget appropriate situtional triggers, comorhid adolescent prychopathology, and interfering parental behaviors. However, little work has been done to undestand processes through which parnt teen confliat unfolds among adolescents with $A D H D$. The purpose of this study is to exmine: (1) situations that precede arguments between parents and alolescents with ADHD and (2) parent and alolescent characteristics that increase risk for frequent and hexted arguments within this population. We hypothesized that parents would report arguments across a ange of issues related to school and home problems. Moreover, we antidipated that elevited parent and youth prychological problams would increase risk for parent. teen conflict.

\section{Methods}

\section{Participants}

Data for the current study was collected from adolescents and their parents prior to being enrolled in a andomized controlled trial examining a prychosocial trextment for adolescents with $\mathrm{ADHD}(\mathrm{N}-128)$ at a large urhan university reseaxh dinic between 2011 and 2013 (Sibley a al. 2016). The sample was approximaty $61 \%$ Hispanic and $15 \%$ Black/African-American, which reflects the metropoIitm area's ethnic diversity. Adolescents were betwen the ages of 11 to $15(M-12.74, S D-0.85)$ and were $64.8 \%$ male. Sample charateristios are provided in Table 1.

\section{Procedures}

Participants were recruited through school mailings and parent inguiries and the primary caregiver was administered a phone screen contrining the DSM-N-TR ADHD symp-

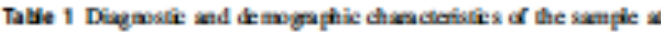
baseline $(N-128)$

\begin{tabular}{|c|c|}
\hline \multicolumn{2}{|l|}{ Dencgeplis weilio: } \\
\hline Age $(M, 5 D)$ & $12.74(85)$ \\
\hline Mule (\$) & $83(64.8 \%)$ \\
\hline Fonak (\$) & $45(3525)$ \\
\hline Pantey exegiver (Moted) & $112(88.25)$ \\
\hline \multicolumn{2}{|l|}{ Racolealnicily (क) } \\
\hline White ave-Hipatic & 9.4 \\
\hline Black ach-Fisparic & 8.6 \\
\hline Hispuetic any tax & 758 \\
\hline Oher & 6.2 \\
\hline \multicolumn{2}{|l|}{ Deagadse veivios at bueline } \\
\hline \multicolumn{2}{|l|}{ ADFD aboge } \\
\hline ADHD_peolominanty inatontine (\%) & 39.1 \\
\hline ADFD-combinal (\%) & 609 \\
\hline ODDICD (\$) & 578 \\
\hline Ampectine Pollons (\$) & 19.4 \\
\hline Aatiery paxlens (\$) & 19.4 \\
\hline Levaing Gubiiry (क) & 8.8 \\
\hline \multirow[t]{2}{*}{ Malicueal se ADHD (\$) } & 34.4 \\
\hline & Mont (SD) \\
\hline WASI oflinatal fal-sok $1 Q$ & $100 \pi(12.45)$ \\
\hline WIAT rouling actievenmt & 104.40 (10.13) \\
\hline WLAT mall acticremat & 9922 (16.33) \\
\hline
\end{tabular}

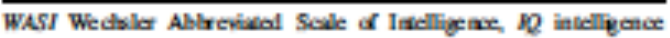

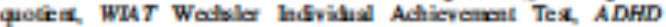

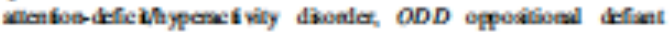
Swoales, $C D$ eoeduct divale 
toms and questions shout impairment. To participate in reserrch, adolescents were required tax (a) meet DSM-IV. TR (Amarican Psychintric Assocition 2000) arierin for ADHD, (b) be enrolled in sirth though aighth grade, (c) dipplay significant acadamic impairment, (d) have an esti. mated IQ> $>0$, (e) have no history of an autiem spectrum disorder. At intake, informed consent was obtained and stady eligibility was assessed.

ADHD dingnosis was assessed through prent structured interview (Computerized Diagnontic hnterview Schedale for Chiltren; Shaffer et al. 2000) and parent and texher rating sales (Pelham et al. 1992). Danl clinical neview was paformed by two licensed clinical psychologists to determine dingnosis and eligibility. As par of this process, clinidins used all avilable information to consider age of onset, chronidity, oomortid symptoms, and settings of impuirment when making ADHD dingnoses. Sibley at al. (2016) provides more detriled infomxtion hout screaning and assersment. All measures for the current stady wex $\infty$ l. lected at intake assessment.

\section{Measures}

lssues chedlist

Parents completed the ksues Chedklist ( $\boldsymbol{C}$ : Prinz et al. 1979), a 44-topic questionnaire in which the respondent picks "yes" for topis they discussed with their son' daghter during the past two weeks or "no" if they have not been discussed. For each issue marked, as "yes" the parent mast also use 5 point Likert scale to indicate how intence these discussions were and to provide an open-anded response to indicate the frequency with which these disarsions ocaured during the past two weds. Argument intencity was nted on a 5-point scale, 1 being " $\mathrm{cal} \mathrm{m"} \mathrm{and} 5$ being "very angry." Two scores were obtained: the forquency of conflicts and the mean anger intencity. The ksve's Cherklist posserses established validity as a men. sure of family onnffict compared to dirext obsarvations and nting scale measures (Robin and Forter 1989). In the current study, alpha for frequency was .93 and for intensity was 86 .

\section{Adolescent ADHD symptoms}

DSM-TV-TR ADHD symptoms were obtrined uxing the Dirruptive Bchavior Disorders Rating Scale (DBD; Pelham at al. 1992). The DBD was completed by the parent who was the adolescent's primary caregiver. The DBD lists DSM-TV-TR symptoms of ADHD. Parent's provided rat. ings for each symptom axing a 4-point Likert scale. The prychometric properties of the DBD raing sale are very good in both child and adolescent samples (Evans at al.

르 Spreinger
2013; Pelhum et al. 1992). Mean ADHD symptoms was calculated by thing the avenge score of all the ADHD symptoms items $(a-0.91)$.

\section{Adolescent comorbid symptoms}

Adolescents ompleted the Youth Self Reot (YSR; Achenbach 199 1), a selfadministered broxlband survey of youth prychopthology, to assess symptoms of comothid depression. Adolescent repout was chosen given evidence that selfrepont is the most valid source for youth inter malizing symptoms (Hope et al. 1999). To mensure depressive symptoms, adolescent T-secoes from the $\$ \mathrm{item}$ Withdnwn/Depressed suhocale dimansion of was used ( $a$ -0.71; Achenhach and Rescorla 2001). Aggression was measured using the Child Behwior Chedtlist (CBCL. Achenhach 1991). The CBCL is a well validated prent. report questionnaire in which the adolescent was rited on specific dimensions of behavioal and emotional problems. T-scores from the Aggression subscale servad as m index of comothid youth agsression ( $\alpha-0.94$ Achenhach and Rescorla 200 1). Both the CBCL. and YSR have been shown to have strong prychometric properties in assessing adolescent mental health disorders (Achenhach 1991), with strong internal onsistency.

\section{Parent psychological chancteristic}

The Adalt ADHD Self-Report Scale (ASRS; Ndle et al. 2006) mexured parent ADHD symptoms. Eightern ADHD symphoms are ated on a five point scale ( 0 - nover and 4 ury afiai). The ASRS self report rating scale correlutes highly with clinicin ntings of ADHD and displrys strong intemal consistency ( $N$ dlle at al. 2006). ADHD symptoms were cal. culated for exh prent by caloul ting the mean sorre of the ASRS items. Internal consittency for this sale was 0.92 in our study. Purents alvo completed the Symptom Chedtist90Revised (SCL90-R; Derogatis 1994), a 90ittem broulhand sale of atalt prychopathology thx measures nine symptom domains uxing a 5-point Likert sale. The SCL 90 - has good subscale internal consistency and possenses convergent, discriminant and predictive validity (Darogris and Ceary 1977). Tescoes from the deqression (13 items) and hortlity (6 items) subscales served as prental depression and hortility inderes. Internd ornsistency for the depression sale was 0.89 and for the hostility sale was 0.70 .

\section{Stimulant medication status}

To control for nuturalistic medication use, prents wes asked to report if the adolescent was currently receiving naturalistic stimalant medications for ADHD $x$ baseline $(0-\mathrm{no}, 1-$ yes $)$. 


\section{Deta Analyses}

For ench of the 44 topics on the Issues Checklist (IC; Prinz. at al. 1979) we ex mined descriptive statistics for avenge frequency and intensity of arguments over the past two weeks. We pussued a normbased apprach to dinical thresholfing wing avilable sample norms (Edwrids at al. 2001), setting our threshold to one standard devintion above the mean of non-ADHD tean $\mathbf{C}$ scores. This resulked in a threshold of 29 for intencity. For frequancy, these was no publis hed item level mean frequancy dih to inform a dinical threshold. As a renult, we selected an ecologically valid frequency threshold of grexer than $50 \%$ of days per weok. We explored predictors of argument frequency and intencity using two sepante maltiple regression modek. All assumptions of multiple regression were tested prior to analyses. At the first stop of the model (covaristes), adolescent ADHD symptom severity and metication status were entered. At the second step (teen fuctos) adolescent depression and asgression were entered. At the third step (purent factors), purent ADHD, dqqression, and hortility were entared.

\section{Results}

\section{Parent-Adolescent bsues: Frequency and Intensity}

Homewot problems $(M=7.20, S D-4.16$, clanniness (washing, showering, bruching teeth; $M-7.05, S D-4.68$ ), and going to bed on time $(M-6.87, S D-4.90)$ exceeded the clinical threshold for argument frequency (at least $50 \%$ of drys per week). Twenty two other tapis were identified by prents as ocaurring at a sub threshold level (at least once per werk; see Tuble 2). Only ane topic met the clinical threshold for intencity (doing homework; $M-3.04, S D-1.19$ ).

\section{Predictors of Frequency and Intensity}

For frequency, $x$ stop 1, the modd was not significant [ $R^{2}$ $-0.03, F(2,121)-2.15, p-0.12\}$ The incremental change in step 2 from the contribution of alolescent chr xteristics was significant $\left[R^{2} \Delta-0.11, F(4,119)-7.68, p\right.$ $<0.001$ 1). During step 3, incremental model change when purental charactaristics were added to the model was not significant $\left[R^{2} \Delta-0.18, F(7,116)-1.43, p-0.24\right]$. Inter pretation of step 2 indicated thrt after controlling for covrintes, adolescents who displayed higher depression symptoms $(b-0.04, \mathrm{SE}-0.02, \hat{\beta}-0.18, p-0.04)$ and aggression $(b-0.05, \mathrm{SE}-0.02, \hat{\beta}-0.28, p<0.001)=$ home ware moxe likely to be rated as having more frequent rguments with parents. There were no significant pre. dictors for agument inten sily, $R=0.09, F(2,121)-0.45$, $p-0.64$ (See Table 3).

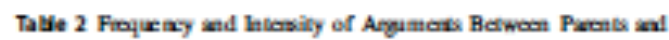
Adulowionts:

\begin{tabular}{|c|c|c|}
\hline & $\begin{array}{l}\text { Finjuency } \\
\text { mixe (SD) }\end{array}$ & $\begin{array}{l}\text { huosify } \\
\text { mon (SD) }\end{array}$ \\
\hline Doing tomencik & $720(4.16)$ & $304(1.19)$ \\
\hline 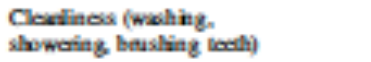 & $205(4.69)$ & $2.20(1.08)$ \\
\hline Bal tinx & $687(4.29)$ & $2.48(1.10)$ \\
\hline Cloving ip boltwat & $581(469)$ & $2.55(1.12)$ \\
\hline Puring away dotod & 5.55 (4.58) & $2.39(1.08)$ \\
\hline Whing the tereribo & $5.11(3.84)$ & $2.36(1.09)$ \\
\hline Muting wo mach abie if bax & $4.91(3.69)$ & $211(0, x)$ \\
\hline 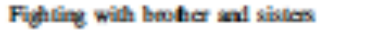 & $4.87(648)$ & $194(1.80)$ \\
\hline Gerling low gealo in school & $4.73(4.06)$ & 2.56 (1..5s) \\
\hline Hew nee doding lowe. & $4.27(4.65)$ & 198 (1.06) \\
\hline Thaing thes w poras & $4.18(4.52)$ & $2.38(1.67)$ \\
\hline Gerting up in th meming & $4.17(504)$ & $1.54(1.65)$ \\
\hline Pheadintomed & $4.10(4.78)$ & $2.45(1.12)$ \\
\hline Helping our amand the house & $395(4.58)$ & $1.87(1.42)$ \\
\hline Whish dodhe weat & $344(263)$ & $193(1.00)$ \\
\hline Mosing up the bowe & $283(4.70)$ & $1.27(1.48)$ \\
\hline Thile miamos & $2.56(4.10)$ & $193(0.8)$ \\
\hline What rasuges eat & $2.56(4.79)$ & $0.87(1.16)$ \\
\hline Lying & $2.28(3.32)$ & $1.53(1.61)$ \\
\hline Gerting w sctionl oa the & $2.27(379)$ & $102(1.47)$ \\
\hline Tuming off lopts in house & $2.24(4.28)$ & $0.71(1.0)$ \\
\hline 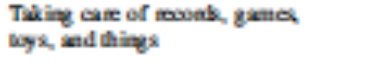 & $211(3.51)$ & $102(1.28)$ \\
\hline How wo spond fire tinx & $207(3.20)$ & $093(1.14)$ \\
\hline Geming in toulie in sctioel & $1.71(3.17)$ & $102(1.99)$ \\
\hline Caring & $1.31(26 \theta)$ & $0.74(1.25)$ \\
\hline What fate wo lane aribs & $1.24(284)$ & $0.51(1 . \infty)$ \\
\hline Who shoul be fifands: & $1.10(247)$ & $0.56(0.8)$ \\
\hline 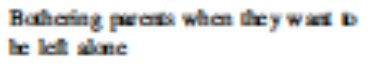 & $108(2.29)$ & $0.72(1.24)$ \\
\hline fing fort & $105(3.07)$ & $0.36(0.78)$ \\
\hline
\end{tabular}

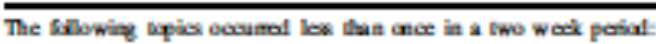

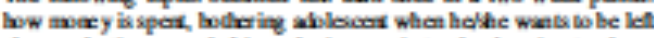

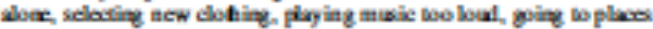

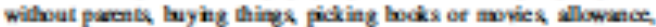

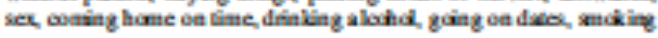

\section{Discussion}

The primary finding of this study are as follows: (1) prent. tean arguments for adolescents with ADHD are often trig. gered by impuirments in homew of and hygiene, as well as bedtime; (2) among these topios, arguments thout home work problems have the greatest tendency to excalute in intensity; (3) arguments occur most frequently when teens with ADHD also possess comothid mood and aggression symptoms. Perhaps surpisingly, prent characteristics did 
Table 3 Prafictes of paral

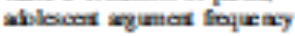

\begin{tabular}{|c|c|c|c|c|c|c|c|}
\hline & $R^{2} A$ & $F \Delta$ & $P$ & $b$ & $\mathscr{S E}$ & $f$ & $p$ \\
\hline Suep Levilives & acs & 215 & 0.12 & & & & \\
\hline Advisicant ADHD sympons (P) & & & & 0.21 & $a 2$ & 008 & 0.36 \\
\hline Medicyion suns. & & & & -0.2 & 0.28 & -0.17 & 007 \\
\hline Suep 2 adviecen charactotitios & a.t & 7.68 & enol & & & & \\
\hline WidMerwa/Mpersiol (A) & & & & 004 & 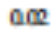 & 0.18 & 0.04 \\
\hline Agresion (P) & & & & $0 \mathrm{cs}$ & $\Delta \infty$ & 0.28 & sonet \\
\hline Suep I puecia eluesciotitios & acos & 1.43 & 0.24 & & & & \\
\hline Pexia A DHID syappouns (P) & & & & 0.04 & $a x$ & $0 D 2$ & 0.85 \\
\hline Pueria dequosive (P) & & & & -000 & $a c$ & -007 & 0.53 \\
\hline Puxar laodility (P) & & & & $-\infty e 0$ & $\Delta \infty$ & -0.14 & 0.16 \\
\hline
\end{tabular}

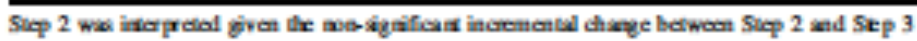

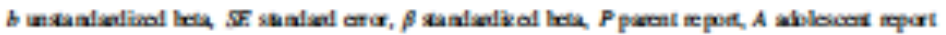

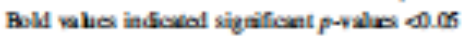

not contribute to the frequency of purent teen conflicts. We discuss each finding below.

Not surpricingly, difficulties with the dily routine fi.e. showering, brushing tecth, completing homework, gating to bed on time) wex a major source of arguments in our sumple, highlighting the impairing role of ADHD-relted ogrnization and self-management problems in adolescence. These argument topics appear to be unique to teens with ADHD. Previous studies report that talking badk to prents, use of drags/alohol, and school problems are more ormmonly endorsed in typically developing youth (Colemm 2011; Papini and Sebby 1988; Papini a al. 1969). Thas, efforts to improve parent teen conflict in youth with $A D H D$ might simultanecushy addess communication slills and rgament scurces (i.e, self-management of the daily rodtine). Extant prychosocial trextments that address both prent teen interxtions and executive function skills trining may be particularly indicated (eg., Sapporting Teens' Autonomy Daily [STAND; Sib ley a al. 2016).

Although a majority of adolescents with ADHD demonstnte the homew od and dily routine difficulties (Harison et al. 2011; Langherg et al. 2016), arguments were more frequently triggered when the teen possessed comorhid ageressive and/or d qressive symptoms. Both of these symptom dusters contain an emotion regulation component thr may inarease risk for tern-initiated conffict with the purent when problem behaviors oceur (Shaw et al. 2014; Graviano and Garcin 2016). However, it also may be the case that deqression-related anhedonin or oppositional behaviors may contribute to increased problems with takss of drily living - thereby increasing the indidence of triggers (Beck 2002; Katon et al. 2010). As a result, longitudinal reserch is greatly needed to understand the processes thrt underlie our cross-sectional findings.

Contray to past wotk (Bdwarts et al. 2001 h, neither the frequency nor intencity of arguments were rel ted to parent prychologial pooblems. As a result, even parents who wex prychologially healthy experience frequent arguments with teans who have ADHD (erpecinlly if the teen had ommorbid mood or aggession problems). Thus, prenting interventions for teens with $A D H D$ may zequire trining in communication and conflict doescalation skills that are cutside the repenoire of typical prents. One stady found that dyads with high purent tean conflict had a rataced rexponse to group purent trining for adolescents with $\mathrm{ADHD}$ (Sibley et al. in press); in contust, individunlixed mprouches with tiloned feedhalk and skill pactice wers partialrly effective in higher conflict dyads. Thas, dinicins should carefully select tresments that are trilored to parent teen conflict level.

\section{Limitations and Further Research Directions}

Our stady contuins limitutions that should be onncidered. First, this study was condacted with middleschool aged adolescents who were primarily middle class and Hispuric. Therefore, these findings may not genenlize to adolescents in high school or fimilies with different altural hackgrounds. Nert, it is importunt to note thrt the majority of the purbijants in this study wer male (83\%). Previous wot on adolescent purent confliat have identified that parents have different erpectations for male versus female youth (Allion and Schaltz 2001). Therefore, these findings may not genenline to famale adolescents with ADHD. Puricipunts in cur stady were putients at a univexity dinic; results also may not gerenline to nonclinical, school bused, or community-clinical sumpler.

The $\mathbf{C}$ was only completed by parents. It is possible that tean report would provide a unique parspective; on the other hand adolescents with ADHD notoicously under-report impuirments, undermining the uflity of self-report in research (Sihley et al. 2010). Dirext observation of examine parent tean conflict could also be examined in future staties. Furthermore, the noms used for the intensity of arguments

르 Spreinger 
were based on predominately White/hon-Hispanic samples (Edwards et al. 2001). Estahlishing a culturospecific threshold for prentteen conflict is a dirextion for future reseunch. Finally, the IC is not an exhrus tive list of topiss thr tigger prent and teen mguments. It is possible thrt addfonal topics not listed on the $\mathrm{K}$ could also be a significant source of conflict parent ieen ADHD dyads.

In conchasion, clinicians should carfully assess parent. ten conflict when planning trexment for alolescents with ADHD. Because stimalmt medication does not prodace mexingful effects on purent teen relational variables (Pel. ham et al. 2017), prychosocial approuches may be indicxted when onffict is high (Batkley at al. 2001; Sibley at al. 2013). Administering the $X$, as well as comorhid mood and behavioral measures, may also illuminze whather treatment should fist adtress rectacing sources of arguments fie. difficulties with homework and the dily routine) versus managing adolescents' amobional rextions to their purents. Intarventions that simulanecusly address ADHD and depression ax also emerging as a promising treatment direction (Meinzer et al. 2018) and could aloo demonstrate m impact on parent teen conflict.

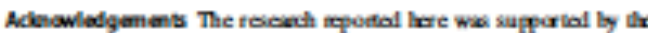

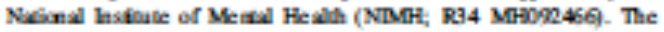

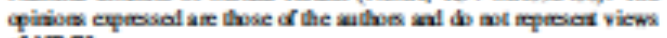
a NDMH.

Funfig This sudy was fandal by NIMH (R34 Mron2466)

\section{Compliance with Ethical Standards}

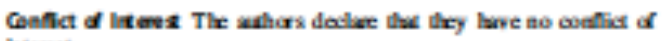
interest.

Esial Apoval All paxaluro possend in sealio inviving

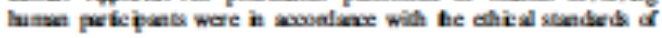

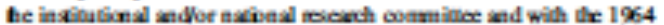

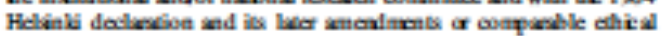
senbank.

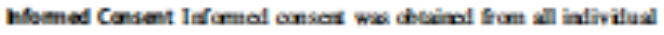
participues inclubl in the soaly.

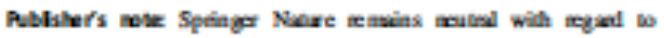

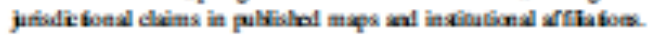

\section{References}

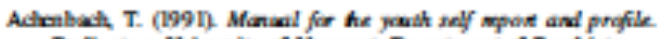

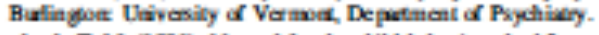

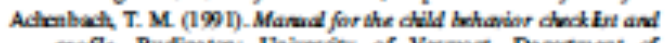

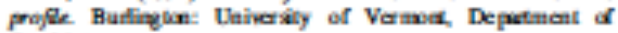
Pychivey.

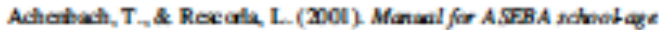

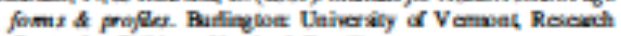
Conter for Civilies, Yauth a Fintilie

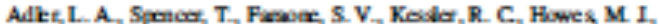
Biolorsas J, \& Sorrik K. (2006). Vulisfy of pilos aluk ADHD selfecpet sole (ASRS) w ale alut AD HD sympons.

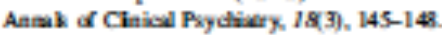

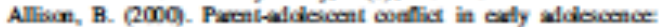

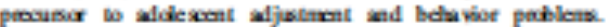

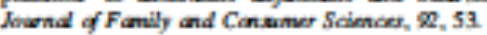

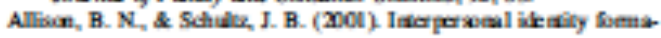

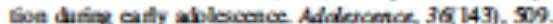

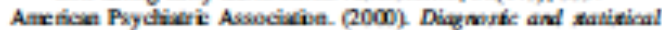

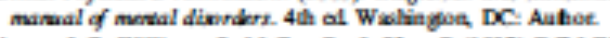

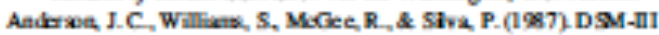

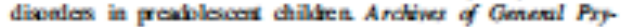
chiatry 44, (62)-76.

Auctach, R. P, Alrh, I R. Z, \& Ho, M R. (2007), Roppanding D

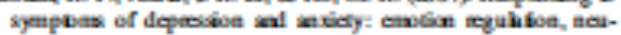

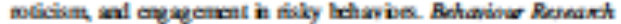
and Theraps, $459 \mathrm{~L}, 2182-219 \mathrm{~L}$

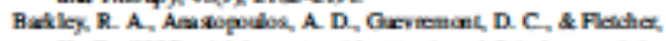

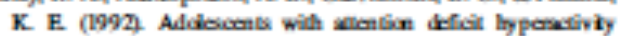

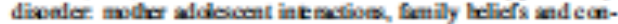

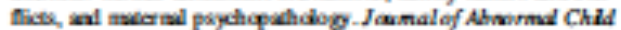
Prychebg, 20, 263-288

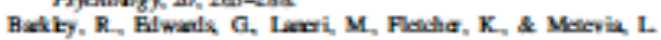

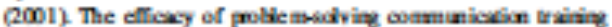

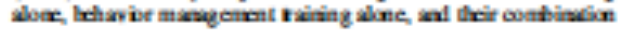

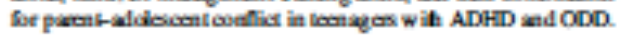

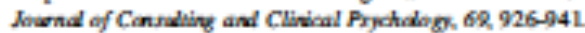

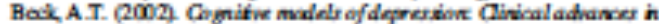
ongitie prochabrapg: thory and afplitation. New Yak Splinger.

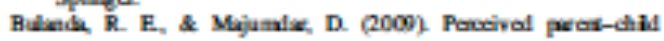

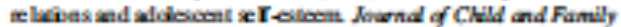
Sindies, $15(2)$, 208-212

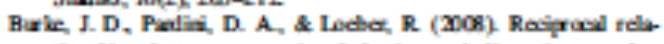

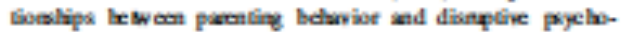

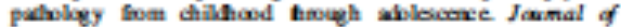
Atnormal Chll Prochalogy, $3,672-6 \%$.

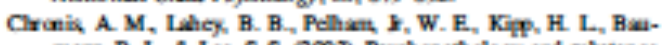

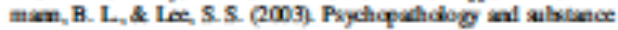

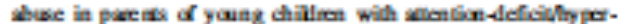
activily diveles Noumd of the Amerion Acoleny of Child \& Adiberent Prychiaty. \&, 1424-1432.

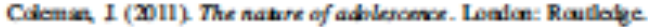

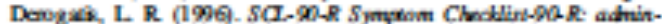

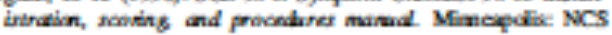
Poesee

Dewge, L R., \& Clowy. P. A. (1977). Canfmaboe of the

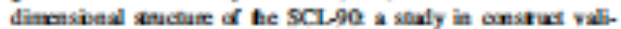

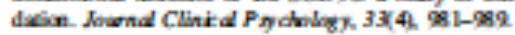

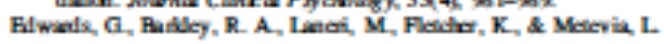

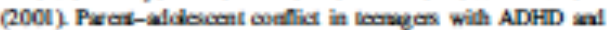

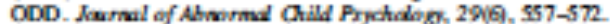

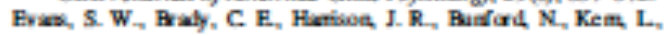
suce, T, \& Aadrew, $C$ (2013). Merauing ADHD al ODD

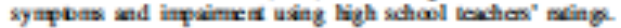

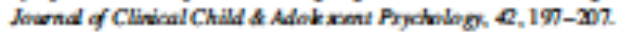

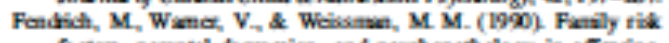

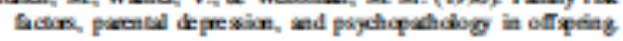
Developmental P gicholog, 26, 40-30. 


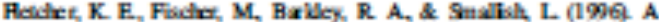

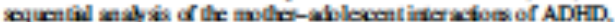

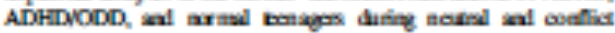

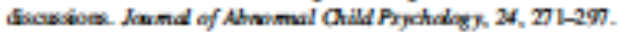

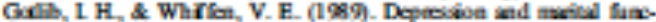

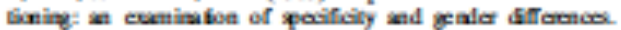
Jowenal of Ahourmal Prochalog, 98, 23-30.

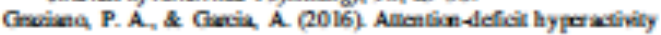

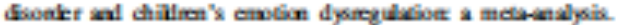
Chininal Prochalogy Review, 46, 106-123.

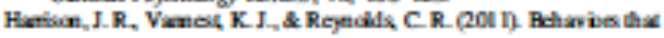

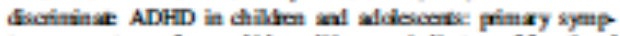

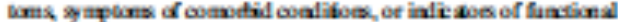

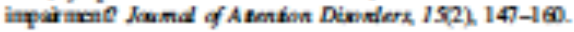

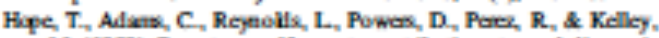

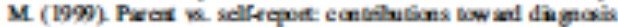

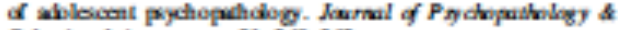
Brhaviond Averiment, 2l, 340-363.

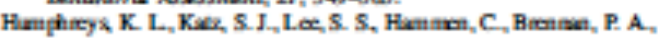

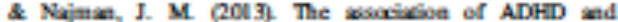

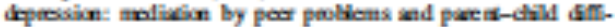

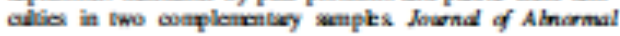
Prychalog, 12233 , 854

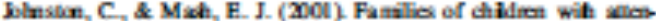

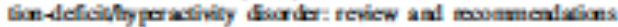

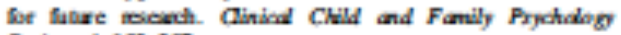
Review, 4, 183-200.

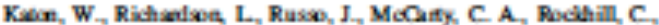

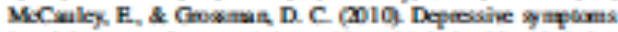

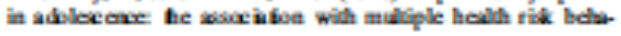
boes. Gintend Hapial Pnotiato, 32(3), 233-239.

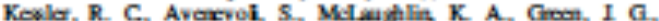

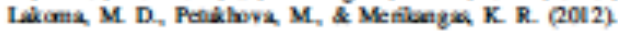

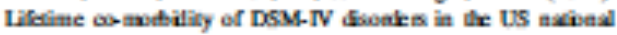

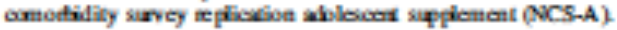
Prochale gioal Modicix, 42(9), 1997-2010.

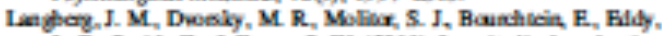
L D, Smid, Z, \& Evens, S. W. (2016). Leeginalind eviluxive

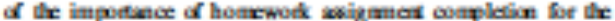

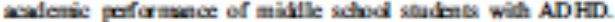

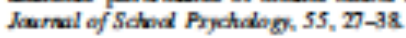

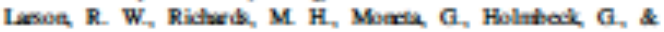

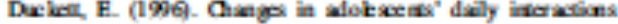
will teir cenilio fan ago 10 wo 18: Giongenen and

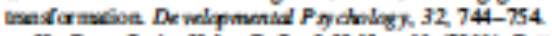

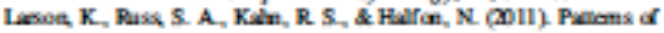

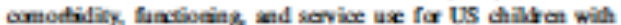
ADHD Pellatrix, 1273), 462-470

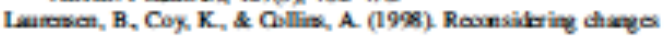

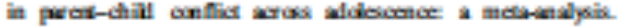
CHild Derolapmex, 6Q 81 7-832

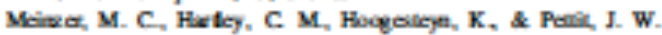
(2018). Denelopmos and oprat ufid of a deposion pereifine

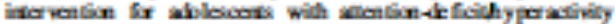
Givalec Cognitive and Rehaviond Prartice, 25(2), 225-239.

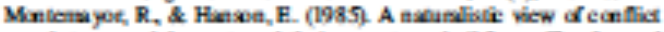

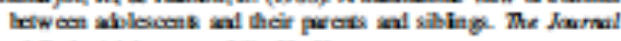
of Eaty Adderionce, S(1), 23-30.

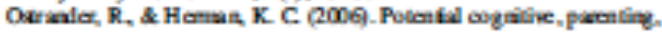
inl derebpamid moliexs of te relusintip leswom ADHD

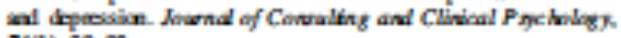
$74(1)$. 8298

Papini, D. R., Clik, S, Bumer, J. K., \& Sarage, C L (1999) Grale,

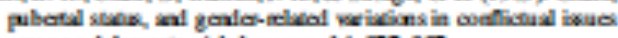

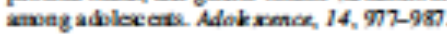

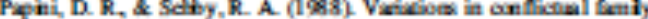

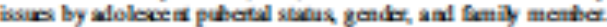
The Nownd of Early Adilencerse, \&1. L-15.

Pellam, W, Geag, E., Gronslur, K., \& Mfilich R. (192). Teacte

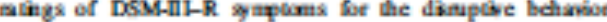

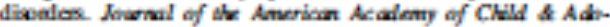
Lencent Prochiator, 31, 210-218.

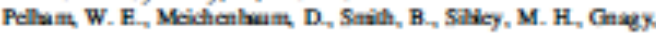
F. \& Buksein, 0 (9017) Acute of bets of MPH an the

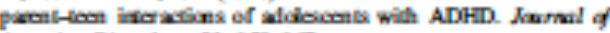
Afontion Dinovilerx, 2l, 158-167.

Pelosion, A. C, Compax, R. E., Bawks Cann I, Suentar, M, Ey.

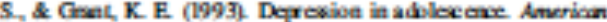
Prochibgic, 48(2), 155-168.

Pinz, R. J., Foder, S. Kent, R. N., \& OTear, K. D. (19)9). Mul-

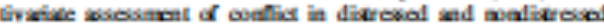

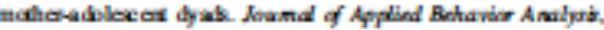
$12,691-200$.

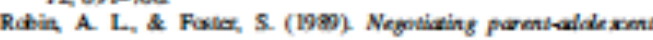
conglide. New Yode Gellsod Pres.

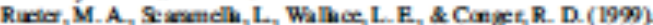

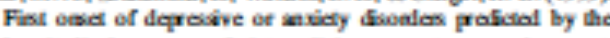

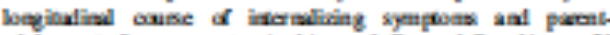

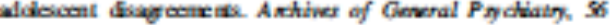
(3). $726-732$

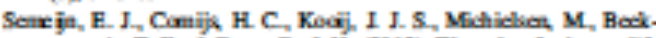

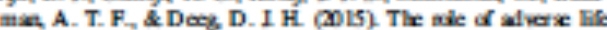
evons an dequobion in eller aluls will ADHD kound of Afnctve Dinonder, 174, 574-579

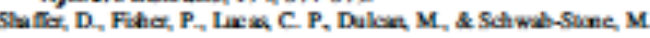

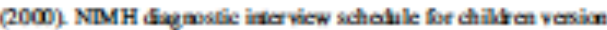

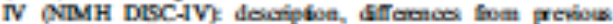

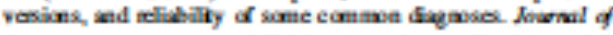

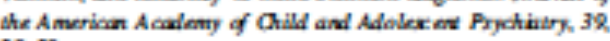
$28-38$

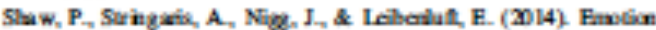

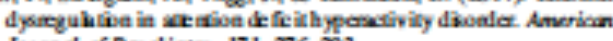
Jowend of Pydtialy, $171,206-293$

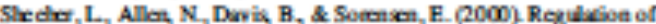

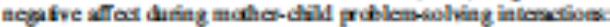

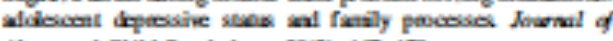
Ahuarmal Child Prochalogy, 28(5), 467-47n.

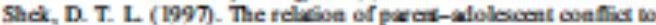

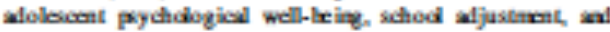

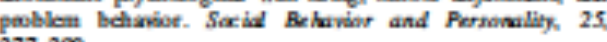
$272-290$.

Slrk D. T. L. (1998). A knginulind seudy of itr relusoes lerweon

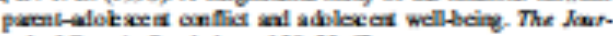
nd of Gentic Pxpotidog, 152,53-67.

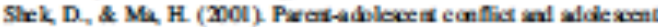

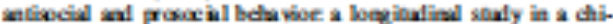

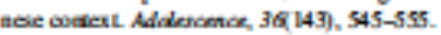

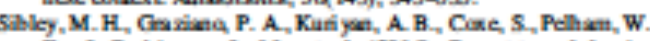

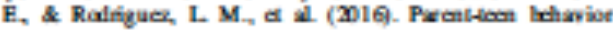

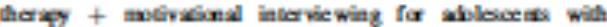

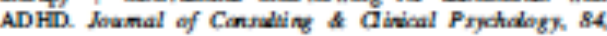
$699-712$

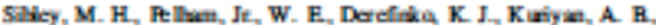
Soncter, F., \& Grwive, P.A. (2D13). A plos utd $\alpha$ appoting

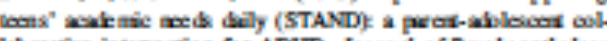

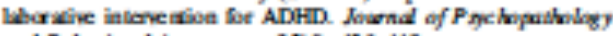
and Bebuival Arnerment, 35.4h, 436-449.

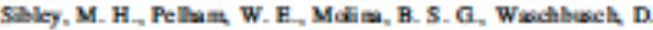

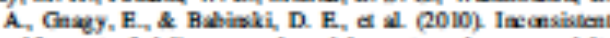

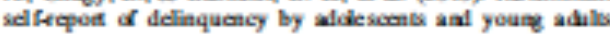

르 Springer 
widh ADHD Jaund of Ahwomal Child Pyotalog, 38, $645-636$.

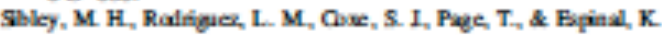

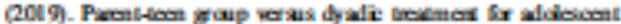

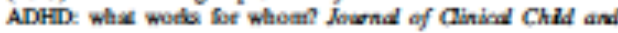
Addericent Prycheb gr. Advietce of Pirl.

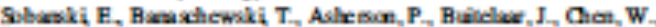

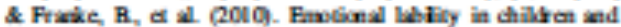

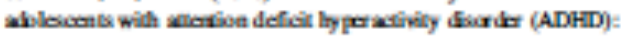

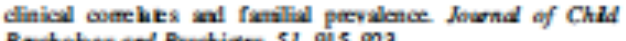
Pnchabgy and Pxpotiatog, 51, 915-92.

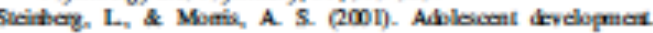

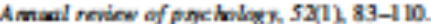

Wimeie, P. M, Slach, A, \& Balley, R. A. $(2010)$. Sveid anl

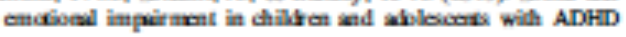

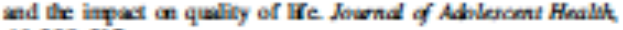
46. 202-2iz 
VITA

ALEXIS M. GARCIA

$2009-2013$

B.A., Psychology - Honors

Florida International University

Miami, Florida

$2014-2017$

M.S., Psychology

Florida International University

Miami, Florida

2017 - Present

Doctoral Candidate in Clinical Psychology

Florida International University

Miami, Florida

2018

Center for Child and Families (CCF) Seed Fund Grant

Florida International University

Miami, Florida

2018

International Society for Research on Aggression, Young

Investigator Award

$2019-2020$

Charleston Consortium Internship Program - Child Track -

Medical University of South Carolina

2020

Medical University of South Carolina Perry Halushka Student Research Day, $1^{\text {st }}$ Place Oral Presentation

\section{SELECTED PUBLICATIONS AND PRESENTATIONS}

Graziano, P., \& Garcia, A.M. (2016). Attention-deficit hyperactivity disorder and children's emotion dysregulation: A meta-analysis. Clinical Psychology Review, 46, 106-123.

Garcia, A.M., \& Graziano, P, A. (2017). The summer healthy-lifestyle intervention program (HIP) for young children who are overweight: Results from an open trial. Symposium presented at the Society of Pediatric Psychology Annual Conference, Portland, OR.

Graziano, P.A., Garcia, A.M, \& Lim, C. (2017). Summer healthy-lifestyle intervention program for young children who are overweight: results from a nonrandomized pilot trial. Journal of Developmental \& Behavioral Pediatrics, 38(9), 723-727. 
Garcia, A.M., \& Graziano, P. (2017). Examining emotion dysregulation in preschoolers with and without attention-deficit/hyperactivity disorder. Poster presented to the Society for Research in Child Development Biannual Meeting, Austin, TX.

Garcia, A., Dick, A., \& Graziano, P. (2018). Psychophysiological and neural correlated of emotion regulation in pre-kindergarten children with and without ADHD. Presented at Brainhack Global 2018, University of Miami.

Garcia, A., Coto., J., Stollstorff, M., \& Graziano, P. (2018). Explaining the link between genetic risk and externalizing and internalizing problems in young children: The role of emotion dysregulation. Poster presented to the International Society for Research on Aggression Biannual World Meeting, Paris, France.

Garcia, A., \& Graziano, P. (2018) The Role of Parental Psychopathology on Behavioral Parent Training: An Examination of Parental ADHD \& Parental Emotion Dysregulation. In A. Garcia (Chair), As If Parenting Wasn't Hard Enough: The Attenuating Role of Parental Psychopathology on Behavioral Parent Training. Paper presented at the Association for Behavioral and Cognitive Therapies Annual Convention, Washington D.C.

Graziano, P.A., Garcia, A.M., \& Landis, T. (2018). To Fidget or not to fidget, that is the question: A systematic classroom evaluation of fidget spinners among young children with ADHD. Journal of Attention Disorders.

Garcia, A. M., Ros, R., Hart, K. C., \& Graziano, P. A. (2018). Comparing working memory in bilingual and monolingual hispanic/latino preschoolers with disruptive behavior disorders. Journal of Experimental Child Psychology, 166, 535-548.

Garcia, A. M., Graziano, P. A., \& Hart, K. C. (2018). Response to time-out among preschoolers with externalizing behavior problems: The role of callousunemotional traits. Child Psychiatry \& Human Development, 1-10.

Garcia, A. M., Medina, D., \& Sibley, M. H. (2019). Conflict between parents and adolescents with ADHD: Situational triggers and the role of comorbidity. Journal of Child and Family Studies, 1-8.

Garcia, A., Hoffman, M., Tomko, R. L., \& Squeglia, L. M. (2020). Associations between parent psychopathology and youth mental health and early alcohol use behaviors. Presented at Research Society on Alcoholism Annual Conference, New Orleans, LA.

Landis, T. D., Garcia, A. M., Hart, K. C., \& Graziano, P. A. (2020). Differentiating symptoms of ADHD in preschoolers: The role of emotion regulation and executive function. Journal of Attention Disorders, 1087054719896858. 